\title{
Reconhecimento de entidades mencionadas em português utilizando aprendizado de máquina
}

\author{
Wesley Seidel Carvalho \\ DISSERTAÇÃO APRESENTADA \\ $\mathrm{AO}$ \\ Instituto DE MATEMÁticA E EstatísticA \\ DA \\ Universidade DE SÃo PaUlo \\ PARA \\ OBTENÇÃO DO TÍTULO \\ $\mathrm{DE}$ \\ Mestre em CiÊnCia dA ComputaÇÃo \\ Programa: Ciência da Computação \\ Orientador: Prof. Dr. Marcelo Finger
}

São Paulo, fevereiro de 2012 


\section{Reconhecimento de entidades mencionadas em português utilizando aprendizado de máquina}

Esta dissertação contém as correções e alterações sugeridas pela Comissão Julgadora durante a defesa realizada por Wesley Seidel Carvalho em 24/02/2012.

$\mathrm{O}$ original encontra-se disponível no Instituto de Matemática e Estatística da Universidade de São Paulo.

Comissão Julgadora:

- Prof. Dr. Marcelo Finger (orientador) - IME-USP

- Prof. Dr. Alair Pereira Lago - IME-USP

- Prof. Dr. Fábio Natanael Kepler - UNIPAMPA 


\section{Agradecimentos}

São tantos os que tenho que agradecer por darem sua contribuição, de uma forma ou de outra, para que este trabalho pudesse ser realizado. Agradeço muito a Deus pelas oportunidades colocadas em meu caminho e por me dar perseverança nos momentos de dificuldade. À minha mãe Laurimar e meu pai Lair (em memória) por terem me guiado no caminho correto, sempre tentando fazer o bem para os seus filhos. Agradeço ainda ao meu irmão Wanderson e à minha irmã Welk pelo apoio e incentivo em todas as minhas empreitadas. Também tenho que fazer o meu agradecimento à minha namorada Ludinéia Costa por ter me aturado durante todo o período de estudo e ter aguentado as minhas noites em claro para que este trabalho pudesse ser concluído.

Sou muito grato por ter tido a oportunidade de ter o prof. Marcelo Finger como meu orientador do Mestrado e por todas as suas valiosas horas investidas em mim e neste trabalho. Deixo também uma palavra de agradecimento aos professores do IME-USP que fizeram parte do meu amadurecimento científico. Alguns deles que gostaria de citar são, além do meu orientador, os professores Alair Pereira Lago e Alfredo Goldman, por suas aulas e discussões.

São também dignos de uma nota de apreço os colegas que conheci durante o período do Mestrado nesta instituição, sendo alguns de outros grupos de pesquisas, porém ocupando o mesmo espaço fisico. Aos meus primeiros amigos do IME, Tales Pinheiro, Sirley Vitorio, Marcelo Reis e Vilc Rufino, pela companhia e estudos iniciais. Agradeço também aos meus colegas William Colen e Michel Oleynik pelos momentos de desenvolvimento do sistema CoGrOO Comunidade e pelas discussões sobre PLN. Não posso deixar de citar o grupo LIAMF e o grupo de XP, com os quais me diverti muito enquanto aprendia.

Finalmente, agradeço às varias pessoas que em algum momento também estiveram envolvidas no desenvolvimento deste Mestrado. 


\title{
Resumo
}

\section{Reconhecimento de entidades mencionadas em português utilizando aprendizado de máquina}

\author{
Autor: Wesley Seidel Carvalho
}

Orientador: Prof. Dr. Marcelo Finger

\begin{abstract}
O Reconhecimento de Entidades Mencionadas (REM) é uma subtarefa da extração de informações e tem como objetivo localizar e classificar elementos do texto em categorias pré-definidas tais como nome de pessoas, organizações, lugares, datas e outras classes de interesse. Esse conhecimento obtido possibilita a execução de outras tarefas mais avançadas. O REM pode ser considerado um dos primeiros passos para a análise semântica de textos, além de ser uma subtarefa crucial para sistemas de gerenciamento de documentos, mineração de textos, extração da informação, entre outros.

Neste trabalho, estudamos alguns métodos de Aprendizado de Máquina aplicados na tarefa de REM que estão relacionados ao atual estado da arte, dentre eles, dois métodos aplicados na tarefa de REM para a língua portuguesa. Apresentamos três diferentes formas de avaliação destes tipos de sistemas presentes na literatura da área. Além disso, desenvolvemos um sistema de REM para língua portuguesa utilizando Aprendizado de Máquina, mais especificamente, o arcabouço de máxima entropia. Os resultados obtidos com o nosso sistema alcançaram resultados equiparáveis aos melhores sistemas de REM para a língua portuguesa desenvolvidos utilizando outras abordagens de aprendizado de máquina.
\end{abstract}

Palavras-chave: Reconhecimento de Entidades Mencionadas, Reconhecimento de Entidades Nomeadas, Processamento de Linguagem Natural, Aprendizado de Máquina, Máxima Entropia. 


\section{Abstract}

\section{Portuguese named entity recognition using machine learning}

Autor: Wesley Seidel Carvalho

Orientador: Prof. Dr. Marcelo Finger

Named Entity Recognition (NER), a task related to information extraction, aims to classify textual elements according to predefined categories such as names, places, dates etc. This enables the execution of more advanced tasks. NER is a first step towards semantic textual analysis and is also a crucial task for systems of information extraction and other types of systems.

In this thesis, I analyze some Machine Learning methods applied to NER tasks, including two methods applied to Portuguese language. I present three ways of evaluating these types of systems found in the literature. I also develop an NER system for the Portuguese language utilizing Machine Learning that entails working with a maximum entropy framework. The results are comparable to the best NER systems for the Portuguese language developed with other Machine Learning alternatives.

Keywords: Named Entity Recognition, Machine Learning, Maximum Entropy Framework, Information Extraction, Natural Language Processing. 


\section{Sumário}

$\begin{array}{ll}\text { Lista de Abreviaturas } & \text { ix }\end{array}$

Lista de Figuras $\quad$ xi

Lista de Tabelas $\quad$ xiii

1 Introdução $\quad 1$

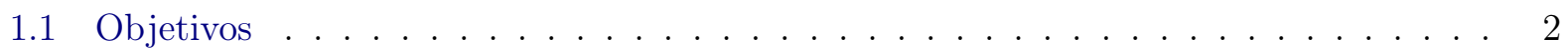

1.2 Organização do Trabalho . . . . . . . . . . . . . . . . . . . . . 2

2 Processamento Estatístico da Linguagem Natural $\quad 3$

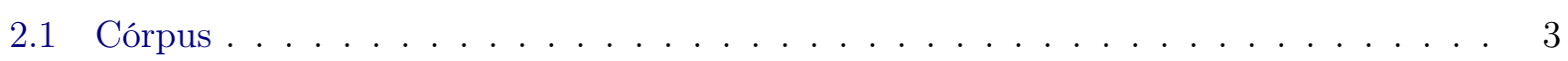

2.1 .1 Texto Marcado . . . . . . . . . . . . . . . . . . . . . . . . 4

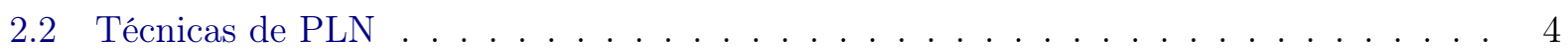

2.2 .1 Tokenização . . . . . . . . . . . . . . . . . . . . . . 4

2.2 .2 Separação de Sentenças . . . . . . . . . . . . . . . . . . . . 5

2.2 .3 Análise Morfossintática . . . . . . . . . . . . . . . . . . . . 5

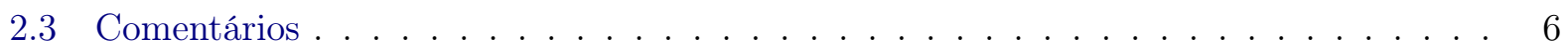

3 Avaliação de Sistemas de Reconhecimento de Entidades Mencionadas $\quad 7$

3.1 Medidas de Avaliação . . . . . . . . . . . . . . . . . . . . . . . 7

3.2 Conferências de Avaliação de REM . . . . . . . . . . . . . . . . . . . . . . . . . . . . . . . . . . .

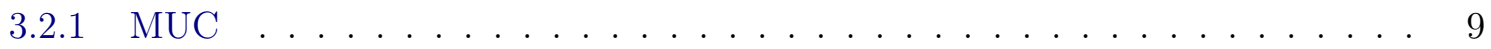

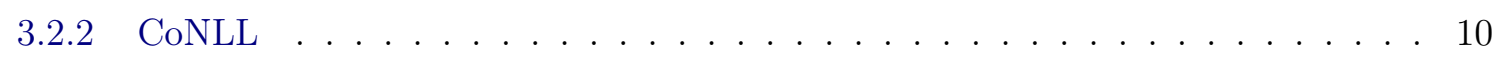

3.2 .3 HAREM . . . . . . . . . . . . . . . . . . . . . . 11

3.3 Comentários . . . . . . . . . . . . . . . . . . . . . . 17

4 Aprendizado de Máquina $\quad 19$

4.1 Introdução . . . . . . . . . . . . . . . . . . . . . . . . . . . . . . . 19

4.1 .1 Divisão do Aprendizado de Máquina . . . . . . . . . . . . . . . . . . 19

4.1 .2 Definições Preliminares . . . . . . . . . . . . . . . . . . . . 20

4.1.3 Paradigmas de Aprendizado de Máquina e Modelos de Linguagem . . . . . . 22

4.1 .4 Validação Cruzada . . . . . . . . . . . . . . . . . . . . . . . . . 22

4.2 Aprendizado de Máquina aplicado ao PLN . . . . . . . . . . . . . . . . . 23

4.2 .1 Maximização de Entropia . . . . . . . . . . . . . . . . . . . . . . 23

4.2.2 Aprendizado Baseado em Transformação Guiada por Erro . . . . . . . . . . . 25 
4.2.3 Aprendizado de Transformação Guiado por Entropia . . . . . . . . . . . . . . 27

5 Trabalhos Relacionados $\quad 29$

5.1 Abordagens na resolução do problema de REM . . . . . . . . . . . . . . . . . . . . 29

5.1 .1 TBL aplicado ao REM . . . . . . . . . . . . . . . . . . . . . . 29

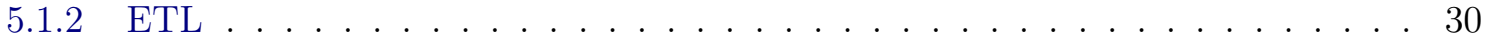

5.1 .3 Máxima Entropia . . . . . . . . . . . . . . . . . . . . . . . . 31

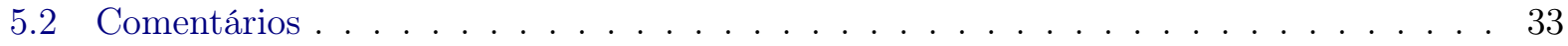

6 Arquitetura do Sistema 35

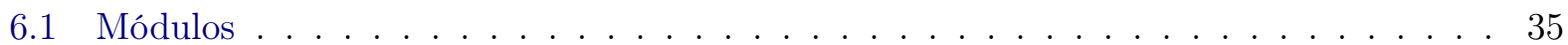

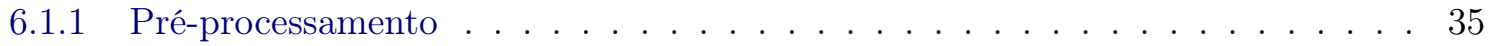

6.1 .2 Filtro de Avaliação . . . . . . . . . . . . . . . . . . . . . . . . . . . 38

6.1 .3 Extração de Características . . . . . . . . . . . . . . . . . . . . . . . . . 39

6.1.4 Estimador de Máxima Entropia . . . . . . . . . . . . . . . . . . . . . . . . . 41

6.1 .5 Etiquetador de EM . . . . . . . . . . . . . . . . . . . . 41

6.1 .6 Avaliador . . . . . . . . . . . . . . . . . . . 43

7 Resultados $\quad 45$

7.1 Metodologia e Córpus Utilizados . . . . . . . . . . . . . . . . . . . . 45

7.1 .1 Preparação dos Córpus . . . . . . . . . . . . . . . . . . 45

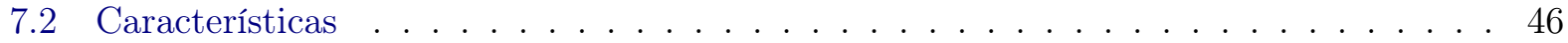

7.2 .1 Estrutura Interna da Palavra . . . . . . . . . . . . . . . . . . . 46

7.2 .2 Léxicas . . . . . . . . . . . . . . . . . . . . . . . . . . . . . . . 49

7.2 .3 Etiquetas Morfológicas . . . . . . . . . . . . . . . . . . . 52

7.2 .4 Modelo Base . . . . . . . . . . . . . . . . . . . . . . . . . . 52

7.2 .5 Outras Características . . . . . . . . . . . . . . . . . 53

7.3 Modelos Melhorados . . . . . . . . . . . . . . . . . . . . . 58

7.3.1 Novo estudo de corte para córpus do HAREM . . . . . . . . . . . . . . . . 59

7.3 .2 Estudo de Córpus . . . . . . . . . . . . . . . . . . . . . . 60

7.4 Avaliação no Segundo HAREM . . . . . . . . . . . . . . . . . . . 60

7.4.1 Cenários de Avaliação . . . . . . . . . . . . . . . . . . . . . 60

7.4 .2 Testes Alternativos . . . . . . . . . . . . . . . . . . . . . . 62

8 Conclusões $\quad 65$

8.1 Trabalho Futuros . . . . . . . . . . . . . . . . . . . 66

$\begin{array}{ll}\text { A Exemplos de Textos do HAREM } & \mathbf{6 7}\end{array}$

A.1 Exemplos por categoria/tipo do Segundo HAREM . . . . . . . . . . . . . 67

$\begin{array}{ll}\text { B Resultados dos Experimentos Alternativos } & 73\end{array}$

$\begin{array}{ll}\text { Referências Bibliográficas } & \mathbf{7 7}\end{array}$

$\begin{array}{lr}\text { Índice Remissivo } & 80\end{array}$ 


\title{
Lista de Abreviaturas
}

\author{
AM Aprendizado de Máquina \\ REM Reconhecimento de Entidades Mencionadas \\ NER Named Entity Recognition \\ EM Entidade Mencionada \\ HAREM Avaliação de Sistemas de Reconhecimento de Entidades Mencionadas \\ CoNLL Conference on Computational Natural Language Learning \\ MUC Message Understanding Conferences \\ TBL Aprendizado Baseado em Transformação Guiada por Erro \\ (Transformation-Based Error-Driven Learning) \\ ETL Aprendizado de Transformação Guiado por Entropia \\ (Entropy Guided Transformation Learning) \\ MENE Sistema de REN construído sobre o arcabouço de Máxima Entropia \\ (Maximum Entropy Named Entity) \\ CD Coleção Dourada
}




\section{Lista de Figuras}

3.1 Árvore de categorias no Segundo HAREM: as categorias, tipos e subtipos representados nas caixas com contorno sólido preto só existem no Segundo HAREM; as categorias, tipos e subtipos representados nas caixas com contorno pontilhado só existem no Primeiro HAREM. Figura extraída de [MS08] . . . . . . . . . . . . . . 12

4.1 Conjunto de treinamento para a identificação de uma maçã. Cada ponto corresponde a uma fruta e as coordenadas indicam a massa e o volume da fruta. Os pontos com um sinal positivo indicam quando a fruta é uma maçã, e sinal negativo outra fruta

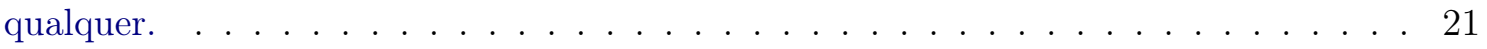

4.2 Exemplo de uma hipótese. A classe $C$ de maçãs é o retângulo no espaço massa-volume. 22

4.3 Esquematização do processo de aprendizado do TBL . . . . . . . . . . . . . . . . 26

4.4 Esquematização do processo do ETL. . . . . . . . . . . . . . . . . . . . . 27

4.5 Excerto de uma Árvore de Decisão na tarefa de segmentação de texto. Figura extraída de $[\mathrm{dSM} 09] \ldots \ldots \ldots \ldots \ldots \ldots$

6.1 Arquitetura do Sistema para a fase de Treinamento. . . . . . . . . . . . . . 36

6.2 Arquitetura do Sistema para a fase de Avaliação. . . . . . . . . . . . . . . . . . . . 36

6.3 Módulo de Pré-processamento. . . . . . . . . . . . . . . . . . . . . . 37

6.4 Módulo de pré-processamento para extração de características. . . . . . . . . . . . . 40

7.1 Uma avaliação mais extensa dos valores de cortes de predicados contextuais para o Modelo MTodas sobre o córpus HAREM. . . . . . . . . . . . . . . . . . . . . . 63

7.2 Resultados de diferentes modelos avaliadas no Segundo HAREM- Cenário Total. . 63

7.3 Resultados de diferentes modelos avaliadas no Segundo HAREM- Cenário Seletivo. . 64 


\section{Lista de Tabelas}

1.1 Exemplos de classificação de entidades e seus possíveis tipos. . . . . . . . . . . . . . 2

2.1 Excerto de texto de Manuel Bernades extraído do córpus Tycho Brahe. . . . . . . . . 4

3.1 Comparação de um texto anotado por um especialista em (A) com um texto de saída anotado por um sistema hipotético em $(\mathrm{B}) . \ldots \ldots \ldots \ldots$

3.2 Um acerto e possíveis erros cometidos pelos sistemas de REM. . . . . . . . . . . . . 8

3.3 Possíveis anotações de um sistema hipotético. . . . . . . . . . . . . . . . . . . . 14

3.4 Resultado da tarefa de identificação dos dados da Tabela 3.2 avaliado nos moldes do Segundo HAREM . . . . . . . . . . . . . . . . . . . . . . . . . . 15

3.5 Melhores resultados da Medida-F de classificação de cada sistema participante do Segundo HAREM no cenário total com ALT estrita. . . . . . . . . . . . . . . . 16

3.6 Melhores resultados da Medida-F de classificação de cada sistema participante do Segundo HAREM no cenário total com ALT relaxada. . . . . . . . . . . . . . . . 16

4.1 Distribuições de probabilidade para a classificação gramatical da palavra "jabulane". 25

4.2 Moldes de regras utilizados por Brill. Cada linha é uma condição que ativa a ação; w e $\mathbf{x}$ são variáveis que representam as palavras presentes no texto de treinamento; $\mathbf{z}$ e $\mathbf{t}$ representam as etiquetas possíveis do conjunto de treinamento. . . . . . . . 26

4.3 Conjunto de moldes de regras para a tarefa de segmentação de texto. . . . . . . . . . 28

5.1 Moldes de regras para TBL aplicado à tarefa de REM. . . . . . . . . . . . . . . 30

6.1 Representação das etiquetas de EM após o Filtro de Avaliação. . . . . . . . . . . . . 37

6.2 Conjunto de Classes de Palavras utilizadas pelo CoGrOO . . . . . . . . . . . . . . . 38

6.3 Exemplos de moldes de predicados contextuais. . . . . . . . . . . . . . . . . 41

6.4 Predicados contextuais dos moldes da Tabela 6.3 aplicados sobre o contexto $b_{4}$ da Tabela 6.1. . . . . . . . . . . . . . . . . . . . . . . . 41

6.5 Exemplos de sequências de etiquetamentos inconsistentes. . . . . . . . . . . . . . 42

6.6 Condições para permissão do etiquetamento do token $t_{i}$, de uma sentença de tamanho $n$. Onde $i$ é a posição na sentença do token a ser analisado, emtag $i$ é a etiqueta a ser

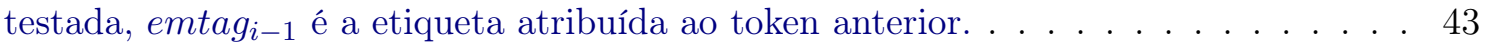

6.7 Resultado da comparação entre os textos Tabela 3.1 obtido pelo módulo Avaliador. . 43

7.1 Córpus utilizados nos experimentos e suas distribuições de EM por categorias. . . . . 46

7.2 Conjunto de características utilizadas para a exploração da estrutura interna da palavra. 47 
7.3 Estudo de Sobreposição de características utilizando o corte igual a 10. Os melhores resultados por córpus estão em negrito. . . . . . . . . . . . . . . . . . . . . . . . . . . 48

7.4 Análise do número para corte de predicados contextuais utilizando as características da estrutura interna da palavra com sobreposição. . . . . . . . . . . . . . . . . . . . 48

7.5 Comparação das diferentes implementações do uso das características léxicas e configurações de cortes aplicados sobre o córpus estudados. Os melhores resultados por córpus estão em negrito. . . . . . . . . . . . . . . . . . . . . . . . . . . . 51

7.6 Avaliação das Características de Estrutura Interna da palavra combinadas com as Características $L_{3}$ e $L_{4}$. . . . . . . . . . . . . . . . . . . . . . . . . . . . . . . . . . . 52

7.7 Avaliação de modelos treinados utilizando apenas as etiquetas morfológicas obtidas pelo CoGrOO. Foram consultados as etiquetas dos tokens $t_{-2}$ a $t_{2}$. . . . . . . . . . . 52

7.8 Modelo-base criado utilizando em conjunto as características de estrutura interna da palavra $(E I)$, características léxicas $\left(L_{4}\right)$ e etiquetas morfológicas $(P o S)$. . . . . . . . 53

7.9 Dicionários baseados no REPENTINO. . . . . . . . . . . . . . . . . . . . . . . 55

7.10 Resumo das características utilizadas. . . . . . . . . . . . . . . . . . . . . 56

7.11 Resultados de cada característica adicionada ao modelo base. Os melhores resultados estão em negrito. . . . . . . . . . . . . . . . . . . . . . . . . . . . . . . . . 57

7.12 Comparação dos modelos MTodas e MSinergia aplicados em cada córpus. . . . . . 58

7.13 Avaliação de cortes para os modelos melhorados utilizando os córpus Mini HAREM e Primeiro HAREM juntos. . . . . . . . . . . . . . . . . . . . . . . . . . . . 59

7.14 Medida-F do modelo MTodas $_{\text {corte=5 }}$ aplicado na avaliação de domínio do córpus. . . 60

7.15 Melhores resultados da Medida-F de classificação de cada sistema participante do Segundo HAREM no cenário total com ALT estrita. Os resultados do nosso sistema estão na linha destacada. . . . . . . . . . . . . . . . . . . . . . . . . . . . . 61

7.16 Comparativo do modelo MTodas $_{\text {corte }=5}$ com os resultados dos sistemas participantes do Segundo HAREM no Cenário Seletivo (Apenas Categorias). . . . . . . . . . . . . 62

B.1 Resultados da avaliação mais extensa de valores de cortes para o modelo MTodas. 73

B.2 Resultados completos dos vários modelos avaliados no Cenário Total do Segundo HAREM. ........................... 74

B.3 Resultados completos dos vários modelos avaliados no Cenário Seletivo do Segundo HAREM 


\section{Capítulo 1}

\section{Introdução}

O Processamento da Linguagem Natural (PLN) é um ramo da ciência da computação que utiliza técnicas computacionais para estudar os problemas relacionados à linguagem natural, seja falada ou escrita. O PLN tem como objetivo aproximar o computador da realidade do homem, desenvolvendo ferramentas que possibilitem uma comunicação mais natural entre homem e máquina.

De acordo com Russell \& Norvig [RN95], extração da informação é a tarefa de identificar ocorrências de uma classe particular de objetos e outras informações tais como eventos, além de identificar as relações entre esses objetos e eventos. O Reconhecimento de Entidades Mencionadas (REM) é uma sub-tarefa da extração de informações e tem como objetivo localizar e classificar elementos do texto em categorias pré-definidas como nome de pessoas, organizações, lugares, datas, e outras classes. Entidade Mencionada (EM) é a tradução livre utilizada por pesquisadores da língua portuguesa para o termo original em inglês named entity e que literalmente poderia ser traduzido para "entidades com nome próprio" ou "entidade nomeada". A tradução para "entidade mencionada" se deve por entender que a ocorrência específica de uma entidade em um dado texto é classificada de acordo com o significado daquela entidade no texto em questão [SC08].

Tomemos como exemplo a frase "O presidente Lula deverá comparecer ao $10^{\circ}$ Fórum Internacional Software Livre na próxima sexta-feira, 26 de junho"1. Sabemos que uma pessoa foi citada, "presidente Lula", e que "10 Fórum Internacional Software Livre" pode ser classificado como um evento assim como "26 de junho" indica um tempo. Podemos ver na Tabela 1.1 alguns exemplos típicos de classificações de entidades mencionadas.

Sistemas mais especializados podem se concentrar em vários outros tipos de entidades, tais como produtos comerciais, armas, especialidades profissionais, artes, proteínas, vírus, genes e outras entidades de interesse. Dessa forma, percebemos que o foco comum de concentração desses possíveis sistemas é a identificação de nomes próprios, as formas características que tais nomes são identificados em uma dada linguagem ou gênero e o conjunto de categorias das entidades dado um domínio de interesse.

Esse conhecimento obtido possibilita a execução de tarefas mais avançadas e pode ser considerado um dos primeiros passos para a análise semântica de textos, além de ser uma sub-tarefa crucial para os sistemas de gerenciamento de documentos, extração da informação, mineração de textos, entre outros, o que torna o REM uma importante tarefa.

Essa obtenção de conhecimento, que ocorre de forma natural para humanos, mostra-se um

\footnotetext{
${ }^{1}$ Texto extraído de: http://fisl.softwarelivre.org/10/www/06/23/presidente-lula-vem-ao-fisl10
} 


\begin{tabular}{|c|c|l|}
\hline Tipo & Etiqueta & Exemplos \\
\hline Pessoa & PER & Indivíduos, personagens fictícios, pequenos grupos. \\
Organização & ORG & Empresas, agências, partidos políticos, grupos religiosos. \\
Localidade & LOC & Bairro, cidade, país. \\
Outros & O & Nomes de carros, títulos de livros, modelos de computadores. \\
\hline
\end{tabular}

Tabela 1.1: Exemplos de classificação de entidades e seus possíveis tipos.

grande desafio para os sistemas especialistas, sendo portanto necessário uma atenção especial ao processo de REM.

\subsection{Objetivos}

O objetivo do nosso trabalho é a construção de um sistema de REM para a língua portuguesa utilizando técnicas de Aprendizado de Máquina; mais especificamente, o arcabouço de Máxima Entropia. Para que possamos medir o desempenho do nosso sistema na execução de sua tarefa, verificaremos algumas das diferentes formas de avaliação de sistemas de REM existentes na literatura. Desta forma seremos capazes de comparar os resultados obtidos pelo nosso sistema com os resultados dos sistemas e técnicas aplicadas sobre o mesmo problema.

Um objetivo secundário deste trabalho é o estudo do impacto das diferentes características textuais que serão exploradas para a identificação e a classificação das EM. Esse tipo de conhecimento pode ser utilizado posteriormente por pesquisadores para a construção de novos sistemas de REM para a língua portuguesa.

\subsection{Organização do Trabalho}

Este trabalho está dividido da seguinte forma: no Capítulo 2 mostramos alguns requisitos necessários ao processamento estatístico de linguagem natural e algumas técnicas de PLN geralmente empregadas no processamento de texto. No Capítulo 3 apresentamos algumas medidas geralmente empregadas na avaliação de sistemas de REM, bem como algumas conferências que foram importantes para a avaliação conjunta de sistemas de REM e suas diferentes abordagens no processo de pontuação destes sistemas. No Capítulo 4 explicamos alguns conceitos preliminares de aprendizado de máquina (AM) e apresentamos algumas técnicas de AM que são importantes para o nosso trabalho. No Capítulo 5 mostramos como algumas das técnicas apresentadas no Capítulo 4 foram utilizadas para a resolução do problema de REM. No Capítulo 6 descrevemos a arquitetura utilizada para a construção do sistema, seus módulos, algumas dificuldades e dúvidas que surgiram durante a sua implementação. No Capítulo 7 discutimos as características textuais exploradas e seus impactos na performance de vários modelos construídos e em seguida testamos um modelo e o avaliamos seguindo os moldes de um evento da área e comparamos nossos resultados com os resultados dos participantes do mesmo evento. Finalmente, no Capítulo 8, expomos as conclusões deste trabalho. 


\section{Capítulo 2}

\section{Processamento Estatístico da Linguagem Natural}

O processamento estatístico da linguagem natural consiste no uso de abordagens quantitativas e probabilísticas para o processamento automático de textos e da linguagem falada. Através de grandes bases de textos, coletados conforme certos critérios, podemos obter informações úteis para o cálculo de diversos tipos de grandezas como, por exemplo, a ocorrência de palavras, sequência de palavras, ocorrência de palavras com características determinadas etc. Neste capítulo veremos alguns requisitos necessários ao processamento estatístico de linguagem natural e algumas técnicas de PLN geralmente empregadas no processamento de texto.

\subsection{Córpus}

O córpus é uma coleção especial de textos coletados conforme critérios específicos e segundo Manning \& Schütze [MS99], é um dos principais requisitos para o processamento estatístico da linguagem natural. Tal recurso é utilizado para treinamento e teste de modelos estatísticos de linguagem natural escrita e falada, bem como para avaliação de componentes de sistemas de linguagem natural.

Na escolha ou preparação de um córpus devem ser levados em consideração os tipos de informações que se quer obter para a resolução de um determinado problema. Por exemplo, se um córpus foi desenvolvido como uma amostra representativa de etiquetagem morfológica de textos históricos, as estimativas obtidas deste podem não ser adequadas para textos contemporâneos. Além disso, devemos ser cuidadosos com a validade dos resultados da análise estatística obtida, observando os critérios de anotação adotados na coleção.

Segundo Krenn (1990, apud [Gd01], p. 9), as principais características observáveis de um córpus são:

- Ocorrência de fenômenos linguísticos no contexto;

- Combinação de aspectos de competência e performance: os dados do córpus refletem o uso da linguagem - todos os dados, mesmo os que são falsos em termos de competência gramatical, devem ser considerados como úteis;

- Informações de frequência de uma variedade de fenômenos em vez de fenômenos selecionados; 
- Consideração de todos os dados existentes pelo esquema de anotação, sem distinção entre termos competentes ou não.

\subsubsection{Texto Marcado}

Dos córpus de textos puros (textos sem marcações) pode ser extraído bastante conhecimento e por isso tais córpus são muito úteis. Várias técnicas fazem uso de um tipo especial de córpus, conhecido como texto marcado ou córpus anotado. Este é criado através de um processo conhecido como anotação, onde informações estruturais são inseridas no texto.

Com textos marcados é possível obter informações sobre o domínio desejado. São utilizados em técnicas computacionais que requerem processamento de propriedades não-observáveis em textos puros. Em alguns deles, apenas as estruturas básicas são marcadas, tais como as fronteiras de sentenças e parágrafos. Já outros possuem uma carga de informação maior tal como toda a estrutura sintática. A marcação mais comum é a codificação das categorias das palavras.

Para marcar a estrutura de um texto, existem vários esquemas. Um esquema bastante empregado na anotação gramatical de um texto é a utilização de um caractere específico entre cada palavra e o código referente à sua categoria. O caractere específico geralmente empregado é uma barra "/" ou um sublinhado "_".

Na Tabela 2.1 é apresentado um pequeno extrato de texto livre e em seguida o mesmo texto marcado com etiquetas morfológicas, extraído do texto de Manuel Bernardes(1644) do córpus Tycho Brahe ${ }^{1}$.

\begin{tabular}{|l|l|}
\hline Texto Puro & Eu disponho para vós o Reino, como meu Pai o dispôs para mim; \\
\hline \multirow{3}{*}{ Texto Marcado } & $\begin{array}{l}\text { Eu/PRO disponho/VB-P para/P vós/PRO o/D Reino/NPR ,/, } \\
\text { como/CONJS meu/PRO Pai/NPR o/CL dispôs/VB-D } \\
\text { para/P mim/PRO ;/. }\end{array}$ \\
\hline
\end{tabular}

Tabela 2.1: Excerto de texto de Manuel Bernades extraído do córpus Tycho Brahe.

Outro esquema atualmente bastante empregado é o SGML. O SGML (do inglês, Standard Generalized Markup Language) é uma linguagem que permite definir uma gramática para os textos, em particular para o tipo de marcação que eles contém. O XML é um conjunto simplificado de SGML e atualmente também vem sendo empregado para anotações de textos.

\subsection{Técnicas de PLN}

Nesta seção veremos algumas técnicas geralmente empregadas no processamento de textos e que são úteis para o entendimento do nosso trabalho.

\subsubsection{Tokenização}

Normalmente, uma das primeiras etapas do processamento de texto é dividir o texto de entrada em unidades chamadas tokens. Cada token representa uma palavra ou algo como um número ou um sinal de pontuação. Esse processo é conhecido como tokenização. Segundo Gasperin \& Lima [Gd01],

\footnotetext{
${ }^{1}$ Tycho Brahe: Corpus histórico do português. Pode ser consultado em: http://www.tycho.iel.unicamp.br/ tycho/ corpus/index.html
} 
a especificação do que deve ser considerado como uma palavra é complexa; a principal informação utilizada é a ocorrência de um espaço em branco, tabulação ou início de uma nova linha. Porém nem mesmo estes sinais são necessariamente confiáveis.

O resultado desse processo na língua portuguesa é uma sequência de palavras intercaladas por espaços ou por símbolos delimitadores. Por exemplo, após o processo de tokenização, a frase "Disseram-me que hoje poderia chover, mas não está parecendo." poderia ser representada como a seguinte sequência de tokens: [Disseram] [-me] [que] [hoje] [poderia] [chover] [, ] [mas ] [não] [está] [parecendo] [.].

Alguns problemas inerentes ao processo de tokenização são:

- Marcas de pontuação: Geralmente as marcas de pontuação vêm junto com as palavras, a exemplo da vírgula, do ponto e vírgula e do ponto final. A remoção dos pontos finais que se encontram com as palavras é um dos problemas, pois um ponto pode indicar, por exemplo, uma abreviação;

- Hífen: O hífen, dentre outras utilidades, pode ser utilizado como separador de sílabas de uma palavra; entre as palavras de um substantivo composto; ou ainda, principalmente na língua inglesa, para auxiliar a qualificação de uma palavra. Nos dois primeiros casos tendese a considerar uma palavra apenas; porém no último caso descrito, pode-se reconhecer as palavras separadamente.

Além destes, existem outros problemas existentes no processo de tokenização tais como a separação de palavras contendo apóstrofos e casos em que o espaços em branco não indicam quebra de palavras. Uma discussão mais detalhada sobre este assunto por ser consultada em [MS99].

\subsubsection{Separação de Sentenças}

Uma intuição simples para definição de sentenças é considerar como sendo uma sequência de palavras ou caracteres que está entre os delimitadores "?", “.” ou "!". No entanto, uma marca de pontuação pode não indicar o fim de uma sentença, mas sim uma abreviação, ou ambas as funções simultaneamente, que neste último caso é um fenômeno chamado haplologia. Além do problema de ambiguidade destes delimitadores, existem frases que contêm outras frases dentro delas, a exemplo das ocorrências de frases com '"' e ().

Mesmo com esses problemas, segundo Riley (1989, apud [MS99], p. 134), 90\% dos pontos são indicadores do fim de uma sentença. Manning \& Schütze [MS99], afirmam que na prática, a maioria das soluções para a separação de sentenças envolvem métodos heurísticos. No entanto, estas soluções requerem marcação manual e conhecimento do domínio por parte do desenvolvedor do sistema de "tokenização". Existem ainda várias outras abordagens para a automatização do processo de separação de sentenças. Dentre elas há propostas de técnicas que utilizam árvores de classificação estatísticas, redes neurais baseadas na distribuição das categorias das palavras, ou ainda abordagem baseada em maximização de entropia.

\subsubsection{Análise Morfossintática}

A Análise Morfossintática é a tarefa de PLN que identifica corretamente a classe de cada uma das palavras que compõem uma sentença. Estas classes de palavras são conhecidas como 
classes gramaticais ou categorias morfossintáticas. Geralmente tais classes são representadas por um conjunto de códigos, e estes são utilizados na etiquetagem das palavras.

Uma das dificuldades desta tarefa é a existência de muitas palavras com diferentes classificações possíveis. Tais palavras, se estiverem fora de contexto, ocasionam a ambiguidade sobre sua interpretação para a correta classificação gramatical. Por exemplo, na frase "Vamos assistir ao jogo", a palavra "jogo" é um substantivo que pode significar, dentre outras, uma partida de futebol. Porém, a mesma palavra empregada na frase "Eu jogo videogame", trata-se de uma flexão na primeira pessoa do singular do presente do indicativo do verbo "jogar". A palavra "jogo" é um exemplo de ambiguidade existente na língua portuguesa.

Segundo Manning \& Schütze [MS99], o conjunto de códigos mais difundido tem sido o conjunto utilizado pelo córpus American Brown (Brown tag set) e as séries de conjuntos desenvolvidos na Universidade Lancaster. O Penn Treebank tag set é uma versão mais simplificada do Brown tag set e tem sido um conjunto de códigos largamente utilizado computacionalmente.

Alves [dAF03] afirma que a partir do momento que temos no texto a informação das classes gramaticais das palavras, fica muito mais fácil resolver problemas mais complexos como a análise sintática, tradução ou até mesmo a extração da informação de textos. As marcações presentes no texto de exemplo da Tabela 2.1 são exemplos de etiquetas morfológicas² ${ }^{2}$.

\subsection{Comentários}

Além das etapas de PLN citadas neste capítulo, existem várias outras, tais como: análise de formatação de baixo nível, etapa em que conteúdos não relevantes podem ser retirados, por exemplo, cabeçalhos de documento, tabelas, diagramas e etc; lemmatização, etapa em que as diversas formas de representação são substituídas pela forma primitiva; stemming, etapa em que consiste a remoção de prefixos e sufixos de acordo com algumas regras previamente determinadas; dentre outras.

Não discutiremos tais etapas por não fazerem parte do objetivo do nosso trabalho. O leitor interessado em maiores detalhes sobre estes assuntos pode consultar Manning \& Schütze [MS99] e Gasperin \& Lima [Gd01]

\footnotetext{
${ }^{2} \mathrm{O}$ conjunto de etiquetas morfológicas utilizadas pelo Tycho Brahe pode ser consultado em: http://www.tycho. iel.unicamp.br/ tycho/corpus/manual/tags.html
} 


\section{Capítulo 3}

\section{Avaliação de Sistemas de Reconhecimento de Entidades Mencionadas}

No intuito de fomentar e avaliar pesquisas em áreas especificas do conhecimento, surgem conferências com este propósito. Para a avaliação de sistemas de REM, algumas técnicas foram propostas em diferentes conferências. Estas conferências consideraram a capacidade do sistema em anotar os textos tal qual faria um especialista linguista, comparando as saídas dos sistemas com textos anotados por humanos. Neste capítulo, veremos algumas medidas geralmente empregadas para avaliação de sistemas de REM e em seguida discutiremos algumas conferências que foram importantes para a avaliação conjunta de sistemas de REM bem como suas diferentes abordagens no processo de pontuação dos sistemas participantes. Esse conhecimento é importante para nossa proposta, pois permite perceber a dificuldade em avaliar e comparar sistemas de REM que foram desenvolvidos para diferentes línguas e em diferentes classes de EM, bem como os métodos de pontuação.

\subsection{Medidas de Avaliação}

As avaliações de sistemas de REM são geralmente baseadas na comparação das saídas dos sistemas com textos anotados por especialistas. Para entender melhor essa tarefa, podemos analisar um exemplo extraído do trabalho de Nadeau \& Sekine [NS07].

Ao comparar o texto anotado por um especialista, conforme pode ser visto na Tabela 3.1(A), com o texto de saída de um sistema hipotético, como no exemplo da Tabela 3.1(B), nos deparamos com cinco diferentes tipos de erros como podemos verificar na Tabela 3.2, e apenas uma marcação completamente correta: <ORGANIZATION>Acme</ORGANIZATION>.

As medidas de avaliação de sistemas de REM levam em conta as noções de precisão, cobertura e medida- $F$, que são métricas empregadas nas avaliações de sistemas de Recuperação da Informação. No contexto de REM, um item relevante é uma EM corretamente identificada e classificada por um sistema, porém há casos em que o sistema pode ser avaliado em apenas uma destas tarefas.

De forma geral, a precisão (P), calculada pela Equação 3.1, mede a taxa do número de itens relevantes recuperados por um sistema dado o número de itens recuperados. A cobertura (C), calculada pela Equação 3.2, mede a taxa do número de itens relevantes recuperados por um sistema 


\begin{tabular}{|c|}
\hline (A) Texto anotado por um especialista \\
\hline $\begin{array}{l}\text { Unlike }<\text { PERSON }>\text { Robert</PERSON }>\text {, }<\text { PERSON }>\text { John Briggs } \\
\text { Jr</PERSON }>\text { contacted }<\text { ORGANIZATION }>\text { Wonderfull } \\
\text { Stockbrockers Inc }</ \text { ORGANIZATION }>\text { in }<\text { LOCATION }>\text { New } \\
\text { York</LOCATION }>\text { and instructed them to sell all his } \\
\text { shares in <ORGANIZATION }>\text { Acme</ORGANIZATION }>\text {. }\end{array}$ \\
\hline (B) Saída de um sistema hipotético \\
\hline $\begin{array}{c}\text { <LOCATION>Unlike</LOCATION> Robert, <ORGANIZATION>John } \\
\text { Briggs Jr</ORGANIZATION> contacted Wonderfull } \\
\text { <ORGANIZATION>StOckbrockers</ORGANIZATION> Inc } \\
\text { <PERSON>in New York</PERSON> and instructed them to sell all his } \\
\text { shares in <ORGANIZATION>Acme</ORGANIZATION>. }\end{array}$ \\
\hline
\end{tabular}

Tabela 3.1: Comparação de um texto anotado por um especialista em (A) com um texto de saída anotado por um sistema hipotético em (B).

\begin{tabular}{|c|c|c|c|}
\hline Solução correta & Saída do sistema & Comentário & Avaliação \\
\hline Unlike & $\begin{array}{c}<\text { LOCATION }> \\
\text { Unlike } \\
</ \text { LOCATION }>\end{array}$ & $\begin{array}{l}\text { O sistema indicou uma } \\
\text { entidade onde não existe }\end{array}$ & Erro \\
\hline $\begin{array}{l}<\text { PERSON }> \\
\text { Robert } \\
</ \text { PERSON }>\end{array}$ & Robert & $\begin{array}{l}\text { Uma entidade foi } \\
\text { completamente perdida } \\
\text { pelo sistema. }\end{array}$ & Erro \\
\hline $\begin{array}{l}<\text { PERSON }> \\
\text { John Briggs Jr } \\
\text { </PERSON }>\end{array}$ & $\begin{array}{l}\text { <ORGANIZATION> } \\
\text { John Briggs Jr } \\
</ \text { ORGANIZATION> }\end{array}$ & $\begin{array}{l}\text { Uma entidade foi identificada, } \\
\text { porém classificada } \\
\text { incorretamente pelo sistema. }\end{array}$ & Erro \\
\hline $\begin{array}{l}\text { <ORGANIZATION> } \\
\text { Wonderfull } \\
\text { Stockbrockers Inc } \\
\text { </ORGANIZATION> }\end{array}$ & $\begin{array}{c}<\text { ORGANIZATION }> \\
\text { Stockbrockers } \\
</ \text { ORGANIZATION }>\end{array}$ & $\begin{array}{l}\text { O sistema indicou corretamente } \\
\text { a classificação da entidade } \\
\text { porém seus limites estão } \\
\text { incorretos. }\end{array}$ & Erro \\
\hline $\begin{array}{l}<\text { LOCATION }> \\
\text { New York } \\
</ \text { LOCATION }>\end{array}$ & $\begin{array}{l}\text { <PERSON }> \\
\text { in New York } \\
</ \text { PERSON }>\end{array}$ & $\begin{array}{l}\text { O sistema indicou uma } \\
\text { entidade porém tanto } \\
\text { seus limites quanto sua } \\
\text { classificação estão incorretos. }\end{array}$ & Erro \\
\hline $\begin{array}{c}<\text { ORGANIZATION }> \\
\text { ACme } \\
<\text { /ORGANIZATION }>\end{array}$ & $\begin{array}{c}\text { <ORGANIZATION }> \\
\text { Acme } \\
</ \text { ORGANIZATION> }\end{array}$ & $\begin{array}{l}\text { O sistema indicou corretamente } \\
\text { tanto os limites da entidade } \\
\text { quanto sua classificação. }\end{array}$ & Acerto \\
\hline
\end{tabular}

Tabela 3.2: Um acerto e possiveis erros cometidos pelos sistemas de REM.

dado o número de itens relevantes na amostra analisada.

$$
\begin{gathered}
\mathrm{P}=\frac{\text { número de itens relevantes recuperados pelo sistema }}{\text { número de itens recuperados }} \\
\mathrm{C}=\frac{\text { número de itens relevantes recuperados pelo sistema }}{\text { número de itens relevantes }}
\end{gathered}
$$

A medida-F nos fornece uma maneira de combinar a precisão e a cobertura em uma única 
medida e é calculada pela Equação 3.3.

$$
F_{\beta}=\frac{\left(\beta^{2}+1\right) P C}{\beta^{2} P+C} .
$$

O parâmetro $\beta$ da Equação 3.3 diferencia a importância da precisão e cobertura, e pode ser manipulado de acordo com a necessidade do sistema. A precisão e a cobertura ficam igualmente balanceadas quando atribuímos o valor 1 ao parâmetro $\beta$. Essa medida é geralmente chamada de $F_{\beta=1}$ ou apenas $F_{1}$ (veja a Equação 3.4 ).

$$
F_{1}=\frac{2 P C}{P+C}
$$

No entanto, para o contexto de avaliação de sistemas de REM, o cálculo da precisão e da cobertura varia de acordo com as especificações de cada conferência de avaliação. Nas próximas seções discutiremos sobre algumas conferências e suas abordagens para a pontuação dos sistemas participantes.

\subsection{Conferências de Avaliação de REM}

\subsubsection{MUC}

O MUC (Message Understanding Conferences), foi uma série de eventos que ocorreram entre 1987 e 1998, e tinha como propósito avaliar e promover o progresso nas pesquisas sobre extração de informações e padronizar a avaliação das tarefas dessa área. O MUC-6 foi o sexto desta série, realizado em novembro de 1995. O REM para a língua inglesa foi uma das tarefas que estavam envolvidas nessa conferência. No MUC-7, realizado em 1998, também foi dado ênfase na avaliação de sistemas de REM.

Para o MUC a tarefa de REM tinha como objetivo reconhecer nome de pessoas, organizações, nome de lugares, expressões temporais e certos tipos de expressões numéricas. Essa tarefa estava dividida em três subtarefas: entidades de nomes próprios (ENAMEX), expressões temporais (TIMEX) e expressões numéricas (NUMEX). Cada subtarefa era ainda subcategorizada da seguinte forma: ENAMEX subcategorizada como organização (ORGANIZATION), pessoa (PERSON) e lugar (LOCATION); TIMEX podendo ser data (DATE) ou medidas de tempo (TIME); e finalmente (NUMEX) podendo ser valores monetários (MONEY) ou percentuais (PERCENT).

Para o processo de avaliação era necessário seguir algumas regras de anotação do texto. A seguir temos um exemplo de como um texto deveria ser anotado para o MUC:

$$
\ldots<\text { ENAMEX TYPE="ORGANIZATION">Giants }</ \text { ENAMEX }>\ldots
$$

Do exemplo temos que a palavra Giants é uma entidade mencionada do tipo ENAMEX subcategorizado como uma organização (ORGANIZATION). No MUC, um sistema de REM é avaliado considerando a sua capacidade de identificar o texto exato (TEXT) e de classificar o tipo correto (TYPE) da EM. Um TYPE é dado como correto se uma EM for classificada corretamente, independentemente dos limites da marcação, desde que haja pelo menos a sobreposição de um dos termos da entidade. Um TEXT é dado como correto se os limites da entidade estão corretos, independentemente da classificação da entidade. 
Assim, para cada EM corretamente identificada, tarefa TEXT, e classificada, tarefa TYPE, são contabilizados dois pontos. Também é admitido crédito parcial para erros que ocorrerem em apenas uma das duas formas.

A precisão é o percentual do número de respostas corretas (COR) dado o número de respostas obtidos pelo sistema $(\mathrm{ACT})$ e a cobertura é o percentual dos número de respostas corretas dado o número de possíveis entidades na solução (POS). A pontuação final é a medida-F.

Para o exemplo da Tabela 3.1, temos a precisão, a cobertura e a medida-F igual a $40 \%$, pois: $\mathrm{COR}=4(2 \mathrm{TEXT}+2 \mathrm{TYPE}), \mathrm{ACT}=10(5 \mathrm{TEXT}+5 \mathrm{TYPE})$ e POS $=10(5 \mathrm{TEXT}+5 \mathrm{TYPE})$.

Segundo Nadeau \& Sekine [NS07], esta abordagem possui a vantagem de considerar todos os tipos de erros apresentados na Tabela 3.2, além de permitir créditos parciais para erros cometidos em apenas uma das formas: TYPE ou TEXT.

A maior medida-F alcançada no MUC-6 foi de 96,42\% [Chi95]. No MUC-7 o melhor sistema obteve a medida-F de 93.39\% [mucb]. De acordo com Palmer [PD97], os sistemas participantes do MUC-6 tiveram bons desempenhos, no entanto, muitos deles utilizaram recursos específicos da língua inglesa para executar a tarefa de REM e não se sabe como seriam os desempenhos desses sistemas em algum outro idioma.

Mais detalhes sobre a organização e resultados do MUC podem ser encontrados em [muca].

\subsubsection{CoNLL}

A CoNLL (Conference on Computational Natural Language Learning) é uma série de conferências que tem como objetivo promover a pesquisa e avaliação em diversas áreas de PLN. Sua primeira edição data de 1997.

A conferência de 2002, CoNLL-2002, tinha como tarefa compartilhada a avaliação de sistemas de REM independente de linguagem. Neste evento foram considerados quatro tipos de EM: pessoas, lugares, organizações e nomes de entidades diversas que não se encaixam em nenhuma das categorias anteriores. Os participantes recebiam dados de treino e teste para duas línguas, holandesa e espanhola, e poderiam também utilizar recursos extras para treinamento, além dos dados fornecidos. Na conferência de 2003, CoNLL-2003, novamente o REM independente de linguagem foi o foco da tarefa compartilhada, porém as línguas alvos desse evento foram as línguas inglesa e alemã. Uma das principais tarefas dos participantes deste segundo evento era descobrir como melhorar o desempenho dos seus sistemas de REM utilizando alguns recursos adicionais fornecidos pelo evento, tais como listas de EM e textos não-anotados.

A avaliação dos sistemas é baseada na comparação da medida-F. Uma EM é considerada correta apenas se o texto exato é identificado e a sua classificação for correta. A precisão é o percentual de EM corretas que são encontradas pelo sistema. A cobertura é o percentual de entidades presentes no texto solução que são encontradas pelo sistema.

Para o exemplo da Tabela 3.1, temos cinco entidades no texto solução e cinco entidades encontradas pelo sistema sendo que apenas uma das entidades encontradas pelo sistema está completamente correta. Portanto, temos a precisão, cobertura e medida-F com o mesmo valor: $20 \%$.

O sistema participante que teve o melhor resultado no evento de 2002, mostrado em [CMP02], conseguiu obter a medida-F de 81,39\% para espanhol e 77,05\% para holandês. As maiores medidasF alcançadas na CoNLL-2003 foram 88,76\% para a língua inglesa e 72,42\% para o alemão, obtido pelo sistema descrito em [FIJZ03]. 
Podemos ver mais informações sobre a série CoNLL em [CoN10]; resultados e maiores detalhes sobre a CoNLL-2002 em [Tjo02] e em [the02], e sobre a CoNLL-2003 em [the03] e em [TD03].

\subsubsection{HAREM}

A Linguateca é um centro de recursos (distribuídos) para o processamento computacional da língua portuguesa. Tem como objetivo facilitar o acesso aos recursos já existentes tais como córpus, enciclopédias, textos em português; desenvolver em colaboração com os interessados, os recursos mais prementes além de organizar avaliações conjuntas que envolvam a comunidade científica de interesse em torno do PLN [Lin10].

O HAREM (Avaliação de Sistemas de Reconhecimento de Entidades Mencionadas) é uma avaliação conjunta de sistemas de Reconhecimento de Entidades Mencionadas organizada pelo Linguateca, iniciado em 2005. Segundo Cardoso [Car06], o HAREM é a primeira avaliação (conjunta) de sistemas de REM em português. Teve como motivação o fato de sentirem que os eventos de avaliação de REM anteriores não tinham abordado a tarefa com profundidade suficiente, e o objetivo de reunir a comunidade científica em torno de outro evento de avaliação dentro do processamento da língua portuguesa. Nesse intuito, os participantes tiveram um papel ativo na organização do HAREM, tendo colaborado na criação das diretivas e na anotação das coleções.

A avaliação do HAREM segue um conjunto de diretivas estabelecidas junto com os participantes do próprio HAREM, a qual denominaram Diretivas de Avaliação do HAREM. Essas diretivas representam o conjunto de pontuações, regras e medidas usadas para comparar as saídas dos sistemas em relação à Coleção Dourada, que é o texto de comparação utilizado pelo evento, criado em conjunto com a comunidade.

Até a realização deste trabalho o HAREM já organizou três eventos de avaliação conjunta:

- Primeiro HAREM: Evento organizado a partir de Setembro de 2004 com a realização da avaliação conjunta em Fevereiro de 2005;

- Mini HAREM: Realizado em Abril de 2006, utilizou a mesma metodologia e a mesma plataforma de avaliação da primeira avaliação;

- Segundo HAREM: Organizado a partir de Novembro de 2007, teve a avaliação conjunta realizada em Abril de 2008.

Nosso trabalho se concentra nas diretivas do Segundo HAREM. No Segundo HAREM os sistemas são avaliados de acordo com a capacidade na tarefa de identificação de entidades e na tarefa de classificação semântica. A avaliação da tarefa de identificação tem como objetivo medir a eficiência do sistema na delimitação correta de entidades mencionadas. A avaliação da classificação semântica tem como objetivo medir a eficácia do sistema na classificação de entidades mencionadas de acordo com uma hierarquia de categorias, tipos e subtipos definidos para o evento. Podemos ver na Figura 3.1 a árvore de categorias utilizadas no Segundo HAREM. No Apêndice A podem ser vistos exemplos de textos organizados por categorias de entidades mencionadas.

Na avaliação do Segundo HAREM é possível escolher as categorias, tipos, subtipos ou outros atributos que os sistemas pretendam etiquetar e serem avaliados, em função do interesse que essas etiquetas possam ter no contexto de outras aplicações desenvolvidas ou a desenvolver por parte dos participantes do evento, e que dependam direta ou indiretamente dessas informações. 


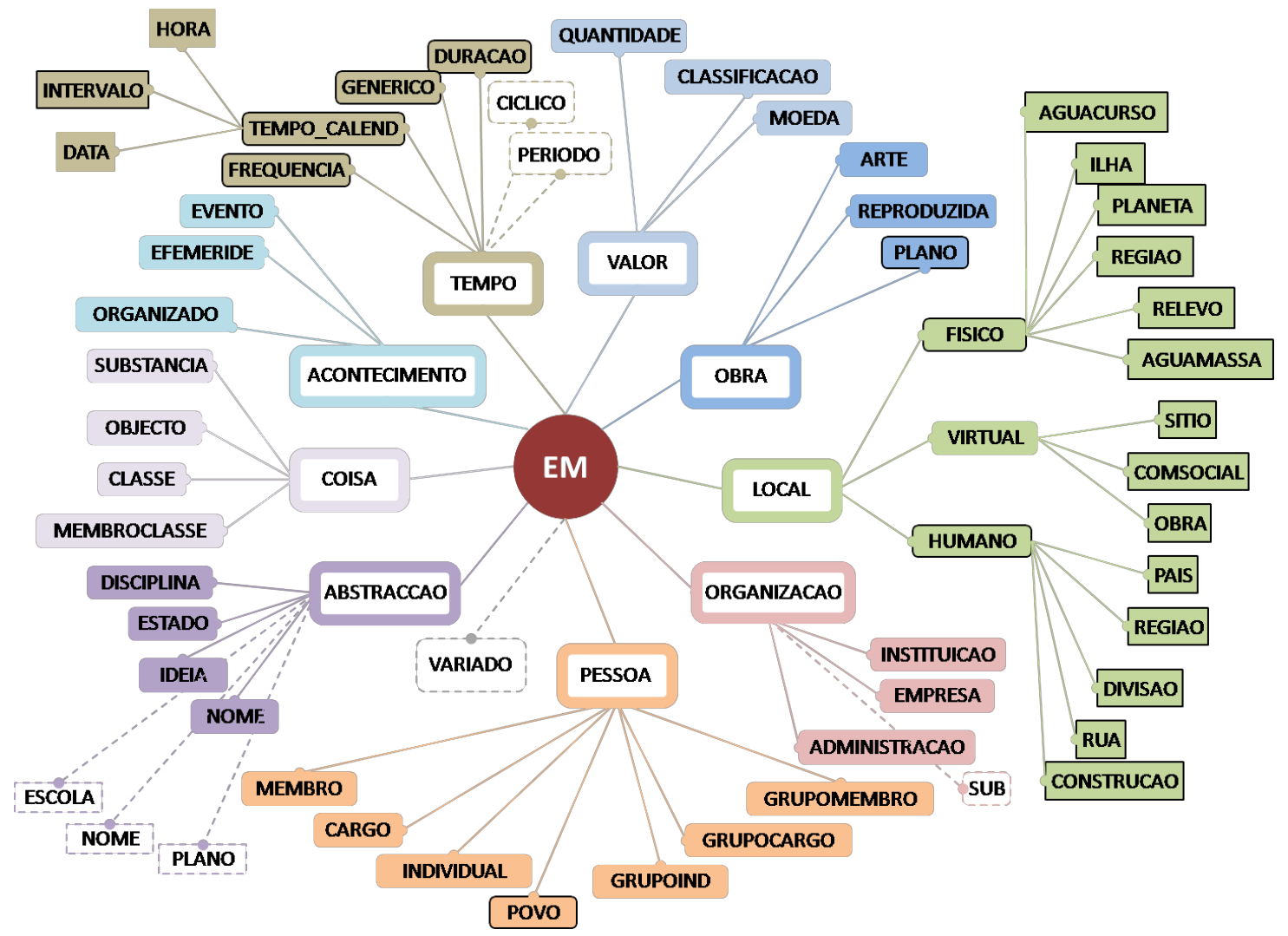

Figura 3.1: Árvore de categorias no Segundo HAREM: as categorias, tipos e subtipos representados nas caixas com contorno sólido preto só existem no Segundo HAREM; as categorias, tipos e subtipos representados nas caixas com contorno pontilhado só existem no Primeiro HAREM. Figura extraída de [MS08].

A cada conjunto diferente de categorias é dado o nome de cenário seletivo de participação. A avaliação em cenários seletivos permite comparar o desempenho dos diferentes sistemas com base em cada uma das categorias que se propuseram reconhecer, assim como em outros conjuntos de categorias que possam fazer sentido.

Além disso, no Segundo HAREM também é dada a possibilidade dos sistemas anotarem as diferentes interpretações de um segmento de texto, utilizando para isso uma etiqueta representativa de alternativas: ALT. A avaliação considerando a etiqueta ALT pode ser estrita ou relaxada. Na avaliação estrita de ALT, todas as alternativas possíveis para um segmento de texto são contabilizadas, e cada alternativa tem um peso igual ao inverso do número de alternativas dentro deste segmento, por exemplo, a todos os valores atribuídos a EM's dentro de um ALT com três elementos será associado um peso de $1 / 3$. Desta forma o sistema só atingirá o valor máximo possível se tiver classificado as três alternativas em seu resultado. Na avaliação relaxada de ALT, é selecionado apenas o elemento ALT que maximiza a classificação do sistema.

\section{Diretivas de Avaliação}

A diretivas de avaliação representam o conjunto de pontuações, regras e medidas usadas para comparar as saídas dos sistemas em relação à Coleção Dourada.

A pontuação é a avaliação qualitativa da relação entre a resposta do sistema e o que está na Coleção Dourada. Cada EM pode receber uma de três pontuações no que diz respeito à sua identificação: 
- Correta: quando a resposta do sistema coincide com a informação na Coleção Dourada;

- Em Falta: quando o sistema não atribui uma dada entidade presente na Coleção Dourada;

- Espúria: quando o sistema encontra uma EM que não existe na Coleção Dourada.

Estas pontuações também são utilizadas para pontuar a classificação através do cálculo de medidas.

As medidas permitem a transformação qualitativa da pontuação em um valor numérico. No Segundo HAREM é utilizado uma medida que combina a pontuação obtida na tarefa de identificação e classificação das categorias, tipos e subtipos, possibilitando a atribuição de diferentes pesos a cada um desses níveis e ainda a penalização por classificações incorretas. Tal medida é referenciada como Classificação Semântica Combinada (CSC). O cálculo da CSC utilizada para avaliar uma dada EM no Segundo HAREM é dada pela Fórmula 3.5.

$$
\begin{aligned}
& 1+\sum_{i=0}^{N}\left(\left(1-\frac{1}{n_{\text {cats }}}\right) \cdot \text { cat }_{\text {certa }} \cdot \alpha+\left(1-\frac{1}{n_{\text {tipos }}}\right) \cdot \text { tipo }_{\text {certo }} \cdot \beta+\left(1-\frac{1}{n_{\text {sub }}}\right) \cdot \text { sub }_{\text {certo }} \cdot \gamma\right) \\
& -\sum_{i=0}^{M}\left(\left(\frac{1}{n_{\text {cats }}}\right) \cdot \text { cat }_{\text {esp }} \cdot \alpha+\operatorname{cat}_{\text {certa }} \cdot \frac{1}{n_{\text {tipos }}} \cdot \text {.ipo }_{\text {esp }_{i}} \cdot \beta+\text { tipo }_{\text {certo }_{i}} \cdot \frac{1}{n_{\text {sub }}} \cdot \text { sub }_{\text {esp }} \cdot \cdot \gamma\right)
\end{aligned}
$$

onde:

$K_{\text {certo }_{i}}= \begin{cases}1 & \text { se o atributo } K_{i} \text { estiver correto } \\ 0 & \text { se } K_{i} \text { estiver incorreto ou omisso }\end{cases}$

$K_{e s p_{i}}= \begin{cases}1-K_{\text {certo }} & \text { se o atributo } K_{i} \text { estiver preenchido } \\ 0 & \text { se } K_{i} \text { estiver omisso }\end{cases}$

$K \in\{c a t, t i p o, s u b\}$

$n_{\text {cats }}=$ número de categorias relativas ao cenário em que o sistema está sendo avaliado.

$n_{\text {tipos }}=$ número de tipos para a categoria em questão.

$n_{\text {sub }}=$ número de subtipos para a hierarquia categoria-tipo em questão.

$N=$ número de diferentes classificações vagas na $\mathrm{CD}$, de acordo com o cenário seletivo.

$M=$ número de classificações espúrias na participação, de acordo com o cenário seletivo.

$\alpha, \beta, \gamma=$ parâmetros correspondentes aos pesos das categorias, tipos e subtipos.

\section{Exemplo de cálculo da CSC}

Supondo que a seguinte EM faça parte da Coleção Dourada:

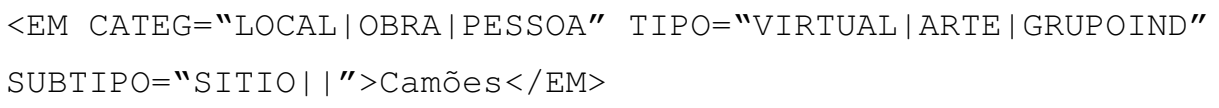


E que os parâmetros do cenário de avaliação tenham os valores: $\alpha=\beta=\gamma=1, n_{\text {cats }}=$ $10, n_{\text {tipo-local }}=4, n_{\text {sub-local-virtual }}=4, n_{\text {tipo-obra }}=4, n_{\text {tipo-pessoa }}=8, n_{\text {sub-obra-arte }}=1 \mathrm{e}$ $n_{\text {sub-local-virtual }}=1$.

\begin{tabular}{|c|c|c|}
\hline Saída & Descrição & Exemplo \\
\hline 1 & $\begin{array}{l}\text { Com as mesmas classificações } \\
\text { que estão na CD. }\end{array}$ & $\begin{array}{l}\text { EM CATEG="LOCAL | OBRA | PESSOA" } \\
\text { TIPO="VIRTUAL | ARTE | GRUPOIND" } \\
\text { SUBTIPO="SITIO||"> }\end{array}$ \\
\hline 2 & $\begin{array}{l}\text { Apenas algumas das } \\
\text { classificações da CD. }\end{array}$ & $\begin{array}{c}<\text { EM CATEG="OBRA | PESSOA" } \\
\text { TIPO="ARTE | GRUPOIND"> }\end{array}$ \\
\hline 3 & $\begin{array}{l}\text { Apenas uma classificação com } \\
\text { categoria correta, porém tipo } \\
\text { e subtipo errados. }\end{array}$ & $\begin{array}{l}<\text { EM CATEG="LOCAL" } \\
\text { TIPO="FISICO" } \\
\text { SUBIPO="AGUAMASSA"> }\end{array}$ \\
\hline
\end{tabular}

Tabela 3.3: Possíveis anotações de um sistema hipotético.

Algumas possíveis saídas de um sistema hipotético estão representadas na Tabela 3.3 e são pontuadas da seguinte forma:

- Avaliação da saída 1 da Tabela 3.3: Nesta saída temos a mesma saída da CD, portanto $M=0$ e $N=3$, desta forma podemos escrever a CSC para esta entidade como:

$$
\begin{aligned}
& 1+\left(1-\frac{1}{n_{\text {cats }}}\right)+\left(1-\frac{1}{n_{\text {tipo-local }}}\right)+\left(1-\frac{1}{n_{\text {sub-local-virtual }}}\right) \\
& +\left(1-\frac{1}{n_{\text {cats }}}\right)+\left(1-\frac{1}{n_{\text {tipo-obra }}}\right)+\left(1-\frac{1}{n_{\text {sub-obra-arte }}}\right) \\
& \quad+\left(1-\frac{1}{n_{\text {cats }}}\right)+\left(1-\frac{1}{n_{\text {tipo-pessoa }}}\right)+\left(1-\frac{1}{n_{\text {sub-pessoa-grupoind }}}\right)
\end{aligned}
$$

resultando em uma CSC igual a 6,825.

- Avaliação da saída 2 da Tabela 3.3: Nesta existem duas categorias corretas (OBRA e PESSOA) e uma categoria em falta, portanto $N=2$. Para este exemplo a CSC é:

$$
\begin{aligned}
1 & +\left(1-\frac{1}{n_{\text {cats }}}\right)+\left(1-\frac{1}{n_{\text {tipo-obra }}}\right) \\
& +\left(1-\frac{1}{n_{\text {cats }}}\right)+\left(1-\frac{1}{n_{\text {tipo-pessoa }}}\right),
\end{aligned}
$$

resultando em uma CSC igual a 4,425.

- Avaliação da saída 3 da Tabela 3.3: Na saída 3 temos um exemplo em que o sistema classifica corretamente apenas uma categoria, $N=1$, porém o tipo e subtipo estão incorretos. Neste caso o espúrio é considerado $M=1$, e temos a CSC:

$$
\begin{aligned}
& 1+\left(1-\frac{1}{n_{\text {cats }}}\right) \\
& -\left(1-\frac{1}{n_{\text {tipo-local }}}\right),
\end{aligned}
$$


resultando em uma CSC igual a 1,65.

\section{Métricas}

As Métricas do Segundo HAREM seguem os critérios de precisão, cobertura, medida-F, sobregeração e sub-geração. Estes dois últimos medem, respectivamente, o excesso de resultados espúrios que um sistema produz e o quanto faltou o sistema analisar, dada a solução conhecida. Neste evento a precisão, cobertura e medida-F são calculadas usando, respectivamente, as equações 3.9, 3.10 e 3.4 .

$$
\text { Precisão }=\frac{\sum(\text { Pontuação obtida por cada EM })}{\text { Pontuação Máxima se as EM recuperadas pelo sistema estivessem corretas }}
$$

$$
\text { Cobertura }=\frac{\sum(\text { Pontuação obtida por cada EM })}{\text { Pontuação Máxima da CD }}
$$

\section{Avaliação da Tabela 3.2 nos moldes do Segundo HAREM}

Considerando a Coleção Dourada e a saída do sistema da Tabela 3.2, e configurando os parâmetros de cenário de participação de forma a permitir a comparação dos resultados deste exemplo com os resultados obtidos com a avaliação conforme as especificações dos outros eventos (MUC e CoNLL), temos que configurar o sistema para identificar e classificar as EM's para as categorias PERSON, ORGANIZATION, LOCATION, $\left(n_{\text {cats }}=3\right)$, sem a proposta de identificação e classificação de tipos e sub-tipos, portanto: $\alpha=1, \beta=\gamma=0$.

Com estas configurações, cada EM poderia ter no máximo a pontuação de CSC igual a 1.6666. Desta forma o valor máximo da CD seria 8,333 e a pontuação da CSC da classificação do sistema seria 2,6666, resultando portanto, para a tarefa de classificação, o mesmo valor (32\%) para a precisão, cobertura e medida-F. O resultado para a tarefa de identificação pode ser visto na Tabela 3.4.

\begin{tabular}{|l|l|}
\hline Descrição & Valor \\
\hline \hline Total de EM's na CD & 5 \\
Total de EM's identificadas pelo sistema & 5 \\
Total corretamente identificadas & 2 \\
Espúrios & 3 \\
Em Falta & 3 \\
Precisão & $40 \%$ \\
Cobertura & $40 \%$ \\
Medida-F & $40 \%$ \\
Sobre-geração & $60 \%$ \\
Sub-geração & $60 \%$ \\
\hline
\end{tabular}

Tabela 3.4: Resultado da tarefa de identificação dos dados da Tabela 3.2 avaliado nos moldes do Segundo HAREM 


\section{Resultados do Segundo HAREM}

No Segundo HAREM, cada sistema participante recebeu um arquivo texto (igual para todos) e tinha um prazo para a devolução do texto anotado seguindo os critérios do Segundo HAREM. Cada participante poderia enviar mais de uma versão anotada do mesmo texto.

Selecionamos os melhores resultados de cada sistema participante do Segundo HAREM, considerando a medida-F da tarefa de classificação de EM's avaliados no cenário total. Podemos ver na Tabela 3.5 os resultados da avaliação dos sistemas com ALT estrita. E na Tabela 3.6 estão apresentados os resultados da avaliação dos sistemas com ALT relaxada.

\begin{tabular}{lrrrrrr}
\hline Sistema & \multicolumn{2}{c}{ Precisão } & \multicolumn{2}{c}{ Cobertura } & \multicolumn{2}{c}{$F_{1}$} \\
\cline { 2 - 7 } & Ident(\%) & Class(\%) & Ident(\%) & Class(\%) & Ident(\%) & Class(\%) \\
\hline \hline Priberam_1 & 69,94 & 64,17 & 72,29 & 51,46 & 71,10 & 57,12 \\
REMBRANDT_2 & 75,77 & 64,97 & 62,14 & 50,36 & 68,28 & 56,74 \\
XIP-L2FXerox_3 & 72,14 & 65,66 & 53,15 & 46,52 & 61,21 & 54,46 \\
REMMA_1_corr & 70,83 & 60,50 & 45,16 & 36,15 & 55,15 & 45,26 \\
R3M_1 & 76,44 & 76,44 & 61,70 & 25,20 & 68,28 & 37,90 \\
SeRELep_1 & 81,78 & 81,78 & 59,15 & 24,15 & 68,65 & 37,29 \\
Cage2_4_corr & 50,59 & 44,99 & 37,87 & 27,57 & 43,32 & 34,19 \\
SEIGeo_4 & 89,63 & 74,85 & 13,58 & 11,66 & 23,59 & 20,18 \\
PorTexTO_4_corr & 70,03 & 67,90 & 8,98 & 8,82 & 15,92 & 15,61 \\
DobrEM_1_corr & 45,30 & 45,30 & 1,79 & 0,73 & 3,44 & 1,44 \\
\hline
\end{tabular}

Tabela 3.5: Melhores resultados da Medida-F de classificação de cada sistema participante do Segundo HAREM no cenário total com ALT estrita.

\begin{tabular}{lrrrrrr}
\hline Sistema & \multicolumn{2}{c}{ Precisão } & \multicolumn{2}{c}{ Cobertura } & \multicolumn{2}{c}{$F_{1}$} \\
\cline { 2 - 7 } & Ident(\%) & Class(\%) & Ident(\%) & Class(\%) & Ident(\%) & Class(\%) \\
\hline \hline Priberam_1 & 71,88 & 65,92 & 74,85 & 53,52 & 73,33 & 59,08 \\
REMBRANDT_2 & 77,26 & 66,22 & 63,84 & 51,73 & 69,91 & 58,08 \\
XIP-L2F/Xerox_3 & 73,65 & 66,64 & 55,27 & 48,40 & 63,15 & 56,07 \\
REMMA_1_corr & 72,64 & 62,26 & 46,60 & 37,50 & 56,78 & 46,81 \\
R3M_1 & 78,20 & 78,20 & 64,36 & 26,33 & 70,61 & 39,40 \\
SeRELep_1 & 83,43 & 83,43 & 61,53 & 25,12 & 70,83 & 38,61 \\
Cage2_4_corr & 53,22 & 47,51 & 39,16 & 28,65 & 45,12 & 35,74 \\
SEIGeo_4 & 90,16 & 75,58 & 14,10 & 12,14 & 24,39 & 20,92 \\
PorTexTO_4_corr & 71,15 & 68,99 & 9,24 & 9,09 & 16,36 & 16,06 \\
DobrEM_1_corr & 45,96 & 45,96 & 1,84 & 0,75 & 3,54 & 1,48 \\
\hline
\end{tabular}

Tabela 3.6: Melhores resultados da Medida-F de classificação de cada sistema participante do Segundo HAREM no cenário total com ALT relaxada.

De acordo com Freitas [FMS ${ }^{+}$10], dos dez sistemas de REM avaliados no segundo HAREM, realizado em Abril de 2008, apenas o sistema R3M adotou a abordagem de aprendizado de máquina, enquanto os outros fizeram uso de codificações manuais de regras em combinação com dicionários e ontologias. Isso mostra que a grande parte da comunidade que se dedica ao REM em português não tem adotado as técnicas de Aprendizado de Máquina, o que é uma situação contrária ao observado nos sistemas de REM para a língua inglesa. Esse fato também foi observado no Primeiro HAREM, onde de nove sistemas, apenas dois foram treinados utilizando textos marcados. 


\section{Ferramenta de Avaliação do Segundo HAREM}

Para avaliação de sistemas aos moldes do Segundo HAREM e comparação de resultados com os sistemas participantes, os organizadores disponibilizaram um serviço de avaliação que segue as diretivas do Segundo HAREM.

Segundo Cardoso [MS08], o SAHARA ${ }^{1}$ (Serviço de Avaliação HAREM Automático) "é um serviço na rede que permite a avaliação imediata de saídas de sistemas de REM de acordo com o ambiente de avaliação usado no Segundo HAREM".

Uma avalição utilizando o SAHARA é realizada em três passos:

1. Validação da participação: Onde é verificado se o arquivo está seguindo as anotações do Segundo HAREM.

2. Configuração: Passo em que é possível manipular os pesos relacionados às categorias, tipos e subtipos, bem como escolher os cenários de participação e avaliação do sistema.

3. Apresentação dos resultados: Exibição de tabelas e gráficos comparativos dos resultados do sistema.

\subsection{Comentários}

Com as conferências aqui citadas, podemos observar as diferenças das abordagens no processo de avaliação dos sistemas participantes de cada evento, bem como os desafios e recursos propostos por cada um. Essas diferenças dificultam a definição do estado-da-arte sobre o problema, porém nos fornecem boas pistas sobre as preocupações que devemos ter ao desenvolver um sistema de REM.

Para o desenvolvimento e teste do nosso sistema optamos por utilizar os moldes de avaliação do CoNLL devido à simplicidade de implementação e por ser o método mais restrito de avaliação de classificação de uma EM se comparado aos outros eventos discutidos.

No entanto, para avaliação final do nosso sistema, utilizamos as diretivas do Segundo HAREM e suas conclusões. Para efetuar a comparação dos resultados dos textos de saída do nosso sistema com os resultados dos sistemas participantes do Segundo HAREM, utilizamos o SAHARA.

${ }^{1}$ http://www.linguateca.pt/SAHARA/ 


\section{Capítulo 4}

\section{Aprendizado de Máquina}

\subsection{Introdução}

O Aprendizado de Máquina (AM) é uma área da Inteligência Artificial que tem como objetivo o desenvolvimento de técnicas computacionais que permitem a construção de sistemas capazes de adquirir conhecimento de forma automática a partir de exemplos. Estas técnicas são possíveis porque os dados não-aleatórios geralmente possuem algum padrão, e tais padrões permitem que a máquina extraia generalizações. Com esses dados, é então possível obter importantes aspectos sobre a massa de dados na qual o modelo foi treinado [Seg07]. Veremos a seguir alguns conceitos preliminares de aprendizado de máquina e apresentaremos algumas técnicas desta área que são importantes para o nosso trabalho.

\subsubsection{Divisão do Aprendizado de Máquina}

Segundo Russell \& Norvig [RN95], geralmente um dos fatores mais importante na determinação da natureza do problema de aprendizado é o tipo de retorno disponível para aprendizado no qual o algoritmo se depara. O AM é usualmente dividido em três tipos: aprendizado supervisionado, não-supervisionado e de reforço.

No aprendizado supervisionado, primeiramente é necessário uma amostra de treinamento em que o algoritmo possa "aprender" uma função a partir dela, e que essa amostra possua exemplos de dados de entrada e saídas desejadas. Esse processo é conhecido como treinamento do modelo ou simplesmente treinamento. Com o modelo treinado, é possível inferir dados ainda não vistos. No contexto de PLN, o texto marcado é utilizado como amostra dos dados.

No aprendizado não-supervisionado também é necessário uma amostra de treinamento, porém essa amostra não possui os exemplos de saídas desejados, apenas exemplos de entrada. O objetivo é encontrar regularidades com essa amostra, isto é, uma estrutura dos dados de entrada, tais como certos padrões que ocorrem mais do que outros e ver o que geralmente ocorre e o que não ocorre [Alp04]. O agrupamento é uma técnica de aprendizado não-supervisionado.

No aprendizado por reforço o algoritmo aprende uma política de como agir dada uma observação do mundo. Cada ação tem algum efeito no ambiente, e o ambiente fornece o gabarito que guia o algoritmo no processo de aprendizagem. Nesses sistemas, a saída é uma sequência de ações a serem executadas. Em tais casos, uma simples ação isolada não é importante, o que é importante é a política de sequência de ações corretas para alcançar o objetivo. O programa de aprendizado de 
máquina por reforço precisa ser capaz de avaliar quão boas são as políticas e aprender a partir de uma boa sequência de ações vista anteriormente para ser capaz de gerar uma boa política [Alp04].

\subsubsection{Definições Preliminares}

Veremos algumas definições de termos da área de AM que serão úteis para o desenvolvimento do nosso trabalho. Para isso tomaremos como ponto de partida o seguinte problema: Suponhamos que desejamos ensinar um programa a classificar frutas, e queremos que ele identifique a classe $C$, que indica o que é uma maçã. Considere que o computador esteja preparado com vários sensores e indicadores para extrair características físicas de objetos; por exemplo, peso, volume, cor, formato e etc. Também é necessário um conjunto de frutas, contendo maçãs e outras frutas, para o processo de aprendizado do computador. Para que o processo de ensino aconteça, devemos pegar as frutas de uma a uma e fornecê-las aos sensores para que possa registrar os dados, e junto com esses dados uma entrada humana, informando a fruta apresentada nos sensores. Para nosso exemplo, a única entrada humana é a indicação de que a fruta apresentada é uma maçã ou não.

Depois de algumas amostras, suponhamos que tenhamos chegado à conclusão de que dentre várias características que as frutas possuem, existem duas que definem dentre todas as frutas, o que é uma maçã. Vamos considerar para ilustração que apenas a massa e o volume são necessários para indicar o que é uma maçã. Claro que existem várias outras características relevantes para essa decisão, porém, escolhemos apenas duas para facilitar o entendimento.

Extraindo as definições de termos de AM do exemplo citado, temos:

- Atributo: Descreve uma característica, ou um aspecto de um exemplo. Do exemplo apresentado temos os atributos massa e volume. Vamos denotar a massa como nosso primeiro atributo de entrada $x_{1}$ e volume como o segundo atributo $x_{2}$.

- Exemplo ou dado: É uma tupla de valores de atributos ou um vetor de valores de atributos. Descreve o objeto de interesse. Então nossa representação de cada fruta é

$$
x=\left[\begin{array}{l}
x_{1} \\
x_{2}
\end{array}\right] .
$$

- Conceito, rótulo ou classe: É um atributo especial que descreve o fenômeno de interesse. É o que desejamos aprender para fazer futuras previsões. O rótulo é representado por uma função do tipo

$$
f(x)= \begin{cases}1 & \text { se } x \text { é um exemplo positivo } \\ 0 & \text { se } x \text { é um exemplo negativo. }\end{cases}
$$

Do nosso exemplo temos a classe $C$, que classifica a fruta como sendo uma maçã, então podemos ter a etiqueta

$$
r= \begin{cases}1 & \text { se exemplo é uma maçã } \\ 0 & \text { se exemplo não é uma maçã. }\end{cases}
$$

- Conjunto de exemplos: É composto por exemplos do domínio de estudo contendo valores de atributos e a classe associada para cada exemplo. Para nosso conjunto $\mathcal{X}$ de exemplos com 
$N$ elementos podemos representar cada fruta por um par $(x, r)$

$$
\mathcal{X}=\left\{x_{t}, r_{t}\right\}, 1 \leq t \leq N
$$

onde o índice $t$ indica diferentes exemplos no conjunto.

O conjunto de exemplos é usualmente divido em dois subconjuntos disjuntos: O conjunto de treinamento usado para aprendizado do conceito e o conjunto de teste usado para medir a eficácia do classificador. Para o problema de reconhecimento de maçã, o conjunto de frutas dispostas nos sensores e a informação de seus rótulos é o conjunto de treinamento, e as que serão fornecidas para reconhecimento automático fazem parte do conjunto de teste. Essa divisão é muito útil, pois suponha que no nosso conjunto de treinamento não houvessem laranjas e no conjunto de testes houvessem algumas. Na etapa dos testes seria possível que o sistema indicasse que uma laranja é uma maçã, e com isso teríamos indícios de que precisaríamos fazer uma outra seleção de características ou que nosso conjunto de treinamento não está bom o bastante, e talvez seja necessário aumentá-lo, quem sabe fornecendo também algumas laranjas para que o sistema possa inferir diferenças.

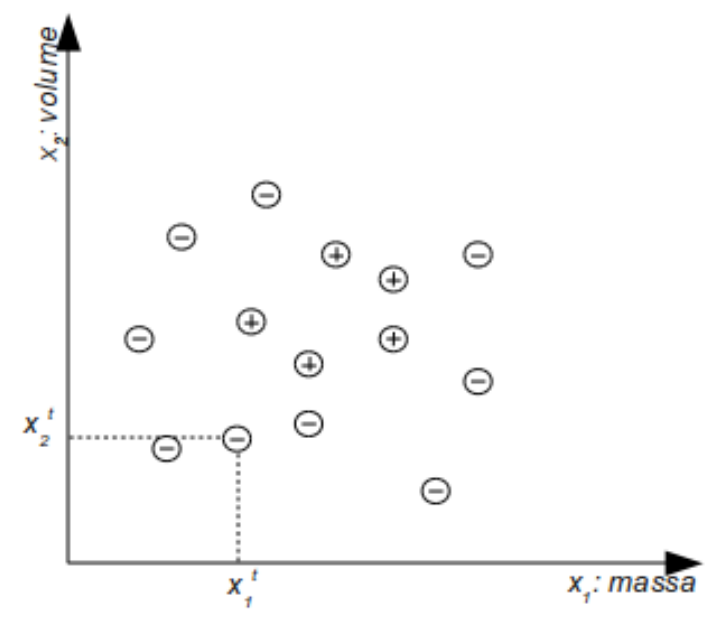

Figura 4.1: Conjunto de treinamento para a identificação de uma maçã. Cada ponto corresponde a uma fruta $e$ as coordenadas indicam a massa e o volume da fruta. Os pontos com um sinal positivo indicam quando a fruta é uma maçã, e sinal negativo outra fruta qualquer.

Podemos representar nosso conjunto de treinamento em um gráfico bi-dimensional $\left(x_{1}, x_{2}\right)$, de acordo com a Figura 4.1, onde cada instância t é um ponto na coordenada e seu tipo é indicado pelo sinal positivo quando for uma maçã e negativo em caso contrário.

Com a análise da Figura 4.1 temos razões para acreditar que de um conjunto de frutas saberemos se uma dada fruta é uma maçã se ela respeitar a equação

$$
m_{1} \leq \text { massa } \leq m_{2} \text { e } v_{1} \leq \text { volume } \leq v_{2}
$$

para possíveis valores de $m_{1}, m_{2}, v_{1}$ e $v_{2}$. A equação 4.5 nos fornece um espaço de hipóteses $\mathcal{H}$, em que cada quádrupla $\left(m_{1}, m_{2}, v_{1}, v_{2}\right)$ define uma hipótese $h \in \mathcal{H}$ e que a classe $C$ seja um retângulo no espaço massa-volume, como representado na Figura 4.2. O algoritmo de aprendizagem, também 
conhecido como indutor, tem o objetivo de encontrar uma hipótese $h$ que se aproxime de $C$ tanto quanto possível.

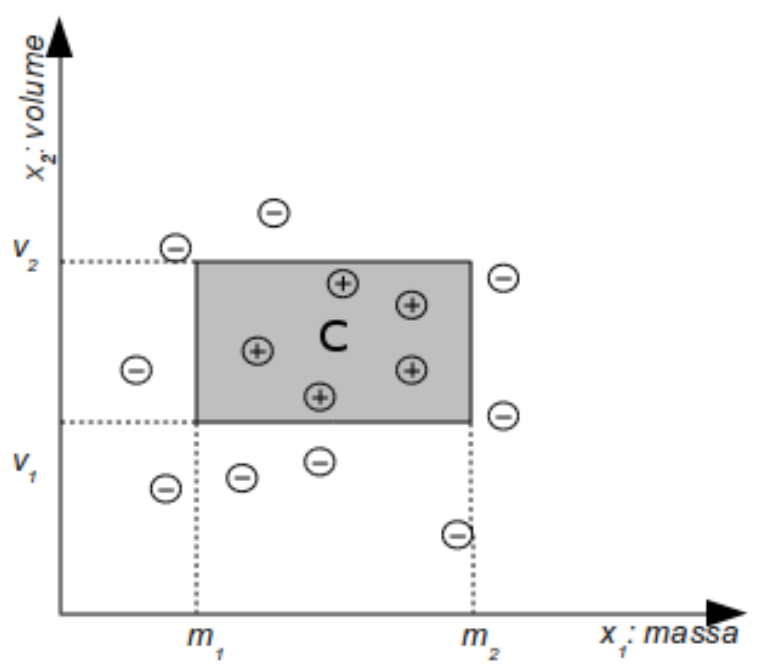

Figura 4.2: Exemplo de uma hipótese. A classe $C$ de maçãs é o retângulo no espaço massa-volume.

Podemos então descrever a tarefa de AM como sendo a tarefa de encontrar uma descrição satisfatória de um conceito a partir de exemplos e de conhecimento prévio do domínio de interesse.

Para um estudo mais aprofundado sobre os conceitos aqui citados e mais detalhes de AM, ver Alpaydin[Alp04].

\subsubsection{Paradigmas de Aprendizado de Máquina e Modelos de Linguagem}

Existem diversos algoritmos para resolver o problema de obtenção de hipóteses, e dependendo da forma de representação e da técnica utilizada para a obtenção das hipóteses como uma função de classificação, esses algoritmos podem ser divididos em diferentes áreas de concentração, tais como métodos simbólicos, estatísticos, redes neurais ou conexionistas e métodos híbridos.

Os métodos estatísticos são baseados em resultados de probabilidade, estatística e teoria da informação, e usam o modelo obtido para encontrar uma boa aproximação do conceito induzido. Para a obtenção de informações sobre o domínio do objeto de estudo, é necessário um conjunto de exemplos sobre esse domínio contendo informações que possam ser usadas para inferir o modelo. No contexto de PLN geralmente são utilizados textos marcados no aprendizado supervisionado para inferência do modelo (vide Seção 2.1.1).

\subsubsection{Validação Cruzada}

Como exemplificado na Seção 4.1.2, para avaliar uma hipótese é necessário separar uma parte dos dados para o conjunto de teste e outra para o conjunto de treinamento. Se o conjunto de dados disponível é grande o bastante, podemos aleatoriamente dividi-lo em $K$ partes. Cada parte é dividida aleatoriamente em duas outras, uma para treino e outra para teste. Porém, infelizmente, nem sempre o conjunto de dados disponível é grande o bastante para que este tipo de divisão possa ser feito. Se o conjunto de testes for muito pequeno, a nossa hipótese poderá não ter uma boa performance em termos de predição. No entanto, se separarmos um conjunto maior para a realização de testes, estaremos diminuindo o conjunto de treinamento. Desta forma, se tivermos 
uma quantidade pequena para treino poderemos ter um impacto negativo significante na eficácia do classificador.

Uma solução para este problema é a Validação Cruzada de $K$ instâncias (do inglês, $K$ Fold Cross-Validation). Na validação cruzada de $K$ instâncias, o conjunto de dados disponível é dividido aleatoriamente em $K$ instâncias de tamanhos $1 / K$. Para gerar cada par de conjunto treinoteste, uma das $K$ instâncias é mantida como conjunto de teste e as outras $K-1$ são utilizadas para treinamento. Esse processo é repetido $K$ vezes usando cada uma das outras $K-1$ instâncias como conjunto de teste e o restante para treino. A taxa de acerto final será dada pela média aritmética simples dos $K$ valores de taxa de acerto encontrados para cada uma das instâncias. Desta forma, mesmo que as instâncias individualmente sejam pequenas demais para fornecer uma avaliação precisa, a combinação dos valores obtidos com cada uma é baseada em uma grande quantidade de dados e por isso mais confiável. Outra vantagem desta abordagem é que ela permite examinar o desempenho em diferentes conjuntos de treinamento.

Mais sobre esse assunto pode ser consultado em Alpaydin[Alp04], Russell \& Norvig [RN95] e Manning \& Schütze [MS99].

\subsection{Aprendizado de Máquina aplicado ao PLN}

Nas seções seguintes veremos algumas técnicas de aprendizado de máquina aplicado em tarefas de PLN que são interessantes para o nosso trabalho.

\subsubsection{Maximização de Entropia}

O modelo de Máxima Entropia (ME), também muito referenciado como arcabouço de máxima entropia, é uma técnica estatística bastante empregada na resolução de várias tarefas de PLN. Uma grande vantagem do seu uso é o fato de permitir ao modelador de uma determinada tarefa concentrar-se na seleção de características úteis ao propósito de sua tarefa deixando para o arcabouço de ME o trabalho de atribuição de pesos para essas características. Outra vantagem é a possibilidade do uso de uma grande variedade de fontes de informações para o processo de classificação.

$\mathrm{Na}$ teoria da informação, a entropia pode ser definida como uma medida única e sem ambiguidade para a incerteza representada por uma distribuição de probabilidade. Em outras palavras, a entropia mede a quantidade de informação em uma variável aleatória. A entropia é maior quando a distribuição de probabilidades se aproxima da distribuição uniforme e seu máximo ocorre quando uma dada distribuição $p$ é uma distribuição uniforme.

O objetivo do arcabouço de ME é construir um modelo de distribuição de probabilidade $p$ que se aproxime de $\bar{p}$, tal que $\bar{p}$ seja uma distribuição de probabilidade empírica obtida através de um conjunto de treinamento. No modelo de ME, cada característica corresponde a uma restrição do modelo e é representada por uma função binária, chamada de função característica. As funções características relacionam as classes com os contextos. Se $A=\left\{a_{1} \cdots a_{q}\right\}$ representa o conjunto de possíveis classes que estamos interessados em prever, e $B$ representa o conjunto de possíveis contextos ou material textual que podemos observar, então uma função característica é uma função 
da forma:

$$
f(a, b)=\left\{\begin{array}{ll}
1 & , \text { se } a=\bar{a} \text { e } b=\bar{b} \\
0 & , \text { caso contrário }
\end{array},\right.
$$

onde $\bar{a}$ é uma classe específica e $\bar{b}$ é um contexto específico.

Para um dado conjunto de funções características, é necessário primeiramente calcular a esperança de cada função baseado nos dados de treinamento. Cada função característica define que a restrição da esperança da função no modelo final seja a mesma da esperança empírica. De todas as distribuições de probabilidades que obedecem essas restrições, é utilizada a distribuição que maximiza a entropia.

O procedimento de estimação de ME combina as evidências obtidas do treinamento utilizando um modelo log-linear e produz um modelo em que a toda função característica $f_{j}$ está relacionado um parâmetro $\alpha_{j}$. O parâmetro $\alpha_{j}$ pode ser interpretado como um "peso" para a sua função $f_{j}$ correspondente

$$
\begin{aligned}
& p(a \mid b)=\frac{\prod_{j=1}^{k} \alpha_{j}^{f_{j}(a, b)}}{Z(b)}, \\
& Z(b)=\sum_{a \in A} \prod_{j=1}^{k} \alpha_{j}^{f_{j}(a, b)},
\end{aligned}
$$

onde $k$ é o número de funções características e $Z(b)$ é um fator de normalização que garante que $\sum_{a \in A} p(a \mid b)=1$. A probabilidade $p(a \mid b)$ é o produto normalizado das funções características que são "ativadas" pelos pares $(a, b)$.

Os pesos $\alpha_{1} \cdots \alpha_{k}$ da distribuição de probabilidade $p *$ que melhor representam os dados de treinamento podem ser obtidos utilizando os algoritmos e técnicas de estimação Escalonamento Iterativo Melhorado (IIS) ${ }^{1}$ [BPP96], Escalonamento Iterativo Generalizado (GIS) ${ }^{2}$ [DR72].

Para esclarecimento do uso do método de máxima entropia, vejamos um simples exemplo.

\section{Exemplo de aplicação de Máxima Entropia}

Suponha que desejamos identificar a classificação morfológica da palavra "jabulane", considerando que o conjunto de etiquetas de classificação $C$ seja: SUBS para substantivo singular, ADJ para adjetivo, SUBP para substantivo plural, VB para verbo e NPS para nome próprio singular.

A distribuição de probabilidade que faz o menor número de suposições sem imposição de restrições, seria a distribuição equiprovável, como podemos ver na Tabela 4.1, linha "a".

Supondo que dado um conjunto de treinamento, foi observado o fato de que a palavra "jabulane" só ocorre para as etiquetas $\{$ SUBS, ADJ, SUBP, VB\}. Com esse novo conhecimento pode-se restringir o modelo de forma a respeitar a equação:

$$
p(S U B S)+p(A D J)+p(S U B P)+p(V B)=1 .
$$

Assim, o modelo é alterado respeitando a restrição dada pela Equação 4.9 e uma nova distri-

\footnotetext{
${ }^{1}$ Improved Iterative Scaling

${ }^{2}$ Generalized Iterative Scaling
} 


\begin{tabular}{|c|c|c|c|c|c|}
\hline & SUBS & ADJ & SUBP & VB & NPS \\
\hline $\mathrm{a}$ & $1 / 5$ & $1 / 5$ & $1 / 5$ & $1 / 5$ & $1 / 5$ \\
\hline $\mathrm{b}$ & $1 / 4$ & $1 / 4$ & $1 / 4$ & $1 / 4$ & 0 \\
\hline $\mathrm{c}$ & $4 / 10$ & $1 / 10$ & $4 / 10$ & $1 / 10$ & 0 \\
\hline $\mathrm{d}$ & $4 / 10$ & $3 / 20$ & $4 / 10$ & $1 / 20$ & 0 \\
\hline
\end{tabular}

Tabela 4.1: Distribuições de probabilidade para a classificação gramatical da palavra "jabulane".

buição é realizada sem fazer suposições além das informações conhecidas, (veja Tabela 4.1, linha "b").

Continuando com o treinamento do modelo, suponha que é observado que $80 \%$ das vezes a palavra "jabulane" é etiquetada como SUBS ou SUBP, fornecendo assim mais uma restrição:

$$
p(S U B S)+p(S U B P)=8 / 10 .
$$

Alteramos novamente o modelo, dessa vez com duas restrições, originando uma nova distribuição, como podemos ver na Tabela 4.1, linha "c".

Agora, suponha que não existam mais informações sobre a palavra em questão, porém, é observado que de cada vinte palavras uma é classificada como VB. Podemos então adicionar a seguinte restrição ao modelo:

$$
p(V B)=1 / 20
$$

Então, para o nosso exemplo, a distribuição de probabilidade que respeita todas as restrições obtidas do conjunto de treinamento é apresentado na Tabela 4.1, linha "d".

Para mais detalhes e maiores discussões sobre os métodos de estimação e aplicações do arcabouço de máxima entropia, consulte Jurafsky [JM08], Ratnaparkhi [Rat98] e Adam Berger [Ber96].

\subsubsection{Aprendizado Baseado em Transformação Guiada por Erro}

O Aprendizado Baseado em Transformação Guiada por Erro (TBL) (a sigla do inglês TransformationBased Error-Driven Learning), também conhecido como método de Brill, é uma técnica de aprendizado supervisionado guiado por erros. Foi introduzido por Eric Brill no contexto de etiquetamento morfológico [Bri95] e posteriormente utilizado em diferentes tarefas de PLN.

O TBL é baseado em regras de transformações. Cada regra é aprendida automaticamente através da avaliação dos erros cometidos por um classificador inicial. O classificador inicial é aplicado em uma versão não-anotada de um texto anotado, reanotando-o. O TBL então compara o texto reanotado com a versão anotada original, gerando uma lista ordenada de regras de transformações. Tais regras são geradas a partir de moldes de regras de transformações fornecidas pelo modelador, e são compostas basicamente por ações e condições. Podemos verificar na Tabela 4.2 alguns moldes aplicado por Brill [Bri95] na tarefa de etiquetamento morfológico. As ações representam as regras que efetivamente atribuem ou alteram a etiqueta de uma palavra. As condições descrevem o contexto em que cada ação deve ser ativada.

Em suma, para desenvolver uma aplicação específica utilizando o TBL é necessário um classificador inicial, um conjunto de regras de transformações (ações e condições) e uma função objetivo 


\begin{tabular}{|l|}
\hline Ação: "Alterar a etiqueta $\boldsymbol{a}$ para $\boldsymbol{b}$ quando...". \\
\hline 1- A palavra anterior (seguinte) for $\boldsymbol{w}$. \\
2- A segunda palavra anterior (seguinte) for $\boldsymbol{w}$. \\
3- Uma das duas palavras seguintes (anteriores) for $\boldsymbol{w}$. \\
4- A palavra corrente for $\boldsymbol{w}$ e a anterior (seguinte) for $\boldsymbol{x}$. \\
5- A palavra corrente for $\boldsymbol{w}$ e a etiqueta da anterior (seguinte) for $\boldsymbol{z}$. \\
6- A palavra corrente for $\boldsymbol{w}$. \\
7- A palavra anterior (seguinte) for $\boldsymbol{w}$ e a etiqueta da anterior (seguinte) for $\boldsymbol{t}$. \\
\hline
\end{tabular}

Tabela 4.2: Moldes de regras utilizados por Brill. Cada linha é uma condição que ativa a ação; $\boldsymbol{w}$ e $\boldsymbol{x}$ são variáveis que representam as palavras presentes no texto de treinamento; $\boldsymbol{z}$ e $\boldsymbol{t}$ representam as etiquetas possiveis do conjunto de treinamento.

para comparar a anotação do classificador inicial ao texto original e escolher uma transformação.

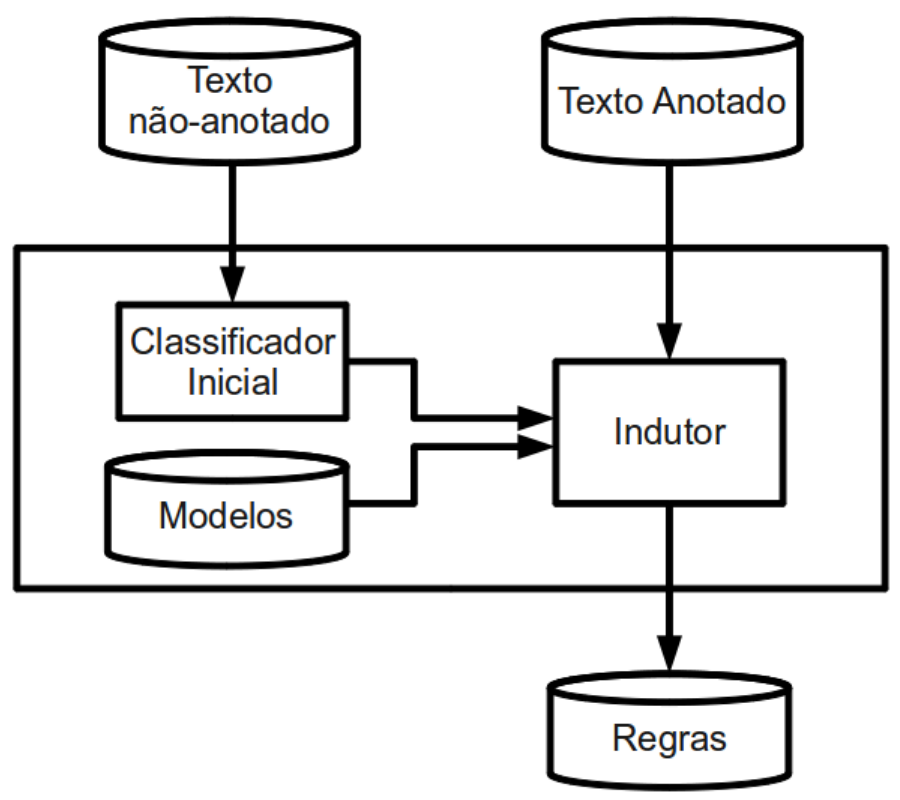

Figura 4.3: Esquematização do processo de aprendizado do TBL.

A Figura 4.3 ilustra como o processo de aprendizado do TBL funciona. Tal processo pode ser descrito como:

1. Aplicar o classificador inicial sobre o córpus não anotado;

2. Verificar as transformações que podem ser aplicadas ao córpus, utilizando as duas versões anotadas;

3. Selecionar a transformação T que obtém a maior pontuação no processo de correção;

4. Armazenar T à lista ordenada de transformações;

5. Aplicar T sobre o córpus;

6. Repetir o processo a partir do passo 2 até que não existam melhoras substanciais. 
Para um exemplo aplicado na tarefa de etiquetamento morfológico, uma possível ação seria:

Altere a etiqueta de verbo para substantivo.

E um exemplo de condição:

A palavra anterior é um artigo definido.

Tal regra de transformação com a condição satisfeita pode atuar sobre a frase:

O/artigo poder/verbo de/preposição voar/verbo.

E corrigir erro contido, aplicando a ação devida:

O/artigo poder/substantivo de/preposição voar/verbo.

Uma variante do método de Brill aplicado ao etiquetamento morfológico para a língua portuguesa pode ser consultada no trabalho de Chacur e Finger [AF99].

\subsubsection{Aprendizado de Transformação Guiado por Entropia}

O Aprendizado de Transformação Guiado por Entropia (ETL) (sigla de Entropy Guided Transformation Learning) é uma estratégia de aprendizado de máquina que combina as vantagens do uso das Árvores de Decisões (AD) em conjunto com o TBL.

Nesta técnica, as AD's são utilizadas para a produção e seleção de moldes de regras de transformações a serem fornecidas ao processo de aprendizado do TBL (ver Seção 4.2.2) para a geração de regras de transformações concretas. A Figura 4.4 ilustra a proposta do método.

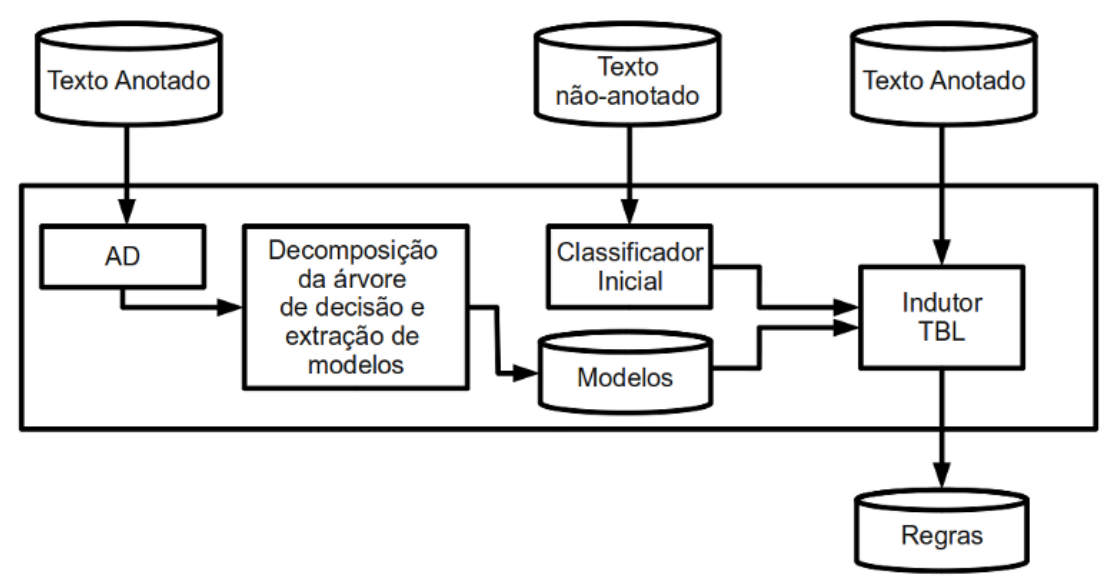

Figura 4.4: Esquematização do processo do ETL.

Esta abordagem foi proposta por Santos [dSM09] e aplicada a três diferentes tarefas da linguística computacional: extração de sintagmas nominais do português, extração de sintagmas básicos do inglês e análise sintática parcial do inglês.

Segundo Santos [dSM09], o processo utilizado para obtenção de moldes a partir da AD inclui uma busca em profundidade transversal sobre a AD. Para cada nó visitado é criado um novo modelo de regra a partir da combinação do modelo criado até o nó pai, adicionando a característica que foi utilizada para separar os dados naquele nó. 
A Figura 4.5 mostra um excerto de uma AD gerada para a tarefa de segmentação de texto do inglês. A segmentação de texto é uma tarefa de PLN que consiste em dividir uma sentença em palavras sintaticamente correlacionadas, porém sem especificar suas funções na sentença e nem a estrutura interna dos constituintes.

Na Tabela 4.3 podemos verificar uma lista de moldes de regras que foram extraídos da AD exibida na Figura 4.5 utilizando o método descrito, onde: CK_0 representa a etiqueta de chunk da palavra corrente (obtido pelo classificador inicial); $\mathrm{CK}_{-}-1$ representa a etiqueta de chunk da palavra anterior; CK_1 representa a etiqueta de chunk da palavra seguinte; POS_0 representa a etiqueta de classificação gramatical da palavra corrente e WRD_0 representa a palavra corrente.

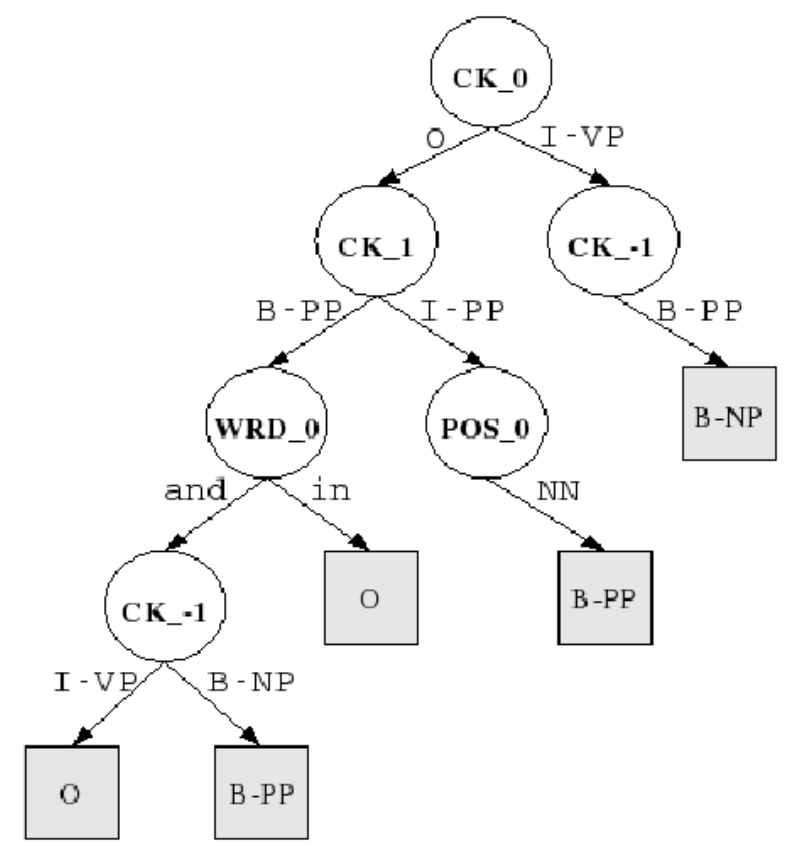

Figura 4.5: Excerto de uma Árvore de Decisão na tarefa de segmentação de texto. Figura extraída de [dSM09].

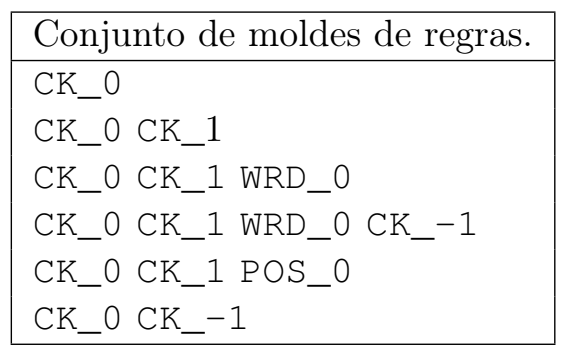

Tabela 4.3: Conjunto de moldes de regras para a tarefa de segmentação de texto.

De acordo com Santos, as características mais informativas são aquelas que aparecem no início do caminho da raiz às folhas, e uma vez que se deseja gerar os moldes de regras mais promissores, apenas os moldes mais informativos são combinados. 


\section{Capítulo 5}

\section{Trabalhos Relacionados}

Diferentes técnicas são aplicadas para a resolução do problema de REM, tais como sistemas baseados em regras e técnicas de aprendizado de máquina, fazendo uso de almanaques de nomes próprios, locais e organizações; e aquisição automática de entidades extraídas de bases de conhecimento específico para o problema. Alguns desses sistemas fazem uso de regras específicas da linguagem adicionados ao uso de técnicas de aprendizado de máquina, fazendo assim o seu sistema mais especializado para uma língua ou outra. Neste capítulo veremos algumas abordagens que utilizaram o aprendizado de máquina para a resolução do problema de REM.

\subsection{Abordagens na resolução do problema de REM}

Antes de citar as diferentes abordagens de AM na tentativa de resolução do problema de REM, é interessante citar aqui o sistema PALAVRAS de Bick [Bic06], dado o seu resultado na participação do Primeiro HAREM. O PALAVRAS-NER descrito em [Bic06] é um sistema de gramática restrita com níveis progressivos e trata o processo de REM como uma tarefa integrada à sua marcação gramatical. Na sua versão original o seu conjunto de entidades mencionadas está dividido em seis categorias e cerca de vinte subcategorias. Em sua participação no Primeiro HAREM, obteve a medida-F de 80,61\% na tarefa de identificação, o que o colocou como vencedor na avaliação desta medida. É, portanto, referenciado em alguns outros trabalhos de REM em português para comparação de resultados da medida-F.

\subsubsection{TBL aplicado ao REM}

Em [MDC07], são apresentadas sete abordagens de modelagem utilizando técnicas de aprendizado de máquina para construção de REM para o português. As entidades podem ser classificadas nas categorias pessoa (PER), localidade (LOC), organização (ORG) e outros (O). Ainda neste trabalho foram utilizados almanaques e combinações das técnicas Modelos Ocultos de Markov (HMM), Máquina de Vetores Suporte (SVM) e Aprendizado Baseado em Transformação (TBL) de diferentes formas (ver Tabela 2 de [MDC07]). Com o SVM combinado com o uso de dicionários conseguiram obter a medida-F de $88,11 \%$, o que é um bom resultado se comparado com o PALAVRAS-NER, apesar de esta comparação não poder ser levada completamente em consideração devido à diferença das métricas adotadas, os córpus utilizados e o número de categorias em que ambos trabalharam. A seguir detalharemos a aplicação do TBL na tarefa de REM para o português. 


\section{TBL}

Segundo Milidiú [MDC07], para aplicar TBL à tarefa de REM, alguns moldes de regras do TBL precisam ser especializados para esta tarefa.

Como visto na Seção 4.2.2, para a construção de uma aplicação utilizando o TBL, é necessário um classificador inicial, um conjunto de regras e uma função objetivo. Nesta modelagem foram testados dois diferentes classificadores iniciais: um classificador BLS (Baseline System) e um classificador HMM. Para representação das regras foram testados muitos conjuntos de moldes efetuando combinações de palavras, etiquetas morfológicas e etiquetas de EM. Ainda segundo Milidiú, o melhor conjunto de moldes encontrados, consiste de alguns moldes genéricos em conjunto com alguns específicos. O molde genérico usa uma combinação de características na vizinhança de dois tokens. Os moldes específicos buscam por padrões específicos, principalmente por sequências de EM, preposições, artigos, advérbios e substantivos.

\begin{tabular}{|l|l|}
\hline 1 & ner $[0]$ word[-1] pos[-1] word[-2] pos $[-2] ;$ \\
\hline 2 & ner[0] word[-1,-3]_where $\{$ pos=PREP $\}$ word[-1,-3]_where $\{$ pos=ART $\}$ pos $[-1] ;$ \\
\hline 3 & ner[0] ner[-2,-2]_where $\{$ ner $=$ LOC $\}$ pos $[-1] ;$ \\
\hline
\end{tabular}

Tabela 5.1: Moldes de regras para TBL aplicado à tarefa de REM.

Na Tabela 5.1 podemos verificar alguns moldes de regras utilizados neste trabalho. O primeiro molde cria boas regras sempre que um erro puder ser corrigido através do uso das duas palavras e etiquetas morfológicas anteriores ao token analisado. O segundo molde gera regras baseadas na junção da preposição com um artigo. O último tenta obter sequências de entidades do tipo lugares.

Depois de treinado o modelo, as duas regras com maiores pontuações são:

1. ner $[0]=\mathrm{COM}$ pos $[-1]=\mathrm{PREP} \rightarrow$ ner $=\mathrm{PER}$;

2. ner $[0]=\mathrm{COM}$ word $[-3,-1]$ _where $\{\operatorname{pos}=\mathrm{ART}\}=0$ pos $[-1]=\mathrm{N} \rightarrow$ ner=PER;

O córpus utilizado nesse trabalho continha 2100 sentenças já anotadas com etiquetas morfológicas e 3325 exemplos de EM, e é referenciado como LearnNEC06. As categorias de EM utilizadas foram: Pessoas, Organizações e Locais. Utilizando o BLS como classificador inicial no processo do TBL, foi alcançado, na média de execuções, a medida-F de $87,26 \%$, e utilizando o HMM como classificador inicial, a medida-F alcançada foi de $75,27 \%$, ambos para a tarefa de classificação.

\subsubsection{ETL}

Em [MdSD08] é apresentado uma abordagem do uso do ETL para a tarefa de REM. Neste trabalho foram utilizados como características: palavras, etiquetas morfológicas, etiquetas de sintagmas nominais e etiquetas de EM. Adicionalmente, foram utilizadas duas outras características:

1. Informação de capitalização, fornece uma classificação do token em uma das seguintes categorias: primeira letra maiúscula, todas as letras maiúsculas, todas as letras minúsculas, número, pontuação, número com "/" ou com "“” em alguma parte, número finalizando com "h" ou "hs" ou outros; 
2. Membro de dicionário que pode estar em uma das seguintes categorias: Upper, Lower, Both or None.

Na etapa da AD, apenas as 100 palavras mais frequentes foram utilizadas. A etiqueta de EM da palavra corrente é a etiqueta aplicada pelo classificador inicial e as etiquetas de EM das palavras vizinhas são as etiquetas reais.

Em uma tentativa de melhorar o sistema produzido, foi utilizada uma estratégia de duas fases: Primeiramente foi treinado um classificador ETL para as entidades: pessoas, organizações e locais. Nesta primeira etapa, utilizaram o córpus LearnNEC06. Em seguida outro classificador ETL foi treinado, desta vez utilizando o primeiro classificador ETL como classificador inicial. Este segundo classificador, foi treinado para as entidades: pessoas, organizações, localidades, datas e valores. Além disso, na etapa de treinamento foram utilizados os córpus Primeiro HAREM, Mini HAREM e LearnNEC06.

Utilizando esta abordagem nos córpus do Primeiro HAREM, alcançaram a medida-F de 63,27\% na tarefa de classificação de entidades no cenário completo e a medida-F de 70,02\% na tarefa de classificação em um cenário seletivo considerando apenas as categorias: Pessoa, Organização, Locais, Datas e Valores.

\subsubsection{Máxima Entropia}

O sistema MENE (do inglês Maximum Entropy Named Entity), de Borthwick [BSAG98], é um sistema de REM construído sobre o arcabouço de Máxima Entropia e foi um dos sistemas participantes do MUC-7. Para o MENE, cada etiqueta $x$ que representa uma entidade pode estar em um dos seguintes estados: $x_{-}$start, $x_{-}$continue, $x_{-}$end e $x_{-}$unique. Adicionalmente é inserido ao conjunto de possíveis etiquetas a etiqueta "other" indicando que o token em questão não é uma EM. Por exemplo, a frase "Jerry Lee Lewis Flew to Paris" poderia ser etiquetado como "person_start, person_continue, person_end, other, other, location_unique".

O conjunto de etiquetas em seus possíveis estados mais a etiqueta "other" formam o conjunto $F$, que chamaremos de Classes, utilizado para a formulação do problema de REM sobre o arcabouço de Máxima Entropia. O conjunto de todas as possíveis condições que possibilitam tomar uma decisão sobre o conjunto $F$ é chamado de Contexto. Cada item desse conjunto, chamado de Item de Contexto, armazena informações sobre um horizonte limitado do token corrente. O token corrente é denotado como $w_{0}$, e o MENE armazena informações sobre os token $w_{-1} \cdots w_{1}$ para todos os itens de contextos com exceção das características léxicas, que nesse caso tem uma janela maior $w_{-2} \cdots w_{2}$.

Desta forma o problema de REM pode ser reformulado como a busca da probabilidade da Classe $f \in F$ associado ao token de índice $t$ no córpus de treinamento:

$$
p\left(f \mid h_{t}\right)=p(f \mid \text { Informações relativas ao token } t \text { extraídas do córpus }) .
$$

O cálculo de $p\left(f \mid h_{t}\right)$ depende do conjunto de características (features) que é utilizado para prever a classificação de um token. Como visto na seção 4.2.1, as características são funções de valores binários que consultam a classe e o contexto da palavra para determinar seu valor.

No sistema de Borthwick, as características são classificadas como: Binárias, Léxicas, Características de Seção, Características de Dicionários e Características Externas. 
- Características Binárias São características em que a consulta sobre um dado token obtém uma resposta binária: sim ou não. Por exemplo: "O token começa com letra maiúscula?".

- Características Léxicas Para criar os itens de contextos léxicos, os tokens $w_{-2} \cdots w_{2}$ são comparados com um vocabulário e seus índices são armazenados. Todos os tokens que ocorrerem pelo menos três vezes em um córpus de treinamento são armazenados. Exemplo de uma Característica Léxica:

$$
g(h, f)= \begin{cases}1 & \text { se Lexical-History-View }\left(\text { token }_{-1}(h)\right)=\text { "Mr" e } f=\text { person_unique } \\ 0 & \text { caso contrário }\end{cases}
$$

- Características de Seção São características que exploram a estrutura do texto e são ativadas de acordo com a seção a qual o token se encontra no texto. Esta característica foi explorada pelo MENE no MUC-7, pois os artigos-textos disponibilizados para treinamento e testes eram compostos por seis diferentes seções. Exemplo de uma Características de Seção:

$$
g(h, f)= \begin{cases}1 & \text { se Section-View }\left(\text { token }_{0}(h)\right)=\text { "Preamble" e } f=\text { person_unique } \\ 0 & \text { caso contrário }\end{cases}
$$

- Características de Dicionários Estas características são obtidas através de um pré-processamento do texto a ser analisado e atribui a cada token uma das seguintes etiquetas: start, continue, end, unique, e other. Esse processo é realizado para cada dicionário previamente selecionado, por exemplo os dicionários de "primeiros nomes", "nomes de empresas", "nomes de empresas sem sufixos", "escolas e universidades" entre outros. A função 5.4 é um exemplo de uma Características de Dicionário que explora informações obtidas no dicionário de "primeiros nomes".

$$
g(h, f)=\left\{\begin{array}{l}
1 \quad \text { se First-Name-Dictionary-View }\left(\text { token }_{0}(h)\right)=\text { "unique" } \\
\text { e } f=\text { person_start } \\
0 \quad \text { caso contrário }
\end{array}\right.
$$

- Características Externas Além das características anteriormente comentadas, o MENE fez uso de textos de saídas de outros sistemas de REM participantes do MUC para enriquecer seus itens de contextos, utilizando esses textos no córpus de treinamento. Dessa forma pode agregar características que verificam a classificação dada por algum outro sistema. No exemplo abaixo, é verificado a classificação de um token avaliado pelo sistema "Proteus":

$$
g(h, f)=\left\{\begin{array}{l}
1 \quad \text { se Proteus-System-View }\left(\text { token }_{0}(h)\right)=\text { "person_start" } \\
\text { e } f=\text { person_start } \\
0 \quad \text { caso contrário }
\end{array}\right.
$$

Seguindo os critérios de avaliação do MUC-7, o MENE alcançou a medida-F de 92,20\% utilizando apenas padrões obtidos automaticamente, porém, em combinação com saídas de outros sistemas de REM que utilizam regras codificadas manualmente, chegou a alcançar a medida-F de 97,12\%.

\footnotetext{
${ }^{1}$ Sistema de REM participante do MUC-6.
} 


\subsection{Comentários}

Apesar de apenas um dos dez participantes do Segundo HAREM ter utilizado como abordagem o AM para o REM em português, neste capítulo vimos duas diferentes abordagens de AM aplicados ao mesmo problema em português. Utilizando o TBL para a resolução da tarefa de REM sobre um córpus próprio, foi alcançado a medida-F de $87,26 \%$, enquanto que o uso da estratégia ETL sendo avaliada utilizando o córpus do Primeiro HAREM alcançou a medida-F de 63,27\%. A comparação entre estas abordagens não é tão clara, considerando os recursos e os métodos de avaliação que cada abordagem utilizou. De qualquer forma, são bons indicativos para efeito de comparação em futuros sistemas e fornecem boas pistas sobre as características a serem investigadas para a tarefa de REM em português. Além disso, o córpus Primeiro HAREM utilizado na abordagem do ETL está disponível na rede. Isso faz com que sistemas de REM em português a serem desenvolvidos possam ser comparados à abordagem ETL.

Como visto na seção 4.2.1, uma das vantagens do uso do arcabouço de Máxima Entropia é a possibilidade da exploração de uma grande variedade de fontes de informações. Este fato foi reforçado na seção 5.1.3, onde vimos que o MENE explora diversas características do contexto de um termo a ser classificado, além de fazer uso de alguns dicionários e regras. Desta forma, utilizando apenas padrões obtidos automaticamente e seguindo os critérios de avaliação do MUC-7, o MENE alcançou a medida-F de $92,20 \%$

Motivados pelos bons resultados obtidos pelo MENE, desenvolvemos um sistema de REM para português sobre o arcabouço de Máxima Entropia. Com o sistema desenvolvido fomos capazes de explorar várias características do contexto dos termos a serem classificados, bem como diferentes combinações destas características. Também utilizamos alguns dicionários e pequenas regras para auxiliar tanto na identificação quanto na classificação dos termos de um EM. Além disso, verificamos os diferentes valores mínimos de ocorrências que as características estudadas precisam ter nos córpus de treinamento para que possam ser mantidas nos modelos treinados.

Veremos no próximo capítulo a arquitetura do sistema construído, em seguida os resultados obtidos com as diferentes características estudadas, bem como a avaliação do sistema seguindo os critérios do Segundo HAREM. 


\section{Capítulo 6}

\section{Arquitetura do Sistema}

Para alcançar nosso objetivo de construir um sistema flexível utilizando técnicas de AM e que permita ser avaliado em diferentes cenários, experimentar variadas composições de características, explorar diversas fontes de informações e diferentes composições dessas fontes, foi necessário criar uma arquitetura modularizada e que aceite facilmente acoplar diferentes módulos de software. Além disso, também seja flexível no tratamento dos componentes representativos das características a serem exploradas.

Dada a diferença temporal entre o presente trabalho e algumas de nossas referências, utilizamos destas apenas os conceitos teóricos na descrição do problema, e nos concentramos em deixar o mínimo ou nenhum processo manual entre os módulos.

Descreveremos neste capítulo a arquitetura do sistema, seus módulos e algumas dificuldades e dúvidas que surgiram durante a sua implementação.

\subsection{Módulos}

Dividimos a arquitetura do sistema em duas partes, o treinamento e a avaliação. Ambas são compostas por módulos que executam tarefas específicas. Na parte de treinamento é calculada a distribuição de probabilidades conjunta de pares classe-contexto obtida através do estimador de máxima entropia aplicado sobre o córpus de treino. A segunda parte da nossa arquitetura diz respeito à fase de avaliação. Nesta segunda fase, a distribuição de probabilidades é utilizada para inferir as etiquetas de EM de um córpus de teste. E finalmente, as etiquetas preditas pelo sistema são comparadas com as etiquetas obtidas deste córpus. A composição dos módulos e suas interações para a fase de treino e geração do modelo estão na Figura 6.1 e na Figura 6.2 está a ilustração da arquitetura utilizada na fase de avaliação. Todo o sistema foi desenvolvido utilizando a linguagem de programação Java ${ }^{1}$.

\subsubsection{Pré-processamento}

No pré-processamento são realizadas manipulações necessárias à preparação do texto de entrada, tais como a inclusão de mais informações na estrutura do texto, a exemplo da separação de sentenças, separação de tokens, adição de etiquetas morfológicas e conversão do formato da representação das etiquetas de EM.

\footnotetext{
${ }^{1}$ http://java.com
} 


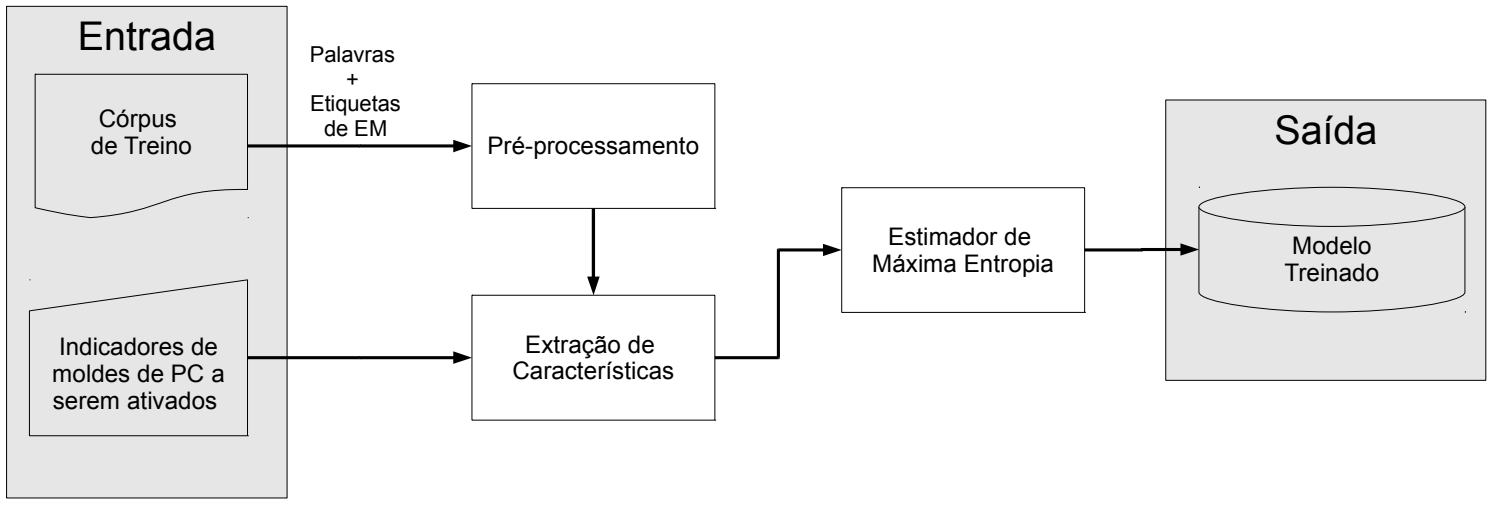

Figura 6.1: Arquitetura do Sistema para a fase de Treinamento.

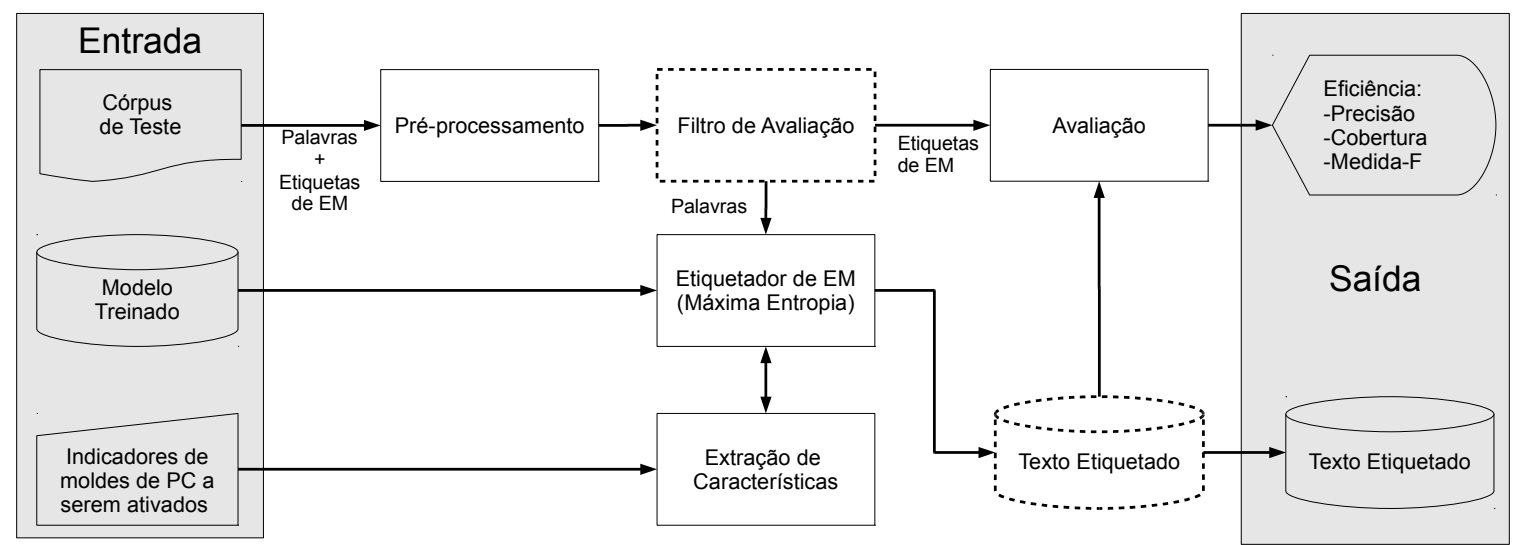

Figura 6.2: Arquitetura do Sistema para a fase de Avaliação.

Neste módulo foram agrupados os sub-módulos responsáveis pelo tratamento inicial do texto, tais como a extração de etiquetas de EM do texto e a atribuição das mesmas no formato adequado para classificação de cada palavra. Este módulo possui a mesma função tanto no momento de treino quanto no de avaliação. A Figura 6.3 ilustra a composição deste módulo. Discutiremos a seguir detalhes sobre o sub-módulos do pré-processamento.

\section{Conversor de Entrada}

O formato dos arquivos de treinamento e teste do nosso sistema é baseado no formato do arquivo de treinamento do módulo NameFinder da API OpenNLP ${ }^{2}$. Este formato foi escolhido por ser de simples manipulação, facilmente adaptável ao formato proposto pelo Segundo HAREM e por facilitar a estrutura necessária de representação de EM em cada token de acordo com o MENE, como visto na seção 5.1.3.

No Conversor de Entrada as palavras são separadas simplesmente por espaços, pois o objetivo neste momento é apenas a extração da relação entre cada palavra e a sua etiqueta de EM representada no texto, deixando o trabalho de tokenização para um módulo posterior. A cada pala-

\footnotetext{
${ }^{2}$ http://incubator.apache.org/opennlp/
} 


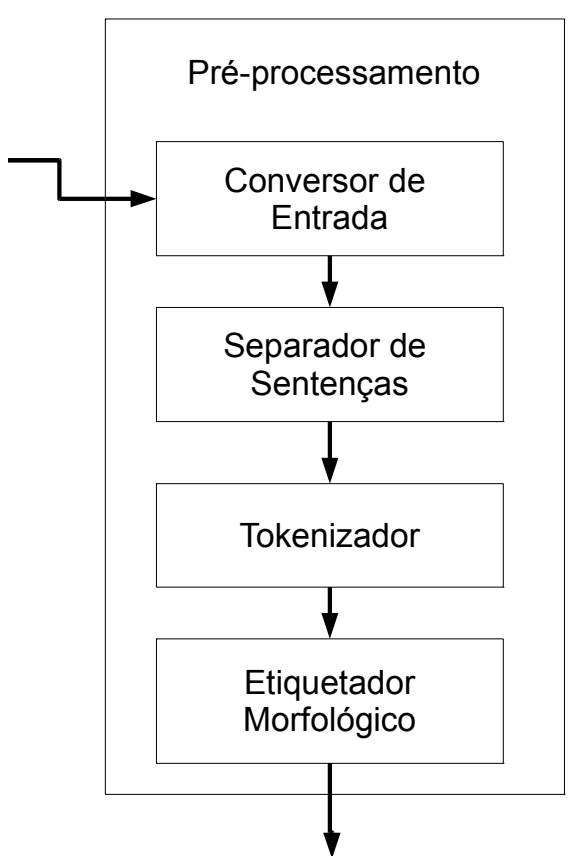

Figura 6.3: Módulo de Pré-processamento.

vra que não faz parte de uma EM é associada a etiqueta $\mathbf{O}$. Cada palavra que faz parte de uma EM é associada uma etiqueta considerando a posição da palavra dentro da anotação de EM, respeitando o seguinte esquema: dado o conjunto de possíveis categorias de EM a serem classificadas, cada pa-

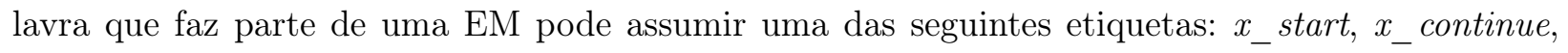
$x_{\text {_ end }}$ e $x_{\text {_ }}$ unique, onde $x$ representa uma categoria de EM.

Podemos ver na Tabela 6.1 a ilustração da transformação aplicada sobre o seguinte trecho de um córpus: "Meu nome é <START:PESSOA> Manoel Gregório Mello <END>, nasci em <START:LOCAL> Recife <END> no dia <START:TEMPO> 10/03/1963<END>.".

\begin{tabular}{|r|l|l|}
\hline posição $(i)$ & palavra $\left(w_{i}\right)$ & EMTag $\left(\right.$ emtag $\left._{i}\right)$ \\
\hline \hline 1 & Meu & $\mathrm{O}$ \\
2 & nome & $\mathrm{O}$ \\
3 & é & O \\
4 & Manoel & pessoa_start \\
5 & Gregório & pessoa_continue \\
6 & Mello & pessoa_end \\
7 &, & $\mathrm{O}$ \\
8 & nasci & $\mathrm{O}$ \\
9 & em & $\mathrm{O}$ \\
10 & Recife & local_unique \\
11 & no & $\mathrm{O}$ \\
12 & dia & O \\
13 & $10 / 03 / 1963$ & tempo_unique \\
14 &. & O \\
\hline
\end{tabular}

Tabela 6.1: Representação das etiquetas de EM após o Filtro de Avaliação.

De acordo com Ratinov \& Roth [RR09], o esquema de representação de segmento de texto que 
estamos utilizando, também conhecido como BILOU, apresenta melhores resultados se comparado ao outro esquema de representação de segmentos, também bastante empregado, chamado BIO. O esquema BILOU, sugere que o classificador "aprenda" a identificar os tokens: primeiro, interno e último (do inglês, Begin, Inside, e Last, respectivamente) de um segmento de texto, bem como os segmentos de tamanho unitário (Unit-length) e os tokens fora de segmento (Outside). O esquema BIO, por outro lado, sugere que o classificador "aprenda" a identificar os tokens: primeiro, interno e externos (do inglês, Begin, Inside, e $\boldsymbol{O}$ utside, respectivamente) aos segmentos de textos.

\section{Sub-Módulos de PLN}

Para as tarefas de PLN do módulo de pré-processamento, utilizamos a API do CoGrOO[CoG]. O CoGrOO é um sistema de correção gramatical desenvolvido para português brasileiro e é composto por diversos módulos de PLN organizados sequencialmente. Com a utilização de alguns módulos do CoGrOO podemos nos concentrar nas transformações do texto necessárias à nossa tarefa e delegar algumas tarefas convencionais de PLN ao CoGrOO. Os módulos que nos interessam do CoGrOO são: Separador de sentenças, Tokenizador e Etiquetador Morfológico.

A última etapa do módulo de pré-processamento PLN é o Etiquetador Morfológico. O Etiquetador Morfológico do CoGrOO utiliza um subconjunto das etiquetas morfológicas utilizadas pelo sistema PALAVRAS de Bick [Bic06]. Em nosso sistema não utilizamos as inflexões das etiquetas morfológicas. Utilizamos apenas as classes de palavras fornecidas pelo CoGrOO. Podemos ver na Tabela 6.2 o conjunto de classes de palavras utilizadas pelo CoGrOO.

Na Seção 5.1.1 é apresentado um trabalho de REM no qual as etiquetas morfológicas foram utilizadas na tarefa de REM. Acreditamos que tais informações também possam adicionar conhecimento ao nosso REM, mesmo que o tempo de execução possa ser afetado de forma negativa.

\begin{tabular}{ll}
\hline Etiqueta $(P o S)$ & Categoria \\
\hline \hline $\mathrm{N}$ & Substantivos \\
PROP & Nomes próprios \\
SPEC & Especificadores, por exemplo, certos \\
& pronomes indefinidos e quantificadores nominais. \\
DET & Determinantes \\
PERS & Pronomes pessoais (definida como pessoa flexionando pronomes) \\
ADJ & Adjetivos \\
ADV & Advérbios \\
V & Verbos (verbos completo, auxiliares) \\
NUM & Algarismos \\
PRP & Preposição \\
KS & Conjunções Subordinadas \\
KC & Conjunções Coordenadas \\
IN & Interjeições \\
\hline
\end{tabular}

Tabela 6.2: Conjunto de Classes de Palavras utilizadas pelo CoGrOO.

\subsubsection{Filtro de Avaliação}

O Filtro de Avaliação, utilizado apenas na fase de avaliação do sistema, separa o texto da estrutura de dados que contém as etiquetas de EM, e guarda a informação da relação entre cada 
palavra e sua etiqueta de EM. As etiquetas de EM servirão de comparação no processo de avaliação que é realizada após a etapa de etiquetagem.

\subsubsection{Extração de Características}

Conforme visto na Seção 4.2.1, cada característica do modelo de Máxima Entropia é representada por uma função binária chamada função característica, no entanto, segundo Alves [dAF03], esta representação é pouco prática pois não permite generalizações, além de necessitar de um número muito grande de funções características para obter a distribuição de probabilidade de classe dado o contexto.

Para contornar tais problemas usaremos o Predicado Contextual, que é uma abordagem de representação de evidências utilizada por Ratnaparkhi em seu etiquetador morfológico [Rat98].

O Predicado Contextual é uma função binária definida como:

$$
p c(b)= \begin{cases}1 & \text { se b satifaz a regra } \bar{r} \\ 0 & \text { caso contrário }\end{cases}
$$

onde $b$ é o contexto observado e $\bar{r}$ é uma determinada regra. Dessa forma podemos alterar um pouco a definição inicial das funções características (ver Equação 4.6), de maneira a torná-las compatíveis aos predicados contextuais, obtendo:

$$
f_{j}(a, b)= \begin{cases}1 & \text { se } a=\bar{a} \text { e } p c(b)=1 \\ 0 & \text { caso contrário }\end{cases}
$$

onde $a$ é uma das possíveis etiquetas que estamos interessados em prever, $\bar{a}$ é uma etiqueta específica e $b$ é o contexto observado. Por exemplo, podemos definir um predicado contextual chamado pc_primeira_maiúscula $\left(b_{i}\right)$ para devolver 1 se a palavra analisada em questão possuir a primeira letra maiúscula. Uma função característica usando este predicado contextual poderia ser:

$$
f_{j}\left(a, b_{i}\right)= \begin{cases}1 & \text { se pc_primeira_maiúscula }\left(b_{i}\right)=1 \text { e } a=\text { "pessoa_start" } \\ 0 & \text { caso contrário. }\end{cases}
$$

Se a função característica acima estiver contida no conjunto de características do modelo, seu parâmetro $\alpha_{j}$ correspondente contribuirá com a probabilidade $p\left(a \mid b_{i}\right)$ quando a palavra analisada iniciar com letra maiúscula e a classe for "pessoa_start".

Para nos auxiliar na implementação destes conceitos, utilizamos a API do OpenNLP, que nos permite lidar apenas com a criação de Eventos. Para o nosso domínio chamaremos de Evento um contexto composto por uma etiqueta de EM e um conjunto de predicados contextuais. Uma etiqueta de EM é uma das possíveis etiquetas que representam uma EM, $\left(O, x_{-}\right.$start, $x_{-}$continue, $x_{-}$end $\mathrm{e}$

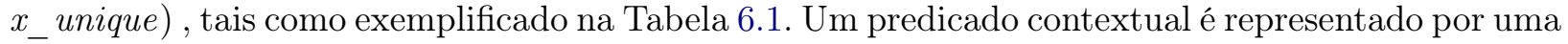
cadeia de caracteres que explora alguma determinada evidência que possamos achar relevante para a identificação e/ou classificação das EM's. Desta forma nos preocupamos apenas com a criação de Moldes de Predicados Contextuais e automatizamos a tarefa de criação de predicados contextuais criando-os para cada token no momento da leitura do texto, como veremos no submódulo Gerenciador de Extração de Características.

O Módulo de Extração de Características está representado na Figura 6.4, e é composto 
pelos sub-módulos Conversor de Sentenças para Eventos, Gerenciador de Extração de Características e um conjunto de Moldes de Predicados Contextuais.

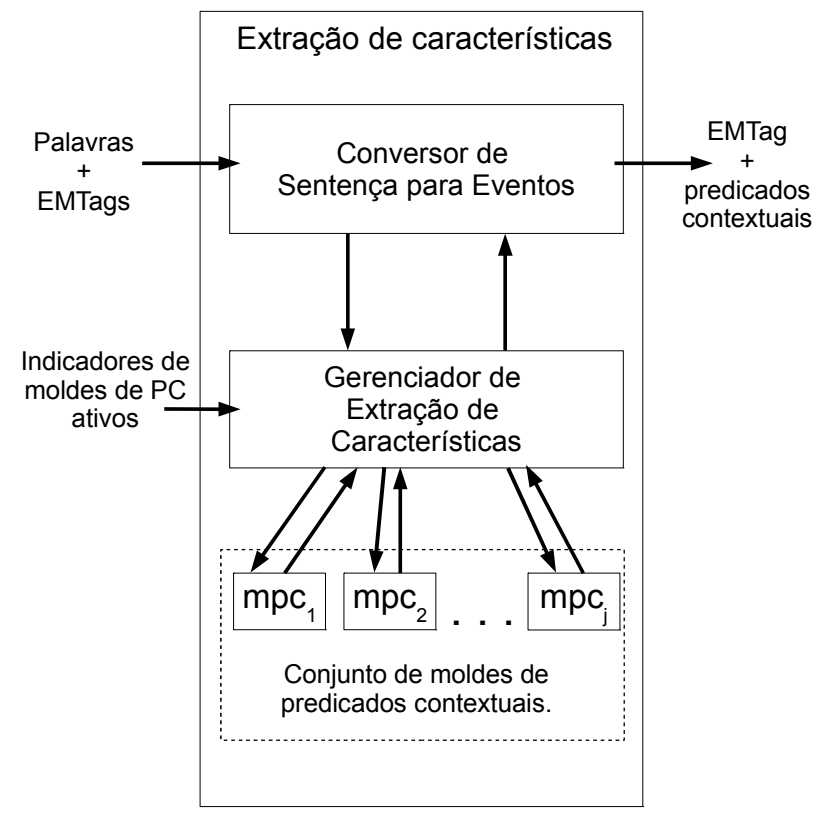

Figura 6.4: Módulo de pré-processamento para extração de características.

\section{Conversor e Gerenciador de Extração de Características}

No Conversor de Sentenças para Eventos os tokens são analisados sequencialmente. Para cada token da sequência é efetuada uma análise contextual considerando o conjunto de moldes de predicados contextuais que foram indicados como ativos na entrada do sistema. Em seguida é criado um Evento representando o contexto do token em questão. O Gerenciador de Extração de Características é o módulo responsável por invocar cada molde de predicado contextual ativo e fornecer suas saídas ao Conversor. Vale salientar que durante a fase de avaliação do sistema, um Evento não possui uma classe de EM relacionada a si, diferentemente do que ocorre na fase de treinamento.

Para esclarecimento dos conceitos aqui descritos, podemos ver na Tabela 6.3 uma lista de Moldes de Predicados Contextuais. Ao aplicarmos os moldes da Tabela 6.3 sobre o contexto $b_{4}$ da Tabela 6.1, obteremos os predicados contextuais da Tabela 6.4.

Os predicados contextuais que poderiam ser obtidos pelos moldes 1, 11 e 12 da Tabela 6.3 não estão representados na Tabela 6.4 de forma intencional, pois para alguns moldes, quando determinada características não ocorre, em vez de devolver um valor padrão, nada é devolvido. Por exemplo, um molde de predicado contextual que testa se o token corrente é composto por números e o hífen internamente, poderia devolver o valor padrão "se_numero_com_hífen $(0)=\mathrm{N}$ " para maioria dos casos.

Segundo Borthwick, a inclusão de retorno padrão em determinadas características (no nosso caso, predicados contextuais) podem não ser prejudiciais à performance do modelo em termos de predição, porém possuem algumas desvantagens, tais como o aumento do tempo de execução do algoritmo de extração de características, considerando que o valor padrão deverá ser emitido para todos os tokens que não atendam à consulta da função característica; e o aumento da dificuldade 


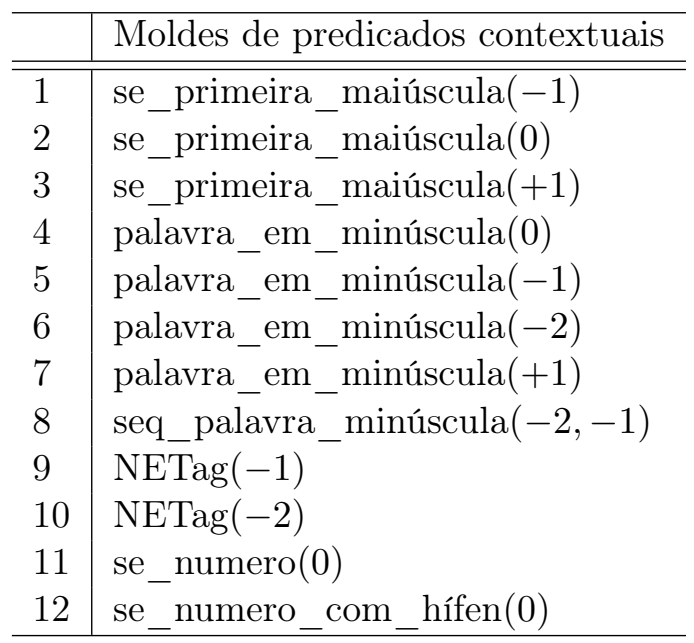

Tabela 6.3: Exemplos de moldes de predicados contextuais.

\begin{tabular}{|l|}
\hline Predicado contextuais de $b_{4}$ \\
\hline \hline se_primeira_maiúscula $(0)=\mathrm{S}$ \\
se_primeira_maiúscula $(+1)=\mathrm{S}$ \\
palavra_em_minúscula $(0)=$ manoel \\
palavra_em_minúscula $(-1)=$ é \\
palavra_em_minúscula $(-2)=$ nome \\
palavra_em_minúscula $(+1)=$ gregorio \\
seq_palavra_minúscula $(-2,-1)=$ nome_é \\
NETag $(-1)=\mathrm{O}$ \\
NETag $(-2)=\mathrm{O}$ \\
\hline
\end{tabular}

Tabela 6.4: Predicados contextuais dos moldes da Tabela 6.3 aplicados sobre o contexto $b_{4}$ da Tabela 6.1.

numérica no procedimento de estimação de máxima entropia, devido ao aumento do número de sobreposições de características.

\subsubsection{Estimador de Máxima Entropia}

Com o conjunto de características definido, podemos realizar o cálculo da maximização de entropia de acordo com a Seção 4.2.1. Para esta tarefa utilizamos a API de Máxima Entropia disponível no OpenNLP, que possui uma implementação do Escalonamento Iterativo Generalizado. Dessa forma poderemos nos concentrar na aplicação destas ferramentas ao nosso problema.

\subsubsection{Etiquetador de EM}

O Etiquetador de EM é responsável por obter a etiqueta que mais se adequa a cada token de uma sentença.

A simples obtenção da etiqueta mais provável para cada token não é o bastante para garantir a correta escolha de uma determinada etiqueta. Além disso, também é necessária tanto a verificação da sequência das etiquetas quanto a posição do token na sentença, visto que existem casos em que determinadas etiquetas só fazem sentido se seguida(s) de outra(s) etiqueta(s).

Por exemplo, considerando que o termo "século 21" seja uma EM do tipo "TEMPO" para a 
frase "Clima de século 21", a correta sequência de etiquetas de EM's para esta frase seria "O, O, tempo_start, tempo_end" e uma sequência inválida no contexto de REM seria "O, O, tempo_start, valor_end". Na Tabela 6.5 vemos outros exemplos de sequências inválidas. Na coluna "Incorreta A" da Tabela 6.5 vemos duas inconsistências: a primeira é o fato de que a etiqueta emtag $_{1}$ possui o sufixo "_continue" no inicio de uma sentença, e a segunda é a etiqueta emtag8 que está finalizando com o tipo "valor" uma sequência de etiquetamento do tipo "tempo". E na coluna "Incorreta B" da Tabela 6.5 existem também duas outras inconsistências: uma é o fato de que a etiqueta emtag possui o

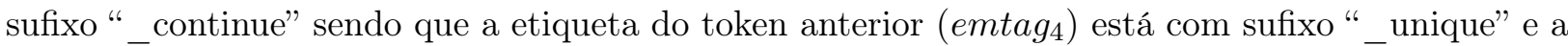
outra é a etiqueta emtag 9 que está com o sufixo "_continue" e não existem tokens posteriores.

\begin{tabular}{|r|l|l|l|l|}
\hline posição & palavra & \multicolumn{2}{|c|}{ EMTag $\left(\right.$ emtag $\left._{i}\right)$} \\
\cline { 3 - 5 }$(i)$ & $\left(w_{i}\right)$ & Correta & Incorreta A & Incorreta B \\
\hline \hline 1 & São & local_start & local_continue & local_start \\
2 & Paulo & local_end & local_end & local_end \\
3 &, & O & O & O \\
4 & 21 & tempo_start & tempo_start & tempo_unique \\
5 & de & tempo_continue & tempo_continue & tempo_continue \\
6 & Novembro & tempo_continue & tempo_continue & tempo_end \\
7 & de & tempo_continue & tempo_continue & O \\
8 & 1994 & tempo_end & valor_end & valor_start \\
9 &. & O & O & valor_continue \\
\hline
\end{tabular}

Tabela 6.5: Exemplos de sequências de etiquetamentos inconsistentes.

Esta verificação de consistência é realizada nesta etapa e segue um conjunto de regras para evitar sequências inadequadas. Para a realização desta tarefa é utilizado um algoritmo guloso que observa os tokens da esquerda para a direita.

Dado uma sentença é realizado o seguinte processo:

1. Para cada token $t_{i}$ da esquerda para a direita de uma sentença, faça:

(a) Obter o conjunto de características $\mathcal{C}$ do contexto de $t_{i}$.

(b) Obter a distribuição de probabilidade $\mathcal{D}$ dado $\mathcal{C}$.

(c) Ordenar a distribuição de probabilidade $\mathcal{D}$.

(d) Selecionar e extrair a etiqueta de EM emtag mais provável de $\mathcal{D}$.

(e) Repetir a partir do passo (d) até que emtag seja consistente de acordo com a Tabela 6.6.

(f) Devolva emtag.

Ratinov \& Roth [RR09], compararam a performance de três algoritmos para inferência de etiquetas de EM: Viterbi, decodificação gulosa esquerda-direita e o algoritmo BeamSearch. Os resultados mostraram que o algoritmo guloso obtém resultados comparáveis aos algoritmos Viterbi e BeamSearch. Além disso, em seus experimentos mostraram que algoritmo guloso é cerca de 100 vezes mais rápido que o Viterbi para a tarefa de inferência de etiquetas para apenas quatro categorias utilizando o esquema BILOU. Outra desvantagem dos algoritmos BeamSearch e Viterbi é a de que ambos precisam transformar as predições do classificador em probabilidades, o que ocasiona um custo adicional de tempo. 


\begin{tabular}{|l|l|l|l|}
\hline \multirow{2}{*}{ emtag $_{i}$} & \multicolumn{2}{|l|}{ Permitido se: } \\
\cline { 2 - 4 } & emtag $_{i-1}$ está em: & $i=1$ & $i=n$ \\
\hline \hline x_start & O, x_end, $\mathrm{x}$ _unique & sim & não \\
x_continue & x_start, __continue & não & não \\
x_end & x_start, x_continue & não & sim \\
x_unique & O, x_end, x_unique & sim & sim \\
O & O, x_end, x_unique & sim & sim \\
\hline
\end{tabular}

Tabela 6.6: Condições para permissão do etiquetamento do token $t_{i}$, de uma sentença de tamanho $n$. Onde

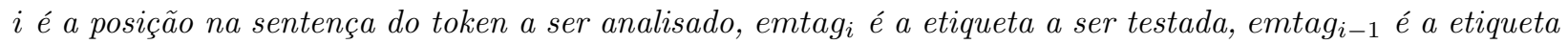
atribuída ao token anterior.

\subsubsection{Avaliador}

O Avaliador é o módulo responsável pelos cálculos de performance do sistema em termos de identificação e classificação das entidades mencionadas. Também é responsável pelo fornecimento de relatórios destas performances em termos de precisão, cobertura e $F_{1}$. O Avaliador segue os moldes da avaliação especificada pela CoNLL, como visto na Seção 3.2.2. Os relatórios fornecidos por este módulo estão com nível de detalhamento de avaliação por categorias de EM's.

A Tabela 6.7 mostra as informações obtidas com o Avaliador ao fornecermos como entrada os textos da Tabela 3.1.

\begin{tabular}{lrrrrrrrrrr}
\hline \multirow{2}{*}{ Categorias } & \multicolumn{9}{c}{ Ocorr. } & \multicolumn{2}{c}{ Pontuação } & \multicolumn{2}{c}{ Precisão } & \multicolumn{2}{c}{ Cobertura } & \multicolumn{2}{c}{$F_{1}$} \\
\cline { 2 - 12 } & Gab & Sis & $\mathrm{Id}$ & Cla & $\mathrm{Id}(\%)$ & $\mathrm{Cl}(\%)$ & $\mathrm{Id}(\%)$ & $\mathrm{Cl}(\%)$ & $\mathrm{Id}(\%)$ & $\mathrm{Cl}(\%)$ \\
\hline \hline LOCATION & 1 & 1 & 0 & 0 & & & & & & \\
ORGANIZATION & 2 & 3 & 2 & 1 & 66,667 & 33,333 & 100 & 50 & 80 & 40 \\
PERSON & 2 & 1 & 0 & 0 & & & & & & \\
\hline TOTAL & 5 & 5 & 2 & 1 & 40 & 20 & 40 & 20 & 40 & 20 \\
\hline
\end{tabular}

Tabela 6.7: Resultado da comparação entre os textos Tabela 3.1 obtido pelo módulo Avaliador.

O cálculo é realizado comparando, para cada sentença, as etiquetas fornecidas pelo Filtro de Avaliação com as etiquetas existentes no texto de saída do módulo Etiquetador de EM's.

$\mathrm{Na}$ tarefa de identificação, uma EM fornecida pelo Etiquetador é considerada correta se todos os termos desta EM coincidirem com os termos da EM correspondente fornecido pelo Filtro de Avaliação. Na tarefa de classificação, apenas as EM marcadas como corretas na tarefa de identificação serão avaliadas. Cada EM corretamente identificada, tem a sua categoria comparada com a categoria da EM fornecida pelo Filtro de Avaliação.

Este módulo é importante pois nos guiará no desenvolvimento do sistema. À medida que forem adicionados novos moldes de predicados contextuais, será possível avaliar o impacto de cada molde na performance. 


\section{Capítulo 7}

\section{Resultados}

Neste capítulo discutiremos as características exploradas e seus impactos na performance de vários modelos construídos. Para cada grupo de característica, testamos sua performance em três córpus, avaliamos e discutimos os resultados. Finalmente, com base nestes resultados, construímos um modelo final e o avaliamos aos moldes do Segundo HAREM e comparamos com os resultados dos participantes do mesmo evento utilizando o SAHARA.

\subsection{Metodologia e Córpus Utilizados}

A fim de treinar e testar os vários diferentes modelos que criamos, utilizamos os recursos dos primeiros eventos realizados pelo HAREM, disponibilizados no sítio do HAREM ${ }^{1}$, a saber:

- Primeiro HAREM Coleção dourada utilizada no primeiro evento do HAREM;

- Mini HAREM Coleção dourada utilizada no Mini HAREM.

Além desses recursos, utilizamos o córpus Selva Falada, que é um subconjunto do córpus Floresta Sintática. O Floresta Sintática é um córpus analisado sintaticamente, criado pelo Linguateca em parceira com o projeto VISL ${ }^{2}$, que contém textos em português (Brasil e Portugal) anotados automaticamente pelo analisador sintático PALAVRAS e revistos por linguistas. O córpus Selva Falada é parcialmente revisto por linguistas e contém marcações semânticas necessárias de EM's que podem ser mapeadas para as categorias do HAREM. Está disponível em formato de Árvore Deitada, que é um formato de representação de conhecimento de texto adotado pela equipe do projeto. Esse recurso está disponível gratuitamente no sítio do Linguateca ${ }^{3}$, e pode ser utilizado para o treino e avaliação de diferentes tarefas do PLN, inclusive para tarefas de aspectos semânticos e discursivos.

\subsubsection{Preparação dos Córpus}

Manipulamos os três córpus de maneira a deixá-los compatíveis com a entrada do nosso sistema como explicado na Seção 6.1.1. Utilizamos o OpenNLP para efetuar as transformações necessárias sobre o córpus Selva Falada e compatibilizá-lo com o formato de entrada do nosso sistema. Vemos na Tabela 7.1 o número de EM por categoria e por córpus após as manipulações realizadas.

\footnotetext{
${ }^{1}$ http://www.linguateca.pt/HAREM/

${ }^{2}$ http://beta.visl.sdu.dk

${ }^{3}$ http://www.linguateca.pt/floresta/corpus.html
} 


\begin{tabular}{lrrrrrr}
\hline Categorias & \multicolumn{2}{c}{ Mini HAREM } & \multicolumn{2}{c}{ Primeiro HAREM } & \multicolumn{2}{c}{ Selva Falada } \\
& \#EM & $(\%)$ & \#EM & $(\%)$ & \#EM & $(\%)$ \\
\hline \hline Abstração & 203 & 5,62 & 406 & 8,18 & 334 & 2,61 \\
Coisa & 169 & 4,68 & 137 & 2,76 & 137 & 1,07 \\
Local & 874 & 24,20 & 1235 & 24,87 & 1648 & 12,89 \\
Obra & 191 & 5,29 & 196 & 3,95 & 426 & 3,33 \\
Organização & 599 & 16,59 & 927 & 18,67 & 3319 & 25,96 \\
Pessoa & 831 & 23,01 & 1033 & 20,80 & 4763 & 37,25 \\
Tempo & 362 & 10,02 & 438 & 8,82 & 267 & 2,09 \\
Valor & 324 & 8,97 & 466 & 9,38 & 784 & 6,13 \\
Acontecimento & 58 & 1,61 & 128 & 2,58 & 1109 & 8,67 \\
\hline \hline Total & 3611 & - & 4966 & - & 12787 & - \\
\hline
\end{tabular}

Tabela 7.1: Córpus utilizados nos experimentos e suas distribuições de EM por categorias.

Cada córpus foi dividido em duas partes. Uma refere-se ao treino e corresponde a $90 \%$ da divisão das frases. O restante é utilizado para teste. Esta divisão foi realizada dez vezes para cada córpus, gerando dez pares de arquivos treino-teste por córpus. A aleatoriedade só foi utilizada na criação dos pares de arquivos, pois nosso objetivo é explorar o impacto de cada grupo de característica sobre o mesmo conjunto de pares de arquivos.

Para cada grupo de características foi criado e testado um modelo sobre cada par de arquivos treino-teste. Em seguida, foi calculada a média aritmética dos resultados sobre cada par de arquivos.

Segundo Ratnaparki [Rat98], o comportamento de características que ocorrem raramente no conjunto de treinamento é de difícil previsão, pois não é estatisticamente confiável. Para contornar esse problema, é realizado um processo de seleção de características que retira do modelo qualquer característica que ocorra menos de um determinado número vezes. Na tarefa de etiquetamento morfológico realizado por Ratnaparki, qualquer característica que ocorra menos do que dez vezes é eliminada. Borthwick, por sua vez, selecionou todas as características que predizem uma etiqueta de EM e que ocorram pelo menos três vezes bem como todas as que predizem a etiqueta "other" e que ocorram pelo menos seis vezes. Com esta estratégia de exigir um número maior de ocorrências para as características que predizem "other", Borthwick mostrou experimentalmente que o tamanho do arquivo modelo final reduziu cerca de $20 \%$ e que não teve impacto na performance.

Veremos nas próximas seções as características exploradas e seus impactos na tarefa de identificação e classificação das EM sobre cada córpus. Veremos também alguns experimentos para avaliar o impacto do corte em alguns grupos de características. No contexto de nosso sistema, os cortes podem ser interpretados como o número mínimo de vezes que o predicado contextual deve ocorrer no conjunto de treinamento para ser incluído no modelo.

\subsection{Características}

\subsubsection{Estrutura Interna da Palavra}

A utilização de características que exploram a estrutura interna da palavra é uma das abordagens utilizadas por Borthwick (vide Seção 5.1.3), e por Milidiú (vide Seção 5.1.2). Tais características são facilmente exploradas utilizando funções binárias que fazem simples verificações na palavra. 
Vemos na Tabela 7.2 o conjunto de características que testamos para a exploração da estrutura interna da palavra e, de forma resumida, alguns exemplos de textos que cada característica explora; e, finalmente, uma breve descrição da intuição sobre a característica.

\begin{tabular}{|c|c|c|c|}
\hline & Característica & Texto de Exemplo & Intuição \\
\hline$e_{1}$ & Todas Maiúsculas & FAPESP & Nome de organizações, siglas. \\
\hline$e_{2}$ & Todas Minúsculas & viajar, reunião & Provavelmente não é uma EM \\
\hline$e_{3}$ & Primeira Maiúscula & Lu, Belém & Forte candidato a EM \\
\hline$e_{4}$ & $\begin{array}{l}\text { Capitalização } \\
\text { Interna }\end{array}$ & WebJet, IstoÉ & $\begin{array}{l}\text { Empresas com letras } \\
\text { maiúsculas internamente }\end{array}$ \\
\hline$e_{5}$ & Apenas Números & $1,354,888$ & Números diversos \\
\hline$e_{6}$ & Números e Letras & XR200, K19 & Produtos, empresas \\
\hline$e_{7}$ & Números com "," ou "." & $1.503,14151.123,10$ & Valores monetários \\
\hline$e_{8}$ & $\begin{array}{l}\text { Números com "/" } \\
\text { "_" ou ":?" }\end{array}$ & $\begin{array}{l}01 / 02 \\
25-1210: 351\end{array}$ & Data e hora \\
\hline$e_{9}$ & $\begin{array}{l}\text { Números finalizando com } \\
\text { "h","hs","m","ms" e "s". }\end{array}$ & 10hs $15 \mathrm{~m} \mathrm{30s}$ & Tempo: hora, minutos... \\
\hline$e_{10}$ & Apenas 1 número & 2 dias ou 4 livros & Números diversos. \\
\hline$e_{11}$ & Apenas 2 números & 11 ou 98 & Anos de 2 dígitos \\
\hline$e_{12}$ & Apenas 4 números & 1939 ou 2001 & Anos de 4 dígitos. \\
\hline
\end{tabular}

Tabela 7.2: Conjunto de características utilizadas para a exploração da estrutura interna da palavra.

Uma vantagem dessas características é a possibilidade da exploração das palavras em outros idiomas, além do português, tais como Espanhol e Inglês.

\section{Sobreposições}

Na implementação do conjunto de características da Tabela 7.2, ficamos em dúvida se representaríamos as características sem nos preocuparmos com a sobreposição.

Se o sistema permitir, por exemplo, sobreposição de características, a característica $e_{3}$ (Primeira Maiúscula) será ativada para as palavras "FAPESP", "WebJet" e "Belém". No entanto, se utilizarmos um esquema hierárquico que não permita sobreposições, a característica $e_{3}$ poderia ser ativada apenas para a palavra "Belém" e "WebJet", considerando que a característica $e_{1}$ (todas maiúsculas) antecedesse a característica $e_{3}$. Da mesma forma a característica $e_{4}$ (Capitalização Interna) poderia não ser ativada em "FAPESP" caso a característica $e_{1}$ fosse testada antes.

Segundo Borthwick [BSAG98], um modelo de Máxima Entropia que permita sobreposição de características terá o mesmo resultado que um modelo que não permita sobreposições.

Realizamos um experimento comparativo entre dois modelos treinados para verificar o impacto do uso das características de estrutura interna da palavra com sobreposição e sem sobreposição. O primeiro modelo utiliza as características de estrutura interna da palavra e permite sobreposição. O segundo utiliza as mesmas características, porém não permite a sobreposição de algumas delas. Utilizamos o valor de corte de predicados contextuais igual a 10. A hierarquia utilizada para o teste sem sobreposição é apresentada no Algoritmo 1. Na Tabela 7.3 estão os resultados obtidos neste experimento.

Todos os resultados se apresentaram melhores para a implementação com sobreposição por não termos efetuado um estudo mais aprofundado sobre os possíveis particionamentos das característi- 


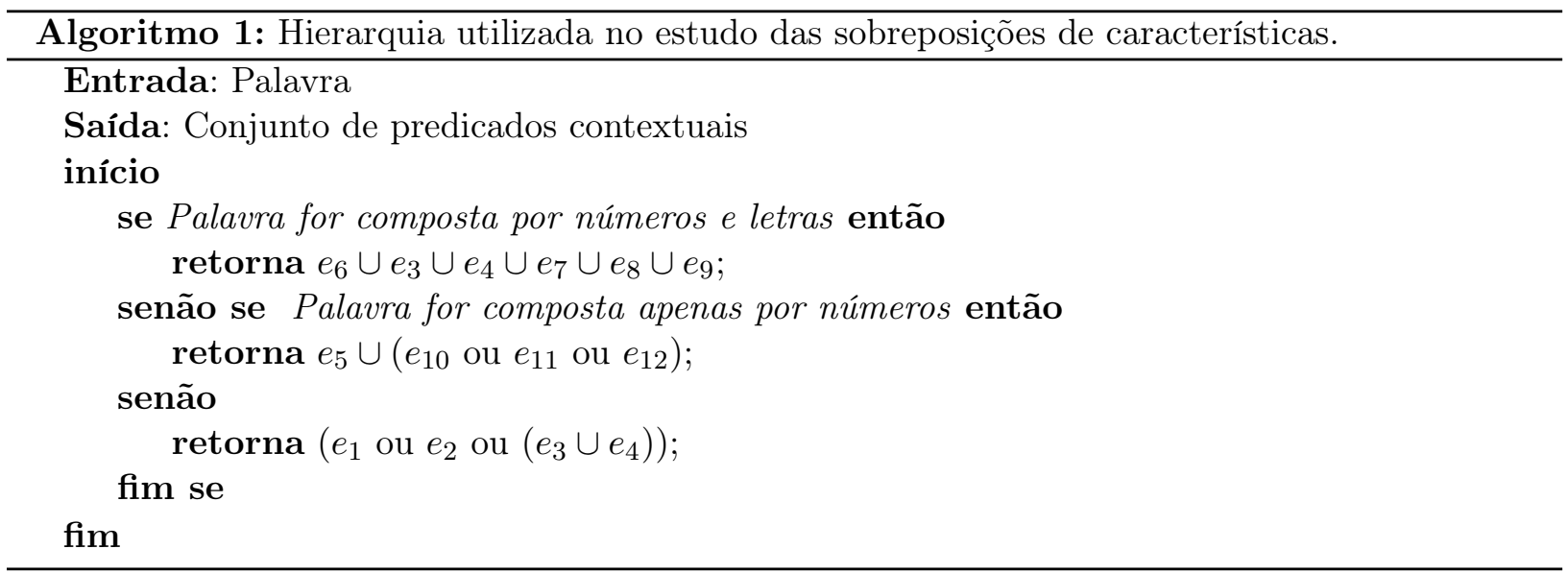

cas. Considerando tal resultado, utilizaremos as características com sobreposições, pois desta forma não precisaremos nos preocupar com o estudo do correto particionamento. No entanto, para um sistema de produção, no qual o tempo é um fator importante, este estudo se faz válido devido à dificuldade numérica do procedimento de estimação de máxima entropia, pois segundo Borthwick 5.1.3, quanto maior o número de sobreposições, mais iterações serão necessárias.

\begin{tabular}{llrrrrrr}
\hline Córpus & Sobre- & \multicolumn{2}{c}{ Precisão } & \multicolumn{2}{c}{ Cobertura } & \multicolumn{2}{c}{$F_{1}$} \\
\cline { 3 - 8 } & posição? & Ident(\%) & Class(\%) & Ident(\%) & Class(\%) & Ident $(\%)$ & Class(\%) \\
\hline \hline Mini & sim & $\mathbf{4 5 , 0 8 8 3 1}$ & $\mathbf{4 1 , 2 7 8 0 7}$ & $\mathbf{9 , 0 3 2 7 5}$ & $\mathbf{8 , 3 8 0 0 5}$ & $\mathbf{1 4 , 9 3 9 7 5}$ & $\mathbf{1 3 , 8 3 2 4 5}$ \\
HAREM & não & 42,24815 & 39,72079 & 8,31002 & 7,87166 & 13,76735 & 13,02675 \\
\hline Primeiro & sim & $\mathbf{4 4 , 6 7 4 7 5}$ & $\mathbf{3 6 , 9 4 3 6 7}$ & $\mathbf{1 0 , 3 1 8 2 1}$ & $\mathbf{8 , 4 1 8 9 7}$ & $\mathbf{1 6 , 6 2 7 9 4}$ & $\mathbf{1 3 , 5 9 3 8 2}$ \\
HAREM & não & 36,82774 & 31,47835 & 6,63823 & 5,68007 & 11,21763 & 9,59697 \\
\hline Selva & sim & $\mathbf{6 5 , 2 9 7 9 5}$ & $\mathbf{5 6 , 9 9 1 0 9}$ & $\mathbf{1 3 , 1 4 3 2 2}$ & $\mathbf{1 1 , 4 7 6 6 5}$ & $\mathbf{2 1 , 8 6 7 9 3}$ & $\mathbf{1 9 , 0 9 3 4 4}$ \\
Falada & não & 59,13378 & 53,56141 & 9,13938 & 8,28670 & 15,81311 & 14,33616 \\
\hline
\end{tabular}

Tabela 7.3: Estudo de Sobreposição de características utilizando o corte igual a 10. Os melhores resultados por córpus estão em negrito.

Além deste experimento, realizamos um estudo do número de corte para este grupo de características. Vemos na Tabela 7.4 que o número de cortes (cinco e dez) só influencia, e de forma pouco significativa, os resultados dos estudos feitos sobre o córpus Mini HAREM, enquanto nos outros não há diferenças.

\begin{tabular}{llrrrrrr}
\hline Córpus & \multirow{2}{*}{ Corte } & \multicolumn{2}{c}{ Precisão } & \multicolumn{2}{c}{ Cobertura } & \multicolumn{2}{c}{$F_{1}$} \\
\cline { 2 - 7 } & & Ident(\%) & Class(\%) & Ident(\%) & Class(\%) & Ident(\%) & Class(\%) \\
\hline \hline Mini & 5 & 45,07398 & 41,08870 & $\mathbf{9 , 0 6 0 4 5}$ & 8,38005 & $\mathbf{1 4 , 9 8 0 5 6}$ & 13,82546 \\
HAREM & 10 & $\mathbf{4 5 , 0 8 8 3 1}$ & $\mathbf{4 1 , 2 7 8 0 7}$ & 9,03275 & 8,38005 & 14,93975 & $\mathbf{1 3 , 8 3 2 4 5}$ \\
\hline Primeiro & 5 & 44,67475 & 36,94367 & 10,31821 & 8,41897 & 16,62794 & 13,59382 \\
HAREM & 10 & 44,67475 & 36,94367 & 10,31821 & 8,41897 & 16,62794 & 13,59382 \\
\hline Selva & 5 & 65,29795 & 56,99109 & 13,14322 & 11,47665 & 21,86793 & 19,09344 \\
Falada & 10 & 65,29795 & 56,99109 & 13,14322 & 11,47665 & 21,86793 & 19,09344 \\
\hline
\end{tabular}

Tabela 7.4: Análise do número para corte de predicados contextuais utilizando as características da estrutura interna da palavra com sobreposição. 


\subsubsection{Léxicas}

Para o estudo do impacto das características léxicas para as tarefas de REM, realizamos seis diferentes experimentos. Em cada um deles fizemos a avaliação do número do corte de predicados contextuais. Utilizamos nestes experimentos uma janela de tamanho igual a cinco, onde os tokens do intervalo $t_{-2}$ a $t_{+2}$ são consultados. De acordo com Borthwick, o sistema obtém uma performance razoável com apenas essas características.

Os experimentos desta seção foram realizados para a comparação da implementação proposta por Borthwick e algumas intuições nossas. A proposta de Borthwick é a construção de um vocabulário utilizando todas as palavras existentes no conjunto de treinamento e que ocorram pelo menos três vezes. No momento da criação de predicados contextuais o token é buscado no vocabulário e, se for encontrado, ele é fornecido ao molde da característica. Caso não seja encontrado, uma representação de palavra desconhecida será fornecida ao molde.

Testamos esta abordagem de quatro formas diferentes. Inicialmente construímos dois vocabulários de cada córpus:

- $V_{1}$ : Vocabulário contendo todas as palavras que, transformadas em minúsculas, ocorreram pelo menos três vezes no córpus. Os números e sinais de pontuações também foram removidos;

- $V_{2}$ : Vocabulário contendo todas as palavras que, transformadas em minúsculas, ocorreram pelo menos três vezes no córpus, desta vez, apenas os números foram removidos.

Em seguida, testamos o uso das características léxicas utilizando os vocabulários construídos em quatro diferentes implementações. Em cada implementação, é verificada a existência de uma determinada palavra, $w$, e emitido um indicador ao molde de predicado contextual. As implementações testadas foram:

- $L_{1}$ : Consulta $w$ em minúsculo em $V_{1}$, se existir, $w$ é fornecido ao molde de predicado contextual, caso contrário, é fornecido "\#rara\#";

- $L_{2}$ : Consulta $w$ em minúsculo em $V_{1}$, se existir, $w$ em minúsculo é fornecido ao molde de predicado contextual, caso contrário, é fornecido "\#rara\#";

- $L_{3}$ : Consulta $w$ em minúsculo em $V_{2}$, se existir, $w$ é fornecido ao molde de predicado contextual, caso contrário, é verificado se $w$ é composto apenas por números, se sim é fornecido "\#número\#" ao molde, se não, é fornecido "\#rara\#";

- $L_{4}$ : Consulta $w$ em minúsculo em $V_{2}$, se existir, $w$ em minúsculo é fornecido ao molde de predicado contextual, caso contrário, é verificado se $w$ é composto apenas por números, se sim é fornecido "\#número\#" ao molde, se não, é fornecido "\#rara\#".

Os modelos $L_{1}$ e $L_{3}$, são parecidos com modelos $L_{2}$ e $L_{4}$, respectivamente, com a diferença de que estes últimos fornecem a palavra em minúscula ao molde de predicado contextual. Fizemos essas implementações para verificar o comportamento do sistema utilizando as palavras independentemente de suas capitalizações.

Realizamos ainda dois outros experimentos utilizando apenas as características léxicas. Desta vez, diferentemente da proposta de Borthwick, não criamos os vocabulários; em vez disso, todas as 
palavras foram fornecidas ao molde de predicado contextual e deixamos que o corte no processo de seleção de características removesse os predicados contextuais. Estes experimentos foram realizados de duas formas diferentes:

- $L_{5}$ : A palavra a ser analisada é fornecida em seu estado normal ao molde de predicado contextual.

- $L_{6}$ : A palavra a ser analisada é transformada para minúscula e em seguida é fornecida ao molde de predicado contextual.

Os resultados de todos esses experimentos podem ser vistos na Tabela 7.5.

Verificamos que o modelo $L_{3}$, utilizando o corte igual a cinco, obteve os melhores valores em todas as medidas para os córpus Primeiro HAREM e Selva Falada. No entanto, para o córpus Mini HAREM, o modelo $L_{4}$ apresentou os melhores resultados.

Vemos que a nossa abordagem de emitir uma indicação de número em vez de indicador de palavra desconhecida quando a palavra em questão for rara, não for um sinal de pontuação e for compostas apenas por números (modelos $L_{3}$ e $L_{4}$ ), aumentou significativamente o resultado em relação aos modelos correspondentes $L_{1}$ e $L_{2}$, sendo que os menores aumentos estão nos resultados do córpus Selva Falada.

Além disso, as tentativas de não utilizar um dicionário de palavras (modelos $L_{5}$ e $L_{6}$ ) também apresentaram melhores resultados do que os modelos que utilizaram dicionários sem pontuações e emitiam apenas indicadores de palavras raras e não emitiam indicadores de números. Mas essas tentativas também ficaram abaixo dos modelos $L_{3}$ e $L_{4}$ em todos os experimentos correspondentes.

Com base nesses resultados, temos indícios de que utilizando apenas as palavras como características, a melhor abordagem é o uso de um dicionário de palavras e sinais de pontuações, e a emissão de um indicador de número caso a palavra seja rara.

Porém, até este experimento, ainda não estávamos certos se forneceríamos ao molde de predicado contextual a palavra em minúscula ou em seu estado normal. Para esclarecer tais dúvidas, realizamos os estudos da próxima seção.

\section{Características Léxicas e de Estrutura Interna da Palavra}

Ao utilizar as palavras transformadas em minúsculas, acreditamos que aumentaríamos o número de exemplos de aplicação das palavras no texto e com isso obteríamos melhores resultados, porém esta intuição não se confirmou em todos os córpus verificados.

É provável que os melhores resultados se apresentaram nos maiores córpus por terem mais exemplos de aplicações das palavras, tanto em seus formatos em minúsculo quanto capitalizado.

Para esclarecer essas dúvidas, realizamos outra bateria de experimentos utilizando as características léxicas, desta vez, combinando-as com as características de estrutura interna da palavra.

Acreditamos que o que se perde ao transformar as palavras em minúsculas para fornecê-las ao predicado contextual léxico será compensado pelas informações obtidas com as características de estrutura interna da palavra.

Para verificar essas intuições realizamos inicialmente dois experimentos. No primeiro utilizamos a combinação do modelo $L_{3} \mathrm{com}$ as características de estrutura interna da palavra, e em outro combinamos o modelo $L_{4}$ também com as características de estrutura interna da palavra. 


\begin{tabular}{|c|c|c|c|c|c|c|c|c|}
\hline \multirow[t]{2}{*}{ Córpus } & \multirow[t]{2}{*}{ Corte } & \multirow[t]{2}{*}{ Modelo } & \multicolumn{2}{|c|}{ Precisão } & \multicolumn{2}{|c|}{ Cobertura } & \multicolumn{2}{|c|}{$F_{1}$} \\
\hline & & & Ident(\%) & Class (\%) & Ident $(\%)$ & Class (\%) & Ident $(\%)$ & Class(\%) \\
\hline Mini & $\overline{5}$ & $\overline{\overline{L_{1}}}$ & 57,92671 & 253,17173 & 25,01011 & 22,92121 & 34,84100 & 31,94467 \\
\hline \multirow[t]{11}{*}{ HAREM } & & $L_{2}$ & 58,11625 & 54,19012 & 25,69734 & 23,91748 & 35,53331 & 33,08879 \\
\hline & & $L_{3}$ & 62,35451 & 55,34742 & 36,70953 & 32,57447 & 46,16560 & 40,97087 \\
\hline & & $L_{4}$ & 63,67273 & 57,02506 & 37,51626 & 33,60098 & 47,16028 & 42,23777 \\
\hline & & $L_{5}$ & 52,76292 & 46,74701 & 29,92408 & 26,49575 & 38,13296 & 33,77154 \\
\hline & & $L_{6}$ & 53,71816 & 48,08162 & 30,38455 & 27,19076 & 38,74153 & 34,67230 \\
\hline & 10 & $L_{1}$ & 53,46166 & 49,13507 & 15,80125 & 14,51265 & 24,28067 & 22,30407 \\
\hline & & $L_{2}$ & 53,44961 & 49,47473 & 16,80832 & 15,54738 & 25,49690 & 23,58819 \\
\hline & & $L_{3}$ & 59,50493 & 51,93192 & 28,41611 & 24,78027 & 38,40784 & 33,50155 \\
\hline & & $L_{4}$ & 59,31322 & 52,68692 & 29,70413 & 26,40916 & 39,52310 & 35,12828 \\
\hline & & $L_{5}$ & 47,00800 & 40,64527 & 21,08946 & 18,22862 & 29,06334 & 25,12315 \\
\hline & & $L_{6}$ & 48,85135 & 42,52682 & 22,03543 & 19,18667 & 30,29501 & 26,37735 \\
\hline Primeiro & 5 & $L_{1}$ & 62,35852 & 55,66621 & 31,85902 & 28,41493 & 42,13202 & 37,58890 \\
\hline \multirow[t]{11}{*}{ HAREM } & & $L_{2}$ & 57,84161 & 52,44530 & 29,48703 & 26,72580 & 39,01206 & 35,36370 \\
\hline & & $L_{3}$ & 65,85448 & 58,28748 & 40,35882 & 35,72170 & 50,02960 & 44,28113 \\
\hline & & $L_{4}$ & 62,81071 & 56,32152 & 38,05715 & 34,13307 & 47,38065 & 42,49176 \\
\hline & & $L_{5}$ & 59,19098 & 51,30969 & 35,01082 & 30,32762 & 43,96566 & 38,09489 \\
\hline & & $L_{6}$ & 56,05012 & 48,66432 & 33,17455 & 28,79506 & 41,64504 & 36,15123 \\
\hline & 10 & $L_{1}$ & 58,23026 & 51,61189 & 23,30557 & 20,67738 & 33,22505 & 29,46949 \\
\hline & & $L_{2}$ & 54,06489 & 48,74127 & 22,78722 & 20,54369 & 32,00791 & 28,85626 \\
\hline & & $L_{3}$ & 63,25999 & 55,39849 & 33,07521 & 28,96327 & 43,40521 & 38,01007 \\
\hline & & $L_{4}$ & 59,99905 & 53,75298 & 32,17765 & 28,82285 & 41,86855 & 37,50566 \\
\hline & & $L_{5}$ & 55,40753 & 46,59734 & 27,10600 & 22,79670 & 36,34989 & 30,57064 \\
\hline & & $L_{6}$ & 52,49531 & 44,65671 & 26,55843 & 22,59536 & 35,21657 & 29,96044 \\
\hline Selva & 5 & $L_{1}$ & 89,19264 & 85,15378 & 73,00773 & 69,70019 & 80,28912 & 76,65248 \\
\hline \multirow[t]{11}{*}{ Falada } & & $L_{2}$ & 85,84916 & 82,08851 & 70,27346 & 67,19302 & 77,28138 & 73,89477 \\
\hline & & $L_{3}$ & 89,31352 & 85,31022 & 75,34811 & 71,96998 & 81,73608 & 78,07195 \\
\hline & & $L_{4}$ & 86,26166 & 82,68613 & 72,54302 & 69,53404 & 78,80786 & 75,54005 \\
\hline & & $L_{5}$ & 88,59780 & 84,66803 & 74,38088 & 71,07969 & 80,86648 & 77,27845 \\
\hline & & $L_{6}$ & 85,23279 & 81,65785 & 71,54968 & 68,54518 & 77,78905 & 74,52427 \\
\hline & 10 & $L_{1}$ & 88,18752 & 84,07993 & 67,68346 & 64,52485 & 76,58132 & 73,01043 \\
\hline & & $L_{2}$ & 85,01773 & 81,17754 & 65,32471 & 62,37232 & 73,87452 & 70,53651 \\
\hline & & $L_{3}$ & 88,10937 & 84,09764 & 70,31937 & 67,11497 & 78,21285 & 74,65006 \\
\hline & & $L_{4}$ & 85,35761 & 81,65580 & 68,08982 & 65,13575 & 75,74947 & 72,46364 \\
\hline & & $L_{5}$ & 87,87582 & 83,80440 & 69,10600 & 65,90246 & 77,36398 & 73,77848 \\
\hline & & $L_{6}$ & 84,72568 & 80,94432 & 66,64495 & 63,66883 & 74,59894 & 71,26846 \\
\hline
\end{tabular}

Tabela 7.5: Comparação das diferentes implementações do uso das características léxicas e configurações de cortes aplicados sobre o córpus estudados. Os melhores resultados por córpus estão em negrito.

Realizamos esses experimentos apenas para o corte igual a cinco, justamente por ter sido o melhor dos valores de cortes que experimentamos no uso de características léxicas, conforme verificamos na Tabela 7.5 da seção anterior. Os resultados estão na Tabela 7.6.

Conforme esperamos, o modelo $L_{4}$ combinado com as características de estrutura interna da palavra apresentou melhores resultados em todos os córpus experimentados. Dado o sucesso do modelo $L_{4}$ em comparação aos demais testados, utilizaremos esta combinação nos futuros experimentos. 


\begin{tabular}{llrrrrrr}
\hline Córpus & \multirow{2}{*}{ Modelo } & \multicolumn{2}{c}{ Precisão } & \multicolumn{2}{c}{ Cobertura } & \multicolumn{2}{c}{$F_{1}$} \\
\cline { 3 - 8 } & & Ident(\%) & Class(\%) & Ident(\%) & Class(\%) & Ident(\%) & Class(\%) \\
\hline \hline Mini & $E I+L_{3}$ & 63,76415 & 50,28730 & 55,19225 & 43,53266 & 59,12099 & 46,62906 \\
HAREM & $E I+L_{4}$ & $\mathbf{6 6 , 4 5 6 5 6}$ & $\mathbf{5 3 , 1 1 5 7 5}$ & $\mathbf{5 6 , 0 6 1 9 8}$ & $\mathbf{4 4 , 8 2 8 4 7}$ & $\mathbf{6 0 , 7 7 3 9 7}$ & $\mathbf{4 8 , 5 8 6 1 7}$ \\
\hline Primeiro & $E I+L_{3}$ & 67,90104 & 53,78099 & 57,46423 & 45,48857 & 62,21610 & 49,26313 \\
HAREM & $E I+L_{4}$ & $\mathbf{6 7 , 9 0 5 3 3}$ & $\mathbf{5 5 , 1 6 5 9 9}$ & $\mathbf{5 7 , 5 9 0 4 3}$ & $\mathbf{4 6 , 7 6 7 0 6}$ & $\mathbf{6 2 , 3 0 7 1 4}$ & $\mathbf{5 0 , 6 0 6 8 3}$ \\
\hline Selva & $E I+L_{3}$ & $\mathbf{8 8 , 4 8 4 8 4}$ & 82,50918 & $\mathbf{7 8 , 9 4 9 5 6}$ & 73,61729 & $\mathbf{8 3 , 4 4 4 3 9}$ & 77,80882 \\
Falada & $E I+L_{4}$ & 88,02284 & $\mathbf{8 2 , 5 9 4 2 3}$ & 78,62361 & $\mathbf{7 3 , 7 7 3 7 1}$ & 83,05581 & $\mathbf{7 7 , 9 3 3 0 0}$ \\
\hline
\end{tabular}

Tabela 7.6: Avaliação das Características de Estrutura Interna da palavra combinadas com as Características $L_{3}$ e $L_{4}$.

\subsubsection{Etiquetas Morfológicas}

Apesar de o MENE não utilizar etiquetas morfológicas $(P o S)$ para auxiliar na tarefa de REM, verificamos que em alguns trabalhos propostos para o REM em português tais informações foram utilizadas, conforme vimos na Seção 5.1.2.

Para que o nosso sistema também seja capaz de utilizar essas informações, adicionamos um sub-módulo de etiquetamento morfológico ao módulo de pré-processamento, conforme descrito na Seção 6.1.1.

A utilidade dessas características foram verificadas através da criação de um modelo contendo apenas as etiquetas morfológicas como características. A vizinhança de tokens utilizada neste estudo é de tamanho igual a cinco: $t_{-2}$ a $t_{+2}$. Realizamos o estudo do corte de predicados contextuais para os valores cinco e dez.

Os resultados desses experimentos estão apresentados na Tabela 7.7.

\begin{tabular}{llrrrrrr}
\hline Córpus & \multirow{2}{*}{ Corte } & \multicolumn{2}{c}{ Precisão } & \multicolumn{2}{c}{ Cobertura } & \multicolumn{2}{c}{$F_{1}$} \\
\cline { 2 - 7 } & & Ident(\%) & Class(\%) & Ident(\%) & Class(\%) & Ident(\%) & Class(\%) \\
\hline \hline Mini & 5 & 63,83484 & $\mathbf{3 9 , 9 9 5 6 3}$ & 43,42677 & 27,20770 & 51,62532 & $\mathbf{3 2 , 3 4 4 3 2}$ \\
HAREM & 10 & $\mathbf{6 3 , 8 4 7 8 9}$ & 39,98124 & $\mathbf{4 3 , 4 5 4 2 4}$ & 27,20770 & $\mathbf{5 1 , 6 4 9 1 9}$ & 32,33968 \\
\hline Primeiro & 5 & 65,74802 & $\mathbf{3 6 , 8 6 2 5 8}$ & 44,98059 & $\mathbf{2 5 , 1 9 2 5 6}$ & 53,38924 & $\mathbf{2 9 , 9 1 4 6 8}$ \\
HAREM & 10 & $\mathbf{6 5 , 7 6 8 9 3}$ & 36,84586 & 44,98059 & 25,17502 & $\mathbf{5 3 , 3 9 5 2 6}$ & 29,89635 \\
\hline Selva & 5 & 70,53174 & 50,82171 & 46,97795 & 33,84557 & 56,38717 & 40,62662 \\
Falada & 10 & 70,53174 & 50,82171 & 46,97795 & 33,84557 & 56,38717 & 40,62662 \\
\hline
\end{tabular}

Tabela 7.7: Avaliação de modelos treinados utilizando apenas as etiquetas morfológicas obtidas pelo CoGrOO. Foram consultados as etiquetas dos tokens $t_{-2}$ a $t_{2}$.

Vemos, baseado nesses resultados, que o uso de etiquetas morfológicas como características, aparenta ser um bom indicador na resolução do nosso problema e além disso, é independente para os valores de cortes que analisamos.

\subsubsection{Modelo Base}

Considerando os resultados dos estudos realizados nas seções anteriores, criamos um modelo combinando os melhores cenários observados. Para referências nas comparações dos próximos experimentos, chamaremos este modelo de modelo-base $(m b)$. O modelo-base foi criado utilizando a seguinte configuração: 
- Características de estrutura interna da palavra: Utilizamos estas características sem nos preocuparmos com as sobreposições, de acordo com os estudos realizados na Seção 7.2.1;

- Características léxicas: Utilizamos a implementação $L_{4}$ para explorar as características léxicas, visto que seu uso combinado com a estrutura interna das palavras apresentou resultado superior a $1 \%$ na medida-F, se comparada à segunda melhor implementação;

- Etiquetas morfológicas: Considerando a performance razoável obtida nos estudos do uso de etiquetas morfológicas apresentados na Seção 7.2.3, utilizaremos estas informações em nosso modelo-base;

- Corte: Utilizamos valor de corte igual a cinco.

Vemos na Tabela 7.8 o resultado do modelo-base aplicado aos córpus estudados.

\begin{tabular}{lcccccc}
\hline Córpus & \multicolumn{2}{c}{ Precisão } & \multicolumn{2}{c}{ Cobertura } & \multicolumn{2}{c}{$F_{1}$} \\
\cline { 2 - 7 } & Ident(\%) & Class(\%) & Ident(\%) & Class(\%) & Ident(\%) & Class(\%) \\
\hline \hline Mini HAREM & 75,00148 & 57,80630 & 64,35055 & 49,58075 & 69,22771 & 53,34623 \\
Primeiro HAREM & 76,53824 & 59,16431 & 65,74270 & 50,80791 & 70,71587 & 54,65700 \\
Selva Falada & 89,66884 & 82,67272 & 78,41523 & 72,29848 & 83,66378 & 77,13696 \\
\hline
\end{tabular}

Tabela 7.8: Modelo-base criado utilizando em conjunto as características de estrutura interna da palavra (EI), características léxicas $\left(L_{4}\right)$ e etiquetas morfológicas (PoS).

Ao compararmos esses resultados aos modelos de estrutura interna da palavra combinado com $L_{4}$ apresentados na Tabela 7.6, verificamos que o uso das etiquetas morfológicas ofereceu um aumento significativo da Medida-F na tarefa de classificação, 4,76\% e 4,05\%, para os córpus Mini HAREM e Primeiro HAREM, respectivamente. No entanto, houve uma queda de $0,8 \%$ desta medida sobre o córpus Selva Falada.

Outra observação importante desta comparação está na tarefa de identificação, onde vemos que as Medida-F's para os córpus do HAREM tiveram aumento de cerca de 8,5\%. Mesmo que o resultado de classificação não tenha melhorado para o córpus Selva Falada, a identificação teve um aumento de pouco mais de $0,5 \%$.

Esses resultados mostram que a utilização das informações obtidas pelas etiquetas morfológicas são eficazes na resolução da tarefa de REM para português se aplicados em textos com o mesmo domínio dos córpus do HAREM. No entanto para o córpus Selva Falada tais características não se mostraram eficientes. Seguindo nosso objetivo, utilizaremos as etiquetas morfológicas como características, pois nosso sistema será avaliado com textos do mesmo domínio do HAREM.

\subsubsection{Outras Características}

Nesta seção verificaremos o impacto do uso de outras características combinadas com o modelo base criado na seção anterior. Todos os estudos da atual seção foram realizados utilizando o corte de predicado contextual igual a cinco. As características estudadas foram:

\section{Características compostas.}

Cada característica explorada no modelo-base foi, até agora, fornecida de forma isolada a um molde de predicado contextual. Reutilizaremos algumas dessas características, fornecendo-as 
a um único molde de predicado contextual afim de explorar a combinação das mesmas. A estas características combinadas em um único molde de predicado contextual, chamaremos de características compostas. Ratnaparki utiliza esta abordagem em seu etiquetador morfológico observando as duas etiquetas morfológicas anteriores ao token em questão, compostas em um único molde. Para o nosso sistema, estudamos as seguintes composições:

- Tokens em minúsculos $(A)$ : Utilizamos os dois tokens anteriores ao token em questão fornecendo-os em minúsculos ao molde.

- Etiquetas morfológicas (B): Considerando o ganho obtido com o uso das etiquetas morfológicas de forma isolada, como visto na Seção 7.2.3, acreditamos que a composição destas informações possa ser útil ao nosso propósito. Utilizamos neste caso as etiquetas de classificação morfológicas dos dois tokens anteriores ao token em questão.

- Etiquetas de EM $(C)$ : No treinamento, utilizamos como características as etiquetas de EM obtidas do conjunto de treinamento, e no momento do etiquetamento as etiquetas consultadas são aquelas obtidas na classificação dos dois tokens anteriores. Foram utilizadas as etiquetas de EM dos dois tokens anteriores ao token em questão.

- Sequência de primeira letra em maiúscula $(D)$ : Considerando a importância da primeira letra como um possível identificador de EM, acreditamos que a composição da verificação desta característica em uma determinada vizinhança possa contribuir para a melhoria do nosso classificador. Esta característica faz uma consulta às palavras da vizinhança verificando se a primeira letra é maiúscula. Os tokens consultados são o corrente, o imediatamente anterior e o imediatamente posterior. Os resultados dessas consultas são fornecidas a um único molde.

2. Etiquetas de EM dos tokens anteriores $(E)$ Assim como na característica $C$ utilizamos as etiquetas de EM dos dois tokens anteriores, porém, neste caso, cada etiqueta é fornecida a um molde separado.

3. Molde para Tempo $(F)$ : Este molde verifica se a palavra corrente está contida em um dicionário de palavras relacionadas ao tempo, $D i c_{t e m p o}$, tais como as estações do ano, nomes dos meses e dias da semana e finalmente suas respectivas abreviações. Outra verificação realizada pelo mesmo molde é a composição da palavra "de" seguida ou seguindo alguma palavra contida no dicionário Dictempo. Esta última verificação é baseada no formato de escrita de datas do tipo: "11 de setembro", "tarde de domingo".

4. Molde para Valor $(G)$ : Se houver algum dígito na palavra a ser analisada, é verificado se a palavra seguinte está contida em um pequeno dicionário manualmente preparado com trinta entradas de unidades monetárias, medidas de distâncias, pesos e alguns valores por extenso. Por exemplo: reais, real, milhões, gramas e $\mathrm{km}$. Este molde foi criado na tentativa de auxiliar a classificação de termos da categoria "valor", como no exemplo da frase: "Hoje corri $40 \mathrm{~km}$ de bicicleta.".

5. Características de dicionários $\left(H_{1}\right.$ e $\left.H_{2}\right)$ : Essas características indicam se uma determinada palavra faz parte de alguma entrada de um dicionário específico. As indicações possíveis são $X \_S T A R T$ e $X \_C O N T I N U E$, onde $X$ é um identificador de dicionário. $X \_S T A R T$ 
indica que a palavra procurada no dicionário foi encontrada na primeira posição de alguma entrada do dicionário $X$, enquanto $X \_C O N T I N U E$ indica que a palavra foi encontrada em qualquer outra posição diferente da primeira em alguma entrada do dicionário.

Por exemplo, se a entrada "Lair Carvalho" existir no dicionário chamado "PESSOA", e se a palavra "Carvalho" for consultada neste dicionário, a característica fornecida será PESSOA_CONTINUE.

O REPENTINO [SPC06] (acrônimo de REPositório para o reconhecimento de ENTIdades com NOme) é um repositório público que contém exemplos de EM, divididas por categorias e sub-categorias conceituais, organizadas numa estrutura hierárquica.

Construímos alguns dicionários baseados em algumas categorias do REPENTINO. A correspondência entre as categorias do REPENTINO e as categorias do Segundo HAREM nem sempre possuem o mesmo propósito. Portanto, para a construção dos nossos dicionários, foi necessário realizarmos uma análise das correspondências entre as categorias/subcategorias do REPENTINO com as categorias/tipos do Segundo HAREM. A correspondência que utilizamos entre as categorias do REPENTINO e as do Segundo HAREM está na Tabela 7.9.

\begin{tabular}{lll}
\hline Dicionário & \multicolumn{1}{c}{ REPENTINO } \\
\hline \hline Obra & Categoria & Subcategoria(s) \\
& $\begin{array}{l}\text { Arte/Media/ } \\
\text { Comunicação } \\
\text { Locais }\end{array}$ & Filme, Música e Arte \& Design \\
& Locais & $\begin{array}{l}\text { Terrestre, Pais/Estado, Infraestrutura } \\
\text { Povoação/Região/Div. Administrativa e } \\
\text { Comercial/Industrial/Financeiro }\end{array}$ \\
\hline Organização & Organizações & $\begin{array}{l}\text { Empresa, Governamental/Administrativa } \\
\text { Ensino/I\&D, Desportiva e Clubes }\end{array}$ \\
\hline Pessoa & Seres & Humano e Coletivo Humano \\
\hline Abstração & Abstração & $\begin{array}{l}\text { Estado/Condição, Disciplina/Arte \& Ofício } \\
\text { e Período/Movimento/Tendência }\end{array}$ \\
\hline Coisa & Substâncias & Grupo, Minério e Substância \\
& Natureza & Animal \\
& Produtos & Ferramentas/Instrumentos, Formato, \\
& & Tarefa Manual/Artesanato e Veículos \\
\hline Acontecimento & Eventos & $\begin{array}{l}\text { Desportivo, Efemérida, Científico, } \\
\text { Político. }\end{array}$ \\
\hline
\end{tabular}

Tabela 7.9: Dicionários baseados no REPENTINO.

Realizamos dois experimentos com os dicionários da Tabela 7.9. No primeiro $\left(H_{1}\right)$, utilizamos os dicionários da Tabela 7.9 e todas as palavras contidas em suas entradas. No segundo experimento $\left(H_{2}\right)$, removemos dos dicionários as palavras que estivessem contidas em uma lista de palavras vazias (do inglês, stoplist).

6. Tamanho da palavra rara $(J)$ : Esta característica verifica se o número de caracteres da palavra em questão é maior ou igual a um valor pré-determinado. Verificamos os tamanhos três e cinco apenas para as palavras raras. Os resultados desta característica somados ao modelo-base, relatados na Tabela 7.11, correspondem ao modelo que testa se a palavra é 
maior ou igual a cinco, pois dos valores que testamos, foi o que se apresentou melhor para os córpus Mini HAREM e Selva Falada.

7. Prefixo e sufixo das palavras $(K)$ : Segundo Ekbal \& Saha [ES10], os prefixos e sufixos são efetivos na identificação de EM's e trabalham bem para línguas indianas, além de serem úteis para a língua inglesa. Em seu NER são utilizados todos os prefixos e sufixos de todas as palavras maior do que um tamanho determinado. Ratnaparki utiliza estas características em seu etiquetador morfológico apenas quando a palavra em questão for rara. Testamos em nosso sistema a utilização destas características para as palavras, cujo tamanho em caracteres, fossem maior que três, verificando as duas implementações comentadas:

- $K_{1}$ Exploramos essas características quando a palavra corrente for rara.

- $K_{2}$ Utilizamos os prefixos e sufixos de todas as palavras.

Os prefixos utilizados são compostos dos seguintes caracteres da palavra: o primeiro, os dois primeiros e os três primeiros. E os caracteres utilizados para a composição dos sufixos são: o último, os dois mais à direita e os três mais à direita. Todos os caracteres são utilizados em minúsculos. Por exemplo se a palavra em questão for "Linguagem" os prefixos utilizados serão "l", "li" e "lin", e os sufixos serão "m", "em" e "gem".

\begin{aligned} & \hline Característica Descrição \\ & \hline$A$ Sequência de tokens em minúsculos. \\ &$B$ Sequência de etiquetas morfológicas. \\ &$C$ Sequência de etiquetas de EM. \\ &$D$ Sequência de tokens com primeira letra em maiúscula. \\ &$E$ Etiquetas de EM dos dois tokens anteriores. \\ &$F$ Molde para Tempo. \\ &$G$ Molde para Valor. \\ &$H_{1}$ Dicionários baseados no REPENTINO utilizando \\ & todas as palavras contidas em suas entradas. \\ &$H_{2}$ Dicionários baseados no REPENTINO utilizando \\ & suas entradas filtradas por uma stoplist. \\ &$J$ Tamanho da palavra rara é maior que cinco? \\ &$K_{1}$ Prefixos e sufixos das palavras raras. \\ &$K_{2}$ Prefixos e sufixos de todas as palavras. \\ & \hline\end{aligned}

Tabela 7.10: Resumo das características utilizadas.

Na Tabela 7.10 pode ser visto um resumo destas características. Os resultados de cada característica adicionada ao modelo-base podem ser vistos na Tabela 7.11.

Vemos que a característica $K_{2}$ adicionada ao modelo-base, apresentou os melhores resultados em todas as medidas de classificação para os córpus Primeiro HAREM e Selva Falada, com valores de medida-F de classificação 4,64\% e 3,55\% superiores ao valores do modelo-base, respectivamente. Além disso, vemos que para a medida-F de classificação para o córpus Mini HAREM, a característica $K_{2}$ só é superada pela característica $H_{2}$ em $0,18 \%$, e aumenta $3,4 \%$ em relação ao modelo-base. Com estes resultados podemos dizer que a afirmação de Ekbal \& Saha de que o uso de prefixos e sufixos são efetivos no auxílio da identificação de EM's também é válida para o português. 


\begin{tabular}{|c|c|c|c|c|c|c|c|}
\hline \multirow[t]{2}{*}{ Córpus } & \multirow[t]{2}{*}{ modelo } & \multicolumn{2}{|c|}{ Precisão } & \multicolumn{2}{|c|}{ Cobertura } & \multicolumn{2}{|c|}{$F_{1}$} \\
\hline & & Ident $(\%)$ & Class(\%) & Ident(\%) & Class(\%) & Ident $(\%)$ & Class(\%) \\
\hline \multirow{13}{*}{$\begin{array}{l}\text { Mini } \\
\text { HAREM }\end{array}$} & $m b$ & 75,00148 & 57,80630 & 64,35055 & 49,58075 & 69,22771 & 53,34623 \\
\hline & $m b+A$ & 74,48325 & 57,69475 & 63,29003 & 49,00506 & 68,38861 & 52,96236 \\
\hline & $m b+B$ & 74,29196 & 57,50106 & 62,71358 & 48,56344 & 67,97277 & 52,62396 \\
\hline & $m b+C$ & 75,54634 & 58,57672 & 63,15089 & 48,95084 & 68,76254 & 53,30778 \\
\hline & $m b+D$ & 76,99680 & 58,30595 & 67,62624 & 51,20350 & 71,97806 & 54,50174 \\
\hline & $m b+E$ & 75,73480 & 58,90370 & 62,36874 & 48,49159 & 68,36683 & 53,16296 \\
\hline & $m b+F$ & 74,92982 & 57,93969 & 64,36937 & 49,74972 & 69,20970 & 53,50210 \\
\hline & $m b+G$ & 75,45797 & 58,34066 & 64,93970 & 50,19488 & 69,75771 & 53,92508 \\
\hline & $m b+H_{1}$ & 74,55334 & 60,43629 & 64,00691 & 51,85737 & 68,84653 & 55,79277 \\
\hline & $m b+H_{2}$ & 76,23660 & 62,13681 & 64,56288 & 52,58581 & 69,86330 & 56,92075 \\
\hline & $m b+J$ & 75,34425 & 58,03779 & 64,44018 & 49,63469 & 69,42619 & 53,47695 \\
\hline & $m b+K_{1}$ & 74,68543 & 60,14156 & 61,72599 & 49,70212 & 67,54946 & 54,39260 \\
\hline & $m b+K_{2}$ & 74,92993 & 61,87761 & 63,53039 & 52,46063 & 68,71901 & 56,74658 \\
\hline \multirow{13}{*}{$\begin{array}{l}\text { Primeiro } \\
\text { HAREM }\end{array}$} & $m b$ & 76,53824 & 59,16431 & 65,74270 & 50,80791 & 70,71587 & 54,65700 \\
\hline & $m b+A$ & 76,87729 & 58,98324 & 65,47289 & 50,22668 & 70,70650 & 54,24487 \\
\hline & $m b+B$ & 76,07125 & 57,91697 & 65,15926 & 49,60303 & 70,18138 & 53,42922 \\
\hline & $m b+C$ & 76,70065 & 58,81606 & 65,43136 & 50,16509 & 70,60641 & 54,13735 \\
\hline & $m b+D$ & 78,14976 & 59,18418 & 69,13466 & 52,33239 & 73,34927 & 55,53487 \\
\hline & $m b+E$ & 77,19090 & 59,27683 & 65,79688 & 50,52237 & 71,02667 & 54,54040 \\
\hline & $m b+F$ & 76,63596 & 59,45302 & 65,73415 & 50,98513 & 70,75305 & 54,88305 \\
\hline & $m b+G$ & 77,11017 & 59,68411 & 66,07752 & 51,13300 & 71,15123 & 55,06502 \\
\hline & $m b+H_{1}$ & 76,19230 & 61,33093 & 65,09813 & 52,40074 & 70,19446 & 56,50301 \\
\hline & $m b+H_{2}$ & 76,22047 & 61,28716 & 65,54740 & 52,70593 & 70,46074 & 56,65635 \\
\hline & $m b+J$ & 76,13792 & 58,75711 & 65,35923 & 50,43624 & 70,32323 & 54,26822 \\
\hline & $m b+K_{1}$ & 76,08141 & 60,50370 & 63,71556 & 50,65993 & 69,34350 & 55,13959 \\
\hline & $m b+K_{2}$ & 76,34081 & 64,52575 & 64,90534 & 54,85411 & 70,15091 & 59,29050 \\
\hline \multirow{13}{*}{$\begin{array}{l}\text { Selva } \\
\text { Falada }\end{array}$} & $m b$ & 89,66884 & 82,67272 & 78,41523 & 72,29848 & 83,66378 & 77,13696 \\
\hline & $m b+A$ & 89,58302 & 82,73687 & 76,32411 & 70,49039 & 82,42342 & 76,12393 \\
\hline & $m b+B$ & 89,64482 & 82,86629 & 77,93365 & 72,03933 & 83,37820 & 77,07275 \\
\hline & $m b+C$ & 90,01010 & 82,86729 & 78,41542 & 72,19234 & 83,81173 & 77,16058 \\
\hline & $m b+D$ & 90,89397 & 82,95527 & 80,75550 & 73,70132 & 85,52364 & 78,05345 \\
\hline & $m b+E$ & 90,10592 & 82,92844 & 78,02513 & 71,80954 & 83,62960 & 76,96776 \\
\hline & $m b+F$ & 89,76276 & 82,77348 & 78,48539 & 72,37596 & 83,74456 & 77,22489 \\
\hline & $m b+G$ & 89,84182 & 82,82983 & 78,48774 & 72,36336 & 83,78043 & 77,24236 \\
\hline & $m b+H_{1}$ & 89,34030 & 82,61994 & 76,95549 & 71,16764 & 82,68504 & 76,46582 \\
\hline & $m b+H_{2}$ & 89,22732 & 82,69307 & 76,96107 & 71,32528 & 82,63908 & 76,58740 \\
\hline & $m b+J$ & 89,88457 & 82,76723 & 78,30441 & 72,10626 & 83,69364 & 77,06780 \\
\hline & $m b+K_{1}$ & 89,47400 & 82,62784 & 76,62773 & 70,76352 & 82,55071 & 76,23370 \\
\hline & $m b+K_{2}$ & 90,26112 & 84,87040 & 81,78569 & 76,89924 & 85,81292 & 80,68681 \\
\hline
\end{tabular}

Tabela 7.11: Resultados de cada característica adicionada ao modelo base. Os melhores resultados estão em negrito.

Os dicionários criados a partir do REPENTINO também foram efetivos na resolução da nossa tarefa para os córpus do HAREM, porém para o Selva Falada o ganho experimentado não foi tão significante, o que era esperado, pois durante a construção dos dicionários, estudamos apenas as categorias do REPENTINO em correspondência com o exemplário de categorias do HAREM. 
O uso das características compostas, com as configurações que utilizamos, com exceção da característica $D$, se mostraram ineficientes a ponto de afetar negativamente as medidas-F dos córpus do HAREM. No entanto a característica $C$ apresentou uma pequena melhoria das medidas-F para o córpus Selva Falada.

Outra observação sobre os resultados é o ganho experimentado com o uso da característica $D$ em todos os córpus estudados. Apesar de já efetuar a consulta sobre a capitalização da palavra corrente ao usar a característica de estrutura interna da palavra, vemos que a observação em conjunto das palavras da vizinhança é de grande auxílio para identificação e classificação da palavra corrente. Os ganhos experimentados das medidas-F de identificação com o uso de tal característica foram de 2,67\%, 2,63\% e 1,86\%, para os córpus Mini HAREM, Primeiro HAREM e Salva Falada e de 1,16\%, $0,88 \%$ e $0,92 \%$ na medida-F de classificação, respectivamente.

\subsection{Modelos Melhorados}

Para avaliar o impacto da combinação das características estudadas na Seção 7.2.5, construímos dois modelos. No primeiro modelo, (MTodas), utilizamos todas as melhores implementações das características apresentadas na Seção 7.2.5 combinadas com o modelo-base, especificamente: $M T$ odas $=m b+A+B+C+D+E+F+G+H_{2}+J+K_{2}$. Para o segundo modelo, combinamos apenas as características que apresentaram sinergia com o modelo base para o córpus Mini HAREM, referenciaremos a este modelo como MSinergia. A composição do modelo MSinergia é dado por: $M$ Sinergia $=m b+D+F+G+H_{2}+J+K_{2}$. Para os experimentos desta seção utilizamos o corte de predicados contextuais igual a cinco.

Os resultados destes modelos aplicados sobre os três córpus estão apresentados na Tabela 7.12.

\begin{tabular}{llrrrrrr}
\hline Córpus & \multirow{2}{*}{ modelo } & \multicolumn{2}{c}{ Precisão } & \multicolumn{2}{c}{ Cobertura } & \multicolumn{2}{c}{$F_{1}$} \\
\cline { 3 - 8 } & & Ident(\%) & Class(\%) & Ident(\%) & Class(\%) & Ident(\%) & Class(\%) \\
\hline \hline Mini & MTod $_{\text {corte }=5}$ & $\mathbf{7 9 , 8 6 7}$ & $\mathbf{6 7 , 5 2 8}$ & 64,463 & 54,509 & 71,298 & 60,285 \\
HAREM & MSin $_{\text {corte }=5}$ & 78,628 & 65,648 & $\mathbf{6 7 , 3 2 0}$ & $\mathbf{5 6 , 2 1 1}$ & $\mathbf{7 2 , 4 9 2}$ & $\mathbf{6 0 , 5 2 7}$ \\
\hline Primeiro & MTod $_{\text {corte }=5}$ & $\mathbf{8 0 , 5 3 6}$ & $\mathbf{6 8 , 3 0 7}$ & 67,836 & 57,515 & $\mathbf{7 3 , 6 2 6}$ & $\mathbf{6 2 , 4 3 5}$ \\
HAREM & MSin $_{\text {corte }=5}$ & 78,789 & 66,939 & $\mathbf{6 8 , 4 9 9}$ & $\mathbf{5 8 , 1 7 7}$ & 73,273 & 62,242 \\
\hline Selva & MTod $_{\text {corte }=5}$ & $\mathbf{9 1 , 0 1 0}$ & $\mathbf{8 4 , 9 5 5}$ & 81,375 & 75,961 & 85,922 & 80,205 \\
Falada & ${\text { M } \text { in }_{\text {corte }=5}}$ & 90,992 & 84,945 & $\mathbf{8 2 , 9 8 3}$ & $\mathbf{7 7 , 4 6 7}$ & $\mathbf{8 6 , 8 0 2}$ & $\mathbf{8 1 , 0 3 3}$ \\
\hline
\end{tabular}

Tabela 7.12: Comparação dos modelos MTodas e MSinergia aplicados em cada córpus.

Vemos que para os córpus do HAREM, os valores das Medidas-F de classificação não apresentaram grandes diferenças por córpus, além disso, enquanto o modelo $M S_{S i n e r g i a_{c o r t e}=5}$ se apresentou melhor para o córpus Mini HAREM, o modelo $M$ Todas $_{\text {corte }=5}$ se apresentou melhor para o córpus Primeiro HAREM, o que dificulta a nossa escolha sobre o melhor modelo. Porém, podemos observar que o modelo MTodas $s_{\text {corte }=5}$ obteve os melhores resultados para a precisão enquanto que o

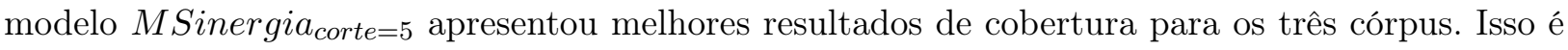
uma informação importante se precisarmos ajustar o sistema para uma medida ou outra.

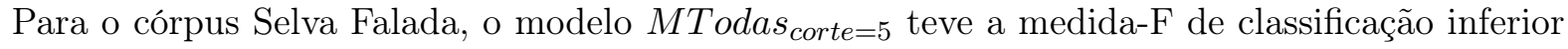
ao uso do modelo-base combinado apenas com a característica $K_{2}$, como visto na Tabela 7.11. No entanto, o modelo MSinergia $a_{\text {corte }=5}$ conseguiu alcançar uma pequena melhora da mesma medida 
em comparação com o melhor valor apresentado na Tabela 7.11.

Com a dificuldade apresentada na definição do melhor modelo na utilização dos córpus do HAREM, veremos na próxima seção uma verificação do número de corte de predicados contextuais utilizando os modelos MTodas e MSinergia afim de definir um modelo para avaliação com o Segundo HAREM.

\subsubsection{Novo estudo de corte para córpus do HAREM}

Para auxiliar na definição do melhor modelo a ser aplicado sobre os córpus do HAREM, considerando a dificuldade apresentada pelos resultados da Tabela 7.12, realizamos outro conjunto de experimentos. Desta vez, juntamos os córpus Primeiro HAREM e Mini HAREM em apenas um arquivo e realizamos a separação dos conjuntos treino-teste de acordo com a Seção 7.1.1. Neste ensaio treinamos os modelos MSinergia e MTodas utilizando os valores três, cinco e dez para o corte de predicados contextuais. Os resultados podem ser vistos na Tabela 7.13.

\begin{tabular}{lrrrrrrr}
\hline \multirow{2}{*}{ Modelo } & corte & \multicolumn{2}{c}{ Precisão } & \multicolumn{2}{c}{ Cobertura } & \multicolumn{2}{c}{$F_{1}$} \\
\cline { 2 - 7 } & & Ident(\%) & Class(\%) & Ident(\%) & Class(\%) & Ident(\%) & Class(\%) \\
\hline \hline MTodas & 3 & $\mathbf{8 1 , 6 6 9}$ & $\mathbf{6 9 , 9 5 3}$ & 67,142 & 57,507 & 73,686 & $\mathbf{6 3 , 1 1 4}$ \\
& 5 & 80,918 & 68,749 & 67,916 & 57,708 & 73,840 & 62,739 \\
& 10 & 80,380 & 67,212 & $\mathbf{6 9 , 2 9 8}$ & $\mathbf{5 7 , 9 4 2}$ & $\mathbf{7 4 , 4 1 8}$ & 62,225 \\
\hline MSinergia & 3 & $\mathbf{7 9 , 8 4 4}$ & $\mathbf{6 7 , 8 4 3}$ & 68,761 & 58,432 & 73,881 & $\mathbf{6 2 , 7 8 0}$ \\
& 5 & 79,536 & 67,106 & 69,615 & $\mathbf{5 8 , 7 4 3}$ & $\mathbf{7 4 , 2 3 7}$ & 62,640 \\
& 10 & 78,752 & 65,526 & $\mathbf{7 0 , 1 0 8}$ & 58,335 & 74,169 & 61,714 \\
\hline
\end{tabular}

Tabela 7.13: Avaliação de cortes para os modelos melhorados utilizando os córpus Mini HAREM e Primeiro HAREM juntos.

Assim como no experimento anterior, o modelo MTodas apresentou os melhores resultados de precisão em todos os cortes em comparação com o modelo MSinergia, enquanto que o modelo MSinergia apresentou os melhores resultados para a cobertura. Além disso, neste experimento verificamos que mesmo criando um modelo que utiliza apenas as características que melhoram o resultado da medida-F de classificação do modelo-base (MSinergia), o modelo que utiliza todas as características (MTodas) apresenta resultados melhores, ainda que pequenos, na mesma medida, chegando à diferença de $0,33 \%, 0,09 \%$ e 0,51\%, para os cortes de predicados contextuais três, cinco e dez, respectivamente.

Além disso, podemos comparar estes resultados aos obtidos por Milidiú et al [MdSD08], trabalho no qual utilizaram ETL conforme visto na Seção 5.1.2. Utilizando esta estratégia no córpus HAREM, alcançaram a medida-F de $63,27 \%$ na tarefa de classificação de entidades, superando a

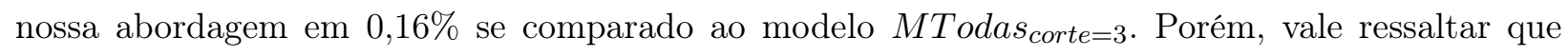
além dos córpus do HAREM também utilizaram o córpus LearnNEC06 para treinamento. Nossos resultados são animadores pois são competitivos com o estado-da-arte para esta tarefa.

Com base nesses resultados adotaremos o modelo MTodas para a avaliação final do nosso sistema no Segundo HAREM. Antes de efetuarmos a avaliação final, verificaremos na próxima seção um estudo sobre a compatibilidade dos córpus disponíveis. 


\subsubsection{Estudo de Córpus}

Verificamos agora a performance do modelo $M$ Todas $_{\text {corte }=5}$ treinando-o com um córpus e avaliando com os dois restantes de forma a verificar a compatibilidade dos córpus na resolução do nosso problema e para escolha do uso dos córpus a serem utilizados no sistema final a fim de avaliar no Segundo HAREM.

\begin{tabular}{llcc}
\multicolumn{2}{c}{ Córpus } & \multicolumn{2}{c}{$F_{1}$} \\
\hline Treino & Teste & Ident $(\%)$ & Class(\%) \\
\hline Mini HAREM & Primeiro HAREM & 62,82649 & 48,85727 \\
& Selva Falada & 44,87429 & 33,49249 \\
\hline Primeiro HAREM & Mini HAREM & 62,94173 & 51,00286 \\
& Selva Falada & 57,86653 & 45,82562 \\
\hline Selva Falada & Mini HAREM & 53,86533 & 37,31846 \\
& Primeiro HAREM & 54,74883 & 36,23891 \\
\hline
\end{tabular}

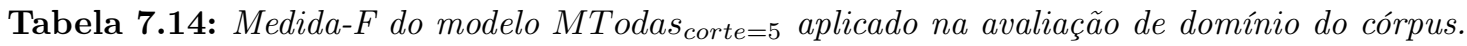

Com os resultados apresentados na Tabela 7.14 verificamos que o modelo treinado com o córpus Selva Falada, mesmo tendo uma quantidade de 3,5 vezes superior de exemplos de EM's em relação ao córpus Mini HAREM, foi 12,62\% inferior a este segundo na medida-F de classificação das EM's do córpus Primeiro HAREM. Da mesma forma, o sistema treinado com o Primeiro HAREM, mesmo possuindo apenas pouco mais de um terço da quantidade de exemplos de EM's do córpus Selva Falada, teve a medida-F 13,69\% superior a este segundo na tarefa de classificação das EM's do córpus Mini HAREM.

Em contrapartida, vemos que os resultados dos modelos treinados com o córpus Primeiro HAREM e o córpus Mini HAREM tiveram uma diferença de 12,33\% de medida-F na tarefa de classificação das EM's do córpus Selva Falada. Esta diferença indica uma relação com o tamanho do córpus de treinamento, visto que o córpus Mini HAREM tem apenas 72,71\% da quantidade de EM's que possui o Primeiro HAREM.

\subsection{Avaliação no Segundo HAREM}

Nesta seção mostramos o comparativo da saída do nosso modelo final com os resultados oficiais do Segundo HAREM. As avaliações desta seção foram obtidas com o SAHARA, conforme visto na Seção 3.2.3. Seguindo a metodologia adotada, verificamos que o modelo MTodas apresentou os melhores resultados de medida-F utilizando os recursos disponíveis, portanto o utilizaremos como nosso modelo oficial para a avaliação no Segundo HAREM, treinando-o com os córpus Primeiro HAREM e Mini HAREM.

\subsubsection{Cenários de Avaliação}

Avaliamos nosso sistema utilizando dois cenários de avaliação do Segundo HAREM, nomeadamente, Cenário Total e Cenário Seletivo. No cenário total é avaliada a capacidade do sistema de identificar e classificar todas as categorias, tipos e subtipos do Segundo HAREM. Mesmo que nosso sistema não tenha a proposta de classificação de tipos e subtipos, a avaliação neste cenário 
é importante ser verificada para que possamos comparar com os demais sistemas participantes do evento. As configurações utilizadas no cenário completo foram: $\alpha=1, \beta=0,5, \gamma=0,25$ com ALT estrita.

O Cenário Seletivo tem o intuito de avaliar a capacidade do nosso sistema de identificar e classificar apenas as categorias propostas pelo Segundo HAREM, portanto, as configurações utilizadas no Cenário Seletivo foram: $\alpha=1, \beta=\gamma=0$ com ALT estrita.

\section{Cenário Total}

Primeiramente vamos verificar o desempenho do nosso sistema considerando o cenário total em comparação com os sistemas participantes do Segundo HAREM.

Antes disso, porém, é necessário saber que nem todos os sistemas se propuseram a identificar e classificar todas as categorias, tipos e subtipos do Segundo HAREM, o que faz com que alguns sistemas possam ser desfavorecidos neste cenário. Mesmo assim, esta comparação foi realizada no âmbito do Segundo HAREM, o que nos permite realizar tal verificação para efeito de comparação com o comportamento do nosso sistema com os demais.

Vemos na Tabela 7.15 os resultados do modelo MTodas $_{\text {corte }=5}$ comparados com os melhores resultados de cada sistema deste evento. Considerando este cenário, a medida-F de classificação do nosso sistema está abaixo do melhor sistema em cerca de 14,64\%, o que deixa nosso sistema na quinta posição.

Este é um bom resultado considerando o número de sistemas participantes e o fato de que a maioria dos sistemas são baseados em regras manuais em combinação com dicionários e ontologias. Dos dez sistema, apenas o R3M adotou o Aprendizado de Máquina, e os resultados mostram que ficamos com a medida-F de classificação cerca de $5 \%$ superior a este no atual cenário.

\begin{tabular}{lrrrrrr}
\hline Sistema & \multicolumn{2}{c}{ Precisão } & \multicolumn{2}{c}{ Cobertura } & \multicolumn{2}{c}{$F_{1}$} \\
\cline { 2 - 7 } & Ident(\%) & Class(\%) & Ident(\%) & Class(\%) & Ident(\%) & Class(\%) \\
\hline \hline Priberam_1 & 69,94 & 64,17 & 72,29 & 51,46 & 71,10 & 57,12 \\
REMBRANDT_2 & 75,77 & 64,97 & 62,14 & 50,36 & 68,28 & 56,74 \\
XIP-L2FXerox_3 & 72,14 & 65,66 & 53,15 & 46,52 & 61,21 & 54,46 \\
REMMA_1_corr & 70,83 & 60,50 & 45,16 & 36,15 & 55,15 & 45,26 \\
MTodas_corte=5 & $\mathbf{6 9 , 3 7}$ & $\mathbf{6 0 , 7 6}$ & $\mathbf{4 8 , 0 4}$ & $\mathbf{3 2 , 6 5}$ & $\mathbf{5 6 , 7 7}$ & $\mathbf{4 2 , 4 8}$ \\
R3M_1 & 76,44 & 76,44 & 61,70 & 25,20 & 68,28 & 37,90 \\
SeRELep_1 & 81,78 & 81,78 & 59,15 & 24,15 & 68,65 & 37,29 \\
Cage2_4_corr & 50,59 & 44,99 & 37,87 & 27,57 & 43,32 & 34,19 \\
SEIGeo_4 & 89,63 & 74,85 & 13,58 & 11,66 & 23,59 & 20,18 \\
PorTexTO_4_corr & 70,03 & 67,90 & 8,98 & 8,82 & 15,92 & 15,61 \\
DobrEM_1_corr & 45,30 & 45,30 & 1,79 & 0,73 & 3,44 & 1,44 \\
\hline
\end{tabular}

Tabela 7.15: Melhores resultados da Medida-F de classificação de cada sistema participante do Segundo HAREM no cenário total com ALT estrita. Os resultados do nosso sistema estão na linha destacada.

\section{Cenário Seletivo}

Na Tabela 7.16 vemos os resultados do modelo MTodas $_{\text {corte }=5}$ comparados aos sete melhores resultados dos sistemas participantes do Segundo HAREM. Vemos que a medida-F de classificação 
do nosso sistema está abaixo do melhor sistema em cerca de 11,60\%, o que deixa nosso sistema na quarta posição neste cenário.

\begin{tabular}{lrrrrrr}
\hline \multirow{2}{*}{ Sistema } & \multicolumn{2}{c}{ Precisão } & \multicolumn{2}{c}{ Cobertura } & \multicolumn{2}{c}{$F_{1}$} \\
\cline { 2 - 7 } & Ident(\%) & Class(\%) & Ident(\%) & Class(\%) & Ident(\%) & Class(\%) \\
\hline \hline Priberam_1 & 70,32 & 66,50 & 72,29 & 55,31 & 71,29 & 60,39 \\
REMBRANDT_2 & 77,00 & 69,54 & 62,10 & 53,10 & 68,76 & 60,22 \\
XIP-L2FXerox_3 & 72,65 & 68,32 & 53,18 & 48,45 & 61,41 & 56,69 \\
MTodas & $\mathbf{6 9}, \mathbf{3 8}$ & $\mathbf{6 0 , 7 7}$ & $\mathbf{4 8 , 0 4}$ & $\mathbf{4 0 , 7 6}$ & $\mathbf{5 6 , 7 7}$ & $\mathbf{4 8 , 7 9}$ \\
REMMA_1_corr & 72,24 & 64,64 & 45,14 & 39,14 & 55,57 & 48,76 \\
R3M_1 & 78,28 & 78,21 & 61,74 & 31,48 & 69,01 & 44,89 \\
SeRELep_1 & 82,59 & 82,59 & 59,10 & 30,14 & 68,90 & 44,16 \\
Cage2_4_corr & 50,74 & 45,16 & 37,82 & 32,61 & 43,34 & 37,87 \\
\hline
\end{tabular}

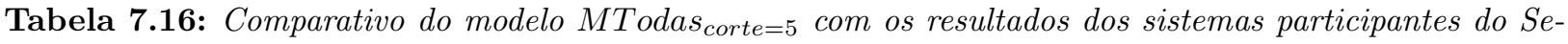
gundo HAREM no Cenário Seletivo (Apenas Categorias).

\subsubsection{Testes Alternativos}

Seguindo a nossa metodologia, verificamos que o modelo MTodas superou o modelo MSinergia com os recursos que tínhamos disponíveis para treino e teste, no entanto, após a avaliação do nosso sistema no Segundo HAREM, realizamos mais alguns experimentos para verificar o comportamento dos nossos modelos com ajustes de cortes de predicados contextuais e manipulações dos córpus de treino.

Inicialmente, realizamos mais um experimento de variação de cortes de predicados contextuais para o modelo MTodas aplicado ao córpus HAREM (Mini HAREM + Primeiro HAREM). Desta vez, dividimos este córpus separando aleatoriamente $75 \%$ das frases para treino e $25 \%$ para teste. Foram feitas quatro divisões seguindo este esquema. Os valores das medida-F's de cada corte estão ilustrados na Figura 7.1.

Vemos, com estes resultados, que para os valores de cortes que testamos, a partir do valor de corte cinco, a média da medida-F do modelo começa a diminuir, levando-nos a concluir que dos cortes estudados, o que mais se adequa ao nosso modelo de fato é o valor cinco.

Além deste experimento, realizamos novos estudos comparativos com a avaliação do Segundo HAREM. Para este conjunto de experimentos alternativos treinamos os dois modelos, MTodas e MSinergia, utilizando o córpus HAREM da mesma maneira que utilizamos na Seção 7.3.1, e uma versão filtrada do mesmo córpus. Na versão filtrada, eliminamos todas as frases que não continham marcação de EM. Desta forma obtemos quatro combinações de modelos, a saber: MTodas,

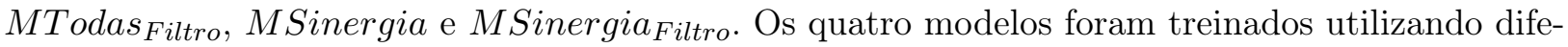
rentes cortes de predicados contextuais e avaliados no Segundo HAREM, com o auxílio do SAHARA.

Na Figura 7.2 estão os resultados das Medida-F's dos modelos avaliados no Cenário Total e na Figura 7.3 estão as Medida-F's dos mesmos modelos avaliados no Cenário Seletivo. Os resultados completos destes experimentos estão no Apêndice B.

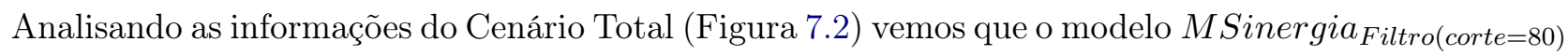
conseguiu alcançar a medida-F de 46,49\%, superando o modelo $M$ Todas $_{\text {corte }=5} \mathrm{em} \mathrm{4 \%}$, diminuindo a diferença entre nosso sistema e o primeiro colocado neste cenário. A nova diferença é de 10,63\%. 


\section{Classificação no Córpus HAREM \\ Modelo Utilizando todas as características}

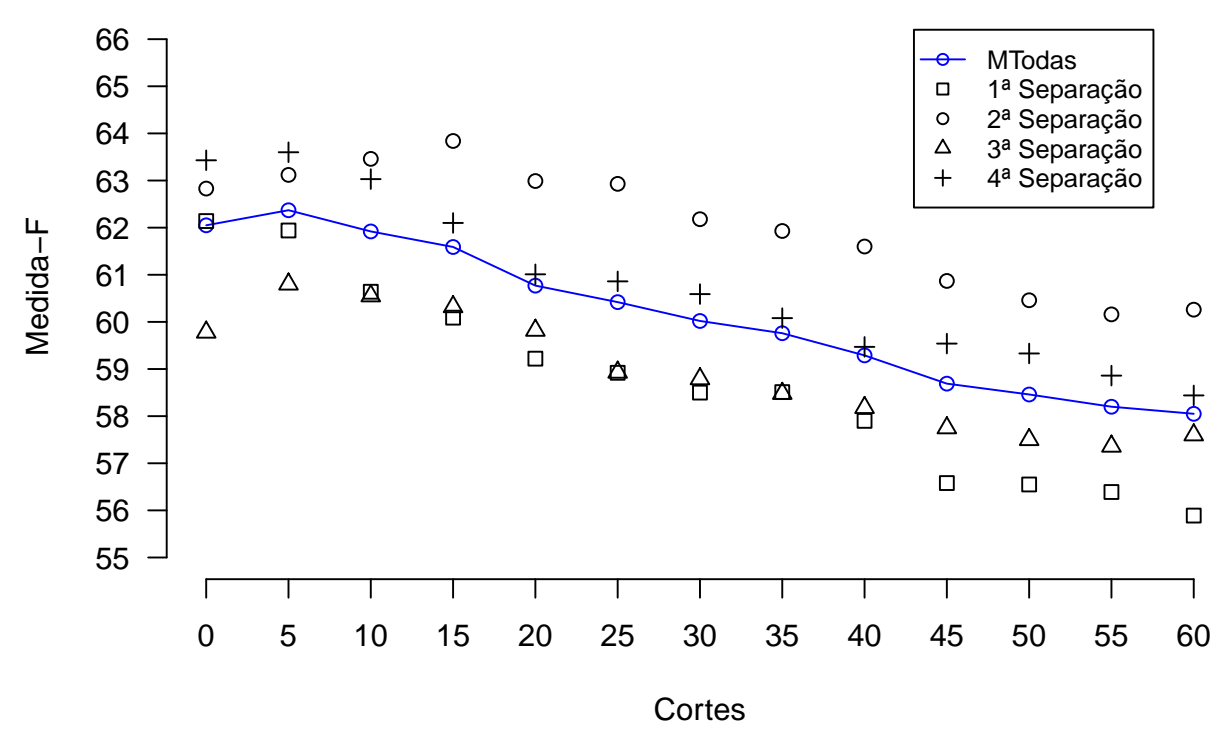

Figura 7.1: Uma avaliação mais extensa dos valores de cortes de predicados contextuais para o Modelo MTodas sobre o córpus HAREM.

Classificação no Segundo HAREM

Cenário Total

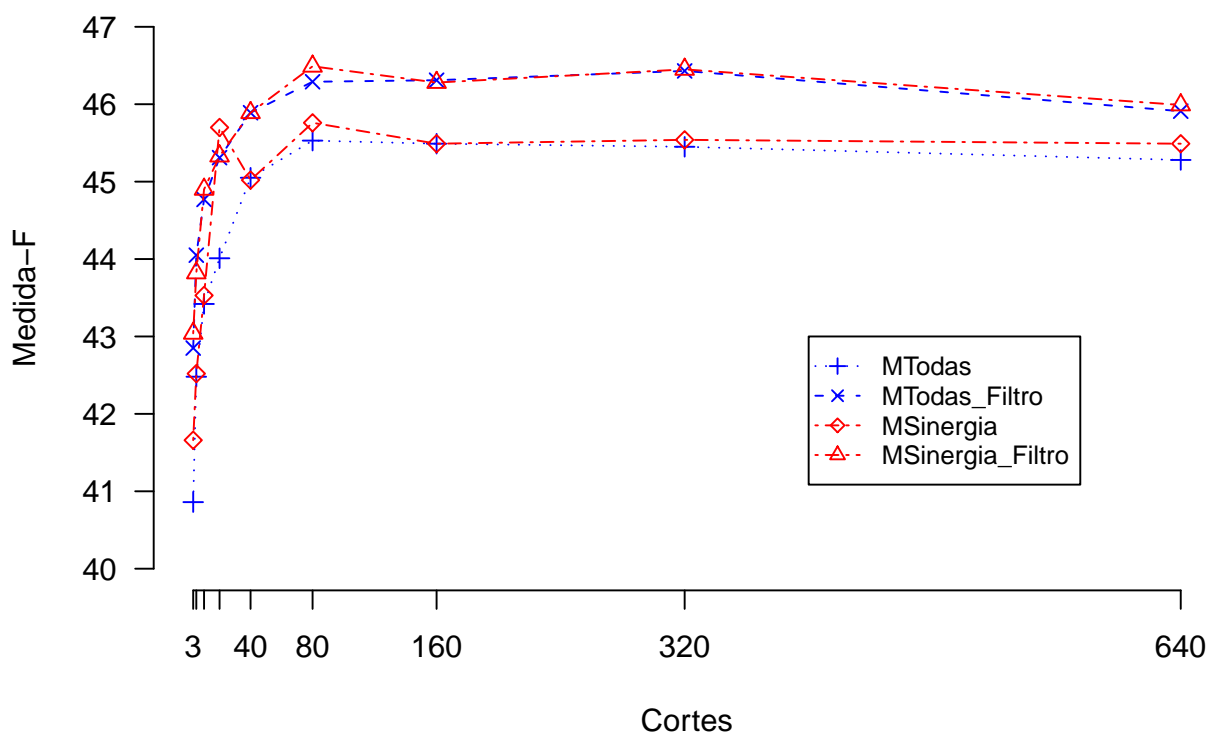

Figura 7.2: Resultados de diferentes modelos avaliadas no Segundo HAREM-Cenário Total.

Esse novo resultado faz com que nosso sistema fique na quarta posição se comparado com os sistemas participantes do Segundo HAREM, ganhando portanto uma posição em comparação com o resultado apresentado na Tabela 7.15.

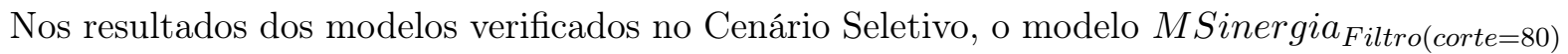
apresentou a medida-F de 52,87\%, sendo o melhor resultado obtido. Esse resultado é 4,08\% superior 


\section{Classificação no Segundo HAREM \\ Cenário Seletivo}

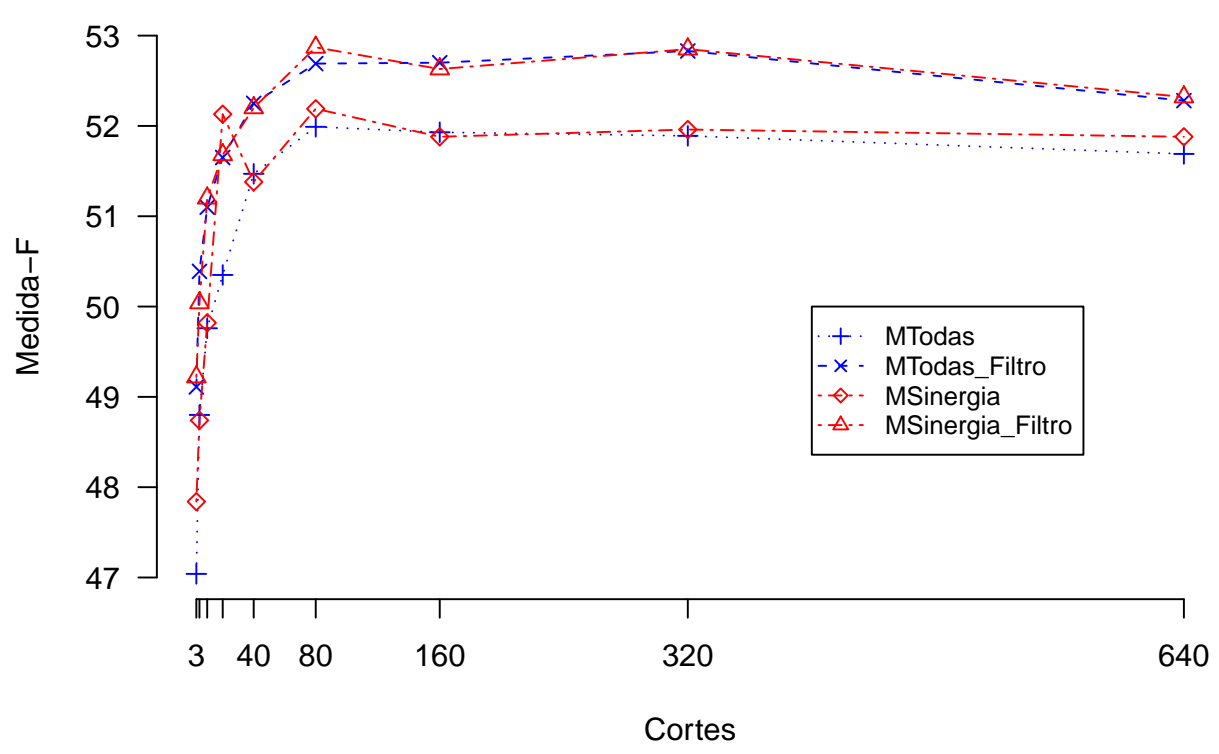

Figura 7.3: Resultados de diferentes modelos avaliadas no Segundo HAREM-Cenário Seletivo.

ao apresentado na Tabela 7.16. Apesar deste ganho, a posição do nosso sistema não se altera perante os outros sistemas neste cenário de avaliação.

Além disso vemos que nosso modelo oficial MTodas, configurado com o valor de corte de predicado contextual igual a 80, apresentou melhor desempenho do que o valor oficialmente utilizado. Os valores do modelo MTodas $_{\text {corte }=5}$ foram superados em 3,05\% no Cenário Total e em 3,2\% no Cenário Seletivo. Diferentemente do que ocorreu com os estudos realizados sobre os córpus do Primeiro HAREM e Mini HAREM, os resultados do Segundo HAREM melhoraram quando aumentamos o número de cortes de predicados contextuais.

Esses resultados mostram que seguindo os estudos de cortes que realizamos com o material de treino e testes que tínhamos disponíveis descartaríamos a hipótese de que aumentar o valor de corte de predicados contextuais melhoraria a performance do sistema.

Esses experimentos só foram possíveis devido à disponibilidade dos recursos de avaliação fornecidos pelos organizadores do HAREM. Não podemos afirmar que experimentaríamos os cortes aqui estudados se tais recursos não estivessem disponíveis. Se esses recursos estivessem disponíveis antes do evento de avaliação do Segundo HAREM, os participantes poderiam utilizá-los para ajustar os sistemas e com isso é possível que seus resultados fossem diferentes dos atuais. 


\section{Capítulo 8}

\section{Conclusões}

Neste trabalho construímos um sistema de REM utilizando o arcabouço de máxima entropia. Com o sistema construído, foi possível explorar diversas características contextuais e características externas que auxiliam na tarefa de identificação e classificação de EM's da língua portuguesa. Treinamos um modelo base utilizando como características contextuais, as palavras, as etiquetas morfológicas e algumas informações estruturais das palavras. Verificamos ainda diversas outras características e suas combinações adicionadas ao modelo base e avaliamos suas contribuições na tarefa de REM em comparação com o modelo base. Utilizamos três córpus separadamente para a verificação das características exploradas.

Para a tarefa de avaliação do sistema, foi necessário verificar algumas das diferentes formas de avaliação deste tipo de sistema presentes na literatura da área. Verificamos três destas formas de avaliação aplicados sobre um mesmo exemplo de texto e comparamos seus resultados. Desta forma, pudemos ser cautelosos em afirmações sobre os diferentes resultados apresentados em diferentes trabalhos sobre o mesmo assunto, bem como os resultados de performance do nosso próprio sistema. Finalmente, avaliamos nosso sistema seguindo as diretivas do Segundo HAREM.

Para a avaliação no Segundo HAREM, utilizamos uma ferramenta disponível pela organização deste evento. O resultado obtido com o nosso sistema ficou abaixo do melhor sistema participante em cerca de 14,64\% no cenário que se propõe a identificar e classificar todas as categorias, tipos e subtipos de EM's do Segundo HAREM, ficando em quinto lugar neste cenário de avaliação, com a $F_{1}$ de $42,48 \%$. Em um cenário seletivo, que se propõe a identificar e classificar apenas as categorias do Segundo HAREM, o resultado foi um pouco melhor, alcançando a $F_{1}$ de $48,79 \%$ e ficando abaixo do melhor sistema em cerca de 11,60\%, o que representa a quarta posição neste cenário. Entretanto, se comparado ao único participante do Segundo HAREM que utilizou como abordagem o AM, neste caso o R3M, nossos resultados superam o $F_{1}$ de classificação em 4,58\% e 3,9\% para os cenários total e seletivo, respectivamente.

Com algumas manipulações dos córpus de treinamento e um estudo do número de corte de características para o processo de estimação de máxima entropia, conseguimos aumentar os $F_{1}$ de classificação do nosso sistema em cerca de $4 \%$ nos dois cenários de avaliação. Desta forma, aumentamos o $F_{1}$ de classificação para $46,49 \%$ no cenário total e 52,87\% no cenário seletivo. Com estes novos resultados nosso sistema ficou na quarta colocação no cenário total, ganhando portanto uma posição se comparado aos resultados anteriores. Quanto ao cenário seletivo, mesmo diminuindo a diferença entre o primeiro colocado, não houve mudança de posição se comparado às posições dos demais sistemas. Vale ressaltar que estes novos resultados foram obtidos com um modelo treinado 
utilizando apenas algumas das características estudadas.

Nosso sistema também apresentou bons resultados se comparados às abordagens TBL e ETL aplicados ao problema de REM. O TBL alcançou o $F_{1}$ de 87,26\% avaliado sobre um córpus contendo 3325 exemplos de EM. O uso da estratégia ETL sendo avaliada utilizando o córpus do Primeiro HAREM, alcançou o $F_{1}$ de $63,27 \%$. Usando o córpus do Primeiro HAREM e seguindo os moldes de avaliação do CoNLL, que é uma avaliação mais restrita se comparada às outras formas de avaliação vistas neste trabalho, nosso sistema atingiu o $F_{1}$ de $63,11 \%$. Devido às diferenças de recursos utilizados entre nossa abordagem e o TBL a comparação não pode ser levada completamente em consideração. Porém no caso do ETL tal comparação é possível e nossos resultados se mostraram competitivos.

Apesar de não ter atingido o estado-da-arte na tarefa de REM em português, fato este observado com a comparação com os sistemas participantes do Segundo HAREM, podemos concluir que o arcabouço de Máxima Entropia é uma abordagem competitiva na resolução desta tarefa. Nosso sistema conseguiu atingir uma das melhores colocações entre os sistemas participantes, utilizando apenas dicionários, córpus de treinamento e sem considerar conhecimento linguístico sobre o assunto a ser resolvido.

\subsection{Trabalho Futuros}

Como proposta de futuros trabalhos, podemos considerar algumas ideias obtidas no decorrer do desenvolvimento deste. Tais ideias variam desde a exploração de características que não foram abordadas neste trabalho, até mesmo a reestruturação da arquitetura do sistema. Dentre algumas possibilidades de futuros trabalhos, sugerimos:

1. A verificação do uso de sintagmas nominais como característica do nosso sistema. Vimos na seção 5.1.2 que o uso de tais características auxiliou a abordagem ETL na tarefa de REM da língua portuguesa. Esta talvez seja uma característica interessante a ser explorada com o nosso sistema;

2. Uma reestruturação da arquitetura do sistema de forma a permitir que a tarefa de identificação de EM seja efetuada em um primeiro passo. De posse destas informações, um segundo passo seria efetuado, desta vez para a tarefa de classificação das EM's identificadas no primeiro passo;

3. A utilização de um algoritmo de otimização para a seleção de características a serem utilizadas pelo algoritmo de maximização de entropia, a exemplo do algoritmo genético. Tal abordagem foi utilizada por Ekbal \& Saha [ES10] no problema de REM para línguas indianas.

Uma característica do nosso sistema é a independência do conjunto de etiquetas de EM. Isso permite que ele seja utilizado em futuras pesquisas testando-o com diferentes córpus e conjunto de etiquetas. Para que isso seja possível, basta a manipulação dos córpus a serem utilizados tornando-os compatíveis com o formato de entrada aceitável pelo nosso sistema.

Esta dissertação, resultados com detalhes de categorias de EM e o sistema aqui implementado podem ser encontrados em http://www.ime.usp.br/ ${ }^{\sim}$ wesleys. 


\section{Apêndice A}

\section{Exemplos de Textos do HAREM}

Neste Apêndice compilamos alguns exemplos de frases extraídas do exemplário do Segundo HAREM e dos córpus do HAREM utilizados nesta dissertação. Os exemplos estão organizados por categoria/tipo/subtipo do Segundo HAREM.

\section{A.1 Exemplos por categoria/tipo do Segundo HAREM}

- Pessoa

\section{- Individual}

* Carta aberta a Sua Santidade, o Papa Bento XVI.

* D. Vanna é uma livreira à moda clássica.

- Cargo

* O presidente da República é, de uma forma geral, o chefe de Estado.

* Jantamos com o Secretário de Turismo, que relatou-nos tudo o que está acontecendo em Presidente Figueiredo no que tange o turismo ecológico.

\section{- GrupoCargo}

* O Conselho de Ministros tomou nota, com satisfação, dos esforços do Secretariado.

* ...juntamente com os outros dois Vice presidentes espanhóis deste Parlamento, tive a honra e o privilégio de acompanhar...

\section{- GrupoMembro}

* A Inglaterra derrotou nesta quarta-feira a Suíça por 2 a 1, em amistoso internacional disputado no Estádio Wembley, em Londres.

* Vamos todos ajudar os Bombeiros.

\section{- Membro}

* George Harrison era conhecido como "o Beatle discreto e quieto".

* De Portugal à Rússia, 40 Metodistas partilharam as suas experiências e perspectivaram o futuro da missão na Europa.

- GrupoInd 
* Já a Família Espírito Santo, que detém cerca de um terço do Banco Espírito Santo, tinha um patrimônio avaliado em quase 1,3 milhões de euros.

* ... tendo sido construído inicialmente para residência da família Barros Lima.

- Povo**

* A esperança média de vida do Terceiro Mundo é absurdamente baixa.

* Ronaldo conquistou a Inglaterra.

\section{- Abstração}

\section{- Disciplina}

* O Socialismo é um sistema sócio-político caracterizado pela apropriação dos meios de produção pela coletividade.

* O Princípio da Incerteza de Heisenberg.

\section{- Estado}

* A síndrome de Alström é uma doença hereditária muito rara.

* Inaugura-se uma quinta fase, de Resistência (1961-1974), com a entrada na década de 60 e o início da luta armada de libertação nacional ...

\section{- Idéia}

* Qualquer dia já ninguém acredita na República e na Democracia.

* Os registradores poderão discutir com o governo a campanha em torno da Gratuidade Universal, que deverá ser lançada em novembro.

- Nome

* O que significa a sigla JCB?

* A revista foi denominada Medicina e Cultura e teve o seu primeiro número publicado em janeiro de 1939.

\section{- Acontecimento}

- Efemeride

* Cinco anos depois do $\mathbf{1 1}$ de Setembro, Bin Laden continua a monte.

* Essa é a grande novidade do Carnaval 94: os peladões.

* Site totalmente dedicado ao episódio da Guerra de Canudos.

- Organizado

* A organização do Rock in Rio 2008 acabou de confirmar mais um grande nome para o seu cartaz.

* Segue reprodução fiel do material de divulgação do VII Congresso Nacional de Registro Civil, publicado na página do Recivil-MG na Internet.

- Evento

* O "Concerto de encerramento da Presidência portuguesa da União Europeia" terá lugar no dia 19 de Dezembro, pelas 21h, no Centro Cultural de Belém.

* A cerimônia aconteceu antes da partida Brasil X Noruega. 
- Coisa

- Classe

* O Doberman é, de maneira geral, um cão muito ativo, enérgico e determinado, extremamente ligado à família a que pertence.

* Os arquivos MP3 estão organizados e renomeados.

- MembroClasse

* O Pastor Alemão foi o primeiro classificado no concurso.

* ...para repassar o comprovante de deposito e receber o seu Recibo de Pagamento da Anuidade.

- Objeto

* Os cientistas deram conta desta enorme onda expansiva cujo tamanho é comparável à órbita de Saturno em volta do Sol.

* ...na qualidade de presidente da Comissão dos Transportes do Parlamento Europeu e também como deputado grego, gostaria de fazer uma referência ao naufrágio do ferry boat Express Samina, ocorrido na passada terça feira.

\section{- Substância}

* Cientistas espanhóis descobrem nova forma de mapear ADN.

* "Por isso, acrescentei Viagra ao tratamento".

- Local

- Humano

* País

- Nosso café faz sucesso na Terra do Sol Nascente.

- Qualquer cidadão da União Europeia pode agora escrever ao Parlamento Europeu.

* Divisão

- A fiscalização aconteceu em Mato Grosso do Sul.

- Desde o início da semana, moradores da Rocinha e do Vidigal aguardam uma nova guerra entre traficantes das duas favelas...

* Região

- As transnacionais expulsam os negócios locais no Terceiro Mundo e apoderamse dos seus mercados.

- Os Estados Unidos não pretendem construir novas bases militares em África, apesar da criação do novo comando militar africano.

\section{* Construção}

- O Aeroporto da Madeira e o Aeroporto de Porto Santo são ponto de partida e de chegada de várias companhias aéreas internacionais.

* Rua

- Já todos ouvimos falar dos incomparáveis museus de Nova Iorque, das luxuosas lojas da 5a Avenida e dos clássicos musicais da Broadway. 
- Virar à direita no cruzamento da Av. Cristóvão Colombo com a R. Santa Izabel.

* Outro

- Corria sempre, pela manhã, na Praia do Cruzeiro, em Icoaraci.

- Ficamos de nos encontrar na estação Jardim São Paulo.

- Fisico

* Aguamassa

- A Lagoa de Araruama é uma lagoa brasileira que tem um grande corpo d'água com saída para o mar, na Região dos Lagos do Estado do Rio de Janeiro.

- A Barragem do Alqueva tem uma extensão de 1160 quilômetros..

* Aguacurso

- Tirou fotografias fantásticas às Cataratas do Niagara.

- A seca que tem atingido o país fez com que os problemas de poluição no rio Trancão se tornassem mais visíveis.

* Relevo

- Grupo viajava em avião que bateu contra montanha na Cordilheira dos Andes.

- Em 1997, João Garcia fez a primeira tentativa de escalar o Everest, face norte, mas apenas conseguiu atingir os $8.200 \mathrm{~m}$.

* Planeta

- A ISS é um esboço do que poderá ser o futuro da a humanidade no espaço, através de sucessivas bases cada vez mais longe do nosso berço (primeiro a Lua, depois possivelmente os pontos lagrangeanos em que as forças da Terra e do Sol ou da Terra e da Lua se equilibram, e mais tarde Marte).

* Região

- Os recursos naturais de África são hoje desejados por todas as grandes economias mundiais.

- O sul da Califórnia, como a nossa Península Ibérica, é um exemplo de contrastes geográficos e climáticos muito abusados.

\section{- Virtual}

* ComSocial

- O anúncio a que me referia estava no Diário de Notícias de ontem.

* Sitio

- Podes tentar fazer uma pesquisa simples no GOOGLE ou no YAHOO.

* Obra

- Esta constatação não significa, contudo, que todos os dados apresentados no

"Código Da Vinci" tenham o mesmo valor.

- Obra

- Arte 
* Leonardo Da Vinci criou muitos quadros. Dois deles são muito conhecidos: Mona Lisa e a Última Ceia.

* A obra prima «A Última Ceia» é um bom exemplo disso.

\section{- Plano}

* O Estado subordina-se à Constituição e funda-se na legalidade.

* O motivo da autuação foi a prática de aumento abusivo de preços acima da variação dos custos de acordo com a nova Lei Antitruste ( $\left.\mathbf{n}^{\mathbf{0}} \mathbf{8 . 8 8 4} / \mathbf{9 4}\right)$.

\section{- Reproduzida}

* O Código Da Vinci foi editado pela Bertrand.

* Eu desconheço que haja entrevista da Playboy em que eu falo isso

\section{- Organização}

\section{- Administração}

* O Ministério da Saúde contratou 30 médicos uruguaios para trabalharem no 112.

* Mas a União Europeia é também um espaço cultural de uma imensa diversidade.

\section{- Empresa}

* A Ferrari lançou, neste domingo, em Maranello, o 53o carro para a disputa de um Mundial de Fórmula 1.

* Tem a fábrica de alumina, a Alunorte, também no Pará, que é um insumo muito importante para o Brasil e o Brasil importava esse insumo.

\section{- Instituição}

* A Igreja Católica sempre se viu, portanto, como uma união ou comunhão na diversidade.

* A Sunab também constatou a prática de aumento abusivo de preços em outros 23 estabelecimentos comerciais.

\section{- Valor}

\section{- Classificação}

* Pela primeira vez desde 2002, o cartaz desta 15a edição traduz um investimento exclusivamente europeu...

* Mas a grande surpresa do relatorio de 99, quando comparado com o de 98, foi Cingapura, que saltou do $\mathbf{1 1 ^ { \circ }}$ para o quarto lugar, passando à frente até do ...

\section{- Moeda}

* Hoje custa menos de 5 reais. O salário mínimo era $\mathbf{R} \$ 200$ !

* A remuneração é de $\mathbf{R} \$ \mathbf{2 . 4 0 9 , 6 6}$, podendo chegar a $\mathbf{R} \$ \mathbf{3 . 6 1 3}$, com a Gratificação de Desempenho...

\section{- Quantidade}

* Paciente de 67 anos é esquecida em aparelho de tomografia.

* Mais de 7.500 músicas em MP3 de todos gêneros. 
APÊNDICE A 


\section{Apêndice B}

\section{Resultados dos Experimentos Alternativos}

Na realização dos experimentos alternativos treinamos o modelo MTodas, apresentado na seção 7.3, com uma maior variedade de valores para o número de cortes de predicados contextuais. Os resultados estão na Tabela B.1.

Além disso, treinamos os demais modelos melhorados, apresentados na seção 7.3, e os avaliamos com a CD do Segundo HAREM com o auxílio do SAHARA. Utilizamos os córpus Mini HAREM e Primeiro HAREM para treinamento dos modelos. Neste experimento, também utilizamos versões filtradas dos mesmos córpus. Nas versões filtradas, eliminamos todas as frases que não continham marcação de EM. Desta forma obtemos quatro combinações de modelos, a saber:

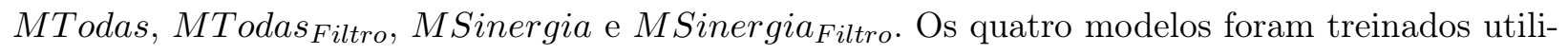
zando diferentes números de cortes de predicados contextuais.

Os cenários de avaliação utilizados são os mesmos da seção 7.4.1. Na Tabela B.2 estão os resultados dos modelos avaliados no Cenário Total e na Tabela B.3 estão os resultados dos mesmos modelos avaliados no Cenário Seletivo.

\begin{tabular}{|c|c|c|c|c|c|c|c|}
\hline \multirow[t]{2}{*}{ Sistema } & \multirow[t]{2}{*}{ Corte } & \multicolumn{2}{|c|}{ Precisão } & \multicolumn{2}{|c|}{ Cobertura } & \multicolumn{2}{|c|}{$F_{1}$} \\
\hline & & $\operatorname{Ident}(\%)$ & Class(\%) & Ident $(\%)$ & Class(\%) & Ident $(\%)$ & Class (\%) \\
\hline \multirow[t]{13}{*}{ MTodas } & 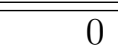 & $\overline{881,25118}$ & $\overline{771,05447}$ & 62,97810 & 55,07691 & 70,94995 & 62,04750 \\
\hline & 5 & 80,31459 & 68,47128 & 67,19605 & 57,28025 & 73,16286 & 62,36994 \\
\hline & 10 & 79,68146 & 67,20300 & 68,10601 & 57,42604 & 73,43145 & 61,92342 \\
\hline & 15 & 79,46304 & 66,47413 & 68,61721 & 57,38573 & 73,63561 & 61,59030 \\
\hline & 20 & 78,89037 & 65,37859 & 68,52039 & 56,77306 & 73,33296 & 60,76626 \\
\hline & 25 & 78,47366 & 64,77332 & 68,63000 & 56,62428 & 73,21167 & 60,41625 \\
\hline & 30 & 78,31148 & 64,29908 & 68,58704 & 56,28964 & 73,11796 & 60,02052 \\
\hline & 35 & 78,02561 & 63,95459 & 68,45706 & 56,09033 & 72,91844 & 59,75623 \\
\hline & 40 & 77,60222 & 63,30513 & 68,39591 & 55,76959 & 72,69935 & 59,29112 \\
\hline & 45 & 77,47013 & 62,67949 & 68,25247 & 55,19210 & 72,55789 & 58,68829 \\
\hline & 50 & 77,35938 & 62,47164 & 68,08221 & 54,95445 & 72,41432 & 58,46377 \\
\hline & 55 & 77,17631 & 62,20132 & 67,88887 & 54,69274 & 72,22532 & 58,19775 \\
\hline & 60 & 77,20011 & 62,02976 & 67,95108 & 54,57301 & 72,27059 & 58,05461 \\
\hline
\end{tabular}

Tabela B.1: Resultados da avaliação mais extensa de valores de cortes para o modelo MTodas. 


\begin{tabular}{|c|c|c|c|c|c|c|c|}
\hline \multirow[t]{2}{*}{ Sistema } & \multirow[t]{2}{*}{ Corte } & \multicolumn{2}{|c|}{ Precisão } & \multicolumn{2}{|c|}{ Cobertura } & \multicolumn{2}{|c|}{$F_{1}$} \\
\hline & & Ident(\%) & Class(\%) & Ident $(\%)$ & Class(\%) & Ident $(\%)$ & Class $(\%)$ \\
\hline \multirow[t]{9}{*}{ MTodas } & 3 & 68,64 & 60,24 & 45,39 & 30,91 & 54,64 & 40,86 \\
\hline & 5 & 69,38 & 60,77 & 48,04 & 32,66 & 56,77 & 42,48 \\
\hline & 10 & 69,40 & 60,35 & 50,24 & 33,91 & 58,28 & 43,42 \\
\hline & 20 & 69,61 & 59,94 & 52,03 & 34,77 & 59,55 & 44,01 \\
\hline & 40 & 70,35 & 60,38 & 53,93 & 35,93 & 61,06 & 45,05 \\
\hline & 80 & 70,72 & 60,59 & 54,84 & 36,47 & 61,78 & 45,53 \\
\hline & 160 & 71,12 & 60,36 & 55,41 & 36,50 & 62,29 & 45,49 \\
\hline & 320 & 71,14 & 60,36 & 55,36 & 36,45 & 62,26 & 45,45 \\
\hline & 640 & 70,99 & 60,08 & 55,32 & 36,34 & 62,18 & 45,28 \\
\hline \multirow[t]{9}{*}{ MTodas Filtro $_{\text {F }}$} & 3 & 68,52 & 59,55 & 49,62 & 33,47 & 57,55 & 42,85 \\
\hline & 5 & 68,86 & 59,87 & 51,64 & 34,85 & 59,02 & 44,05 \\
\hline & 10 & 68,86 & 59,34 & 53,75 & 35,95 & 60,37 & 44,77 \\
\hline & 20 & 69,27 & 59,23 & 55,27 & 36,68 & 61,48 & 45,31 \\
\hline & 40 & 69,47 & 59,24 & 56,58 & 37,45 & 62,37 & 45,89 \\
\hline & 80 & 69,94 & 59,38 & 57,56 & 37,93 & 63,15 & 46,29 \\
\hline & 160 & 70,26 & 59,39 & 57,85 & 37,95 & 63,46 & 46,31 \\
\hline & 320 & 70,60 & 59,44 & 58,28 & 38,09 & 63,85 & 46,43 \\
\hline & 640 & 70,25 & 59,15 & 57,41 & 37,52 & 63,19 & 45,91 \\
\hline \multirow[t]{9}{*}{ MSinergia } & 3 & 68,05 & 59,42 & 47,33 & 32,07 & 55,83 & 41,66 \\
\hline & 5 & 68,14 & 59,35 & 48,99 & 33,12 & 57,00 & 42,52 \\
\hline & 10 & 68,77 & 59,60 & 50,97 & 34,28 & 58,55 & 43,53 \\
\hline & 20 & 70,46 & 60,12 & 55,65 & 36,86 & 62,19 & 45,70 \\
\hline & 40 & 69,89 & 59,64 & 54,60 & 36,16 & 61,31 & 45,02 \\
\hline & 80 & 70,48 & 60,14 & 55,76 & 36,93 & 62,27 & 45,76 \\
\hline & 160 & 70,36 & 59,74 & 55,72 & 36,72 & 62,19 & 45,49 \\
\hline & 320 & 70,69 & 60,10 & 55,56 & 36,66 & 62,22 & 45,54 \\
\hline & 640 & 70,36 & 59,74 & 55,72 & 36,72 & 62,19 & 45,49 \\
\hline \multirow[t]{9}{*}{ MSinergia $_{\text {Filtro }}$} & 3 & 67,40 & 58,30 & 50,81 & 34,11 & 57,94 & 43,04 \\
\hline & 5 & 67,55 & 58,35 & 52,34 & 35,09 & 58,98 & 43,82 \\
\hline & 10 & 68,48 & 58,78 & 54,53 & 36,33 & 60,71 & 44,90 \\
\hline & 20 & 69,28 & 59,26 & 55,30 & 36,71 & 61,50 & 45,33 \\
\hline & 40 & 69,13 & 58,58 & 57,35 & 37,72 & 62,69 & 45,89 \\
\hline & 80 & 69,64 & 59,08 & 58,21 & 38,32 & 63,41 & 46,49 \\
\hline & 160 & 69,68 & 58,75 & 58,36 & 38,18 & 63,52 & 46,28 \\
\hline & 320 & 70,19 & 59,30 & 58,24 & 38,18 & 63,66 & 46,45 \\
\hline & 640 & 69,77 & 58,77 & 57,77 & 37,77 & 63,21 & 45,99 \\
\hline
\end{tabular}

Tabela B.2: Resultados completos dos vários modelos avaliados no Cenário Total do Segundo HAREM. 


\begin{tabular}{|c|c|c|c|c|c|c|c|}
\hline \multirow[t]{2}{*}{ Sistema } & \multirow[t]{2}{*}{ Corte } & \multicolumn{2}{|c|}{ Precisão } & \multicolumn{2}{|c|}{ Cobertura } & \multicolumn{2}{|c|}{$F_{1}$} \\
\hline & & Ident $(\%)$ & Class(\%) & Ident $(\%)$ & Class(\%) & Ident $(\%)$ & Class(\%) \\
\hline \multirow[t]{9}{*}{ MTodas } & 3 & 68,64 & 60,24 & 45,39 & 38,59 & 54,64 & 47,04 \\
\hline & 5 & 69,38 & 60,77 & 48,04 & 40,77 & 56,77 & 48,80 \\
\hline & 10 & 69,40 & 60,35 & 50,24 & 42,33 & 58,28 & 49,76 \\
\hline & 20 & 69,61 & 59,94 & 52,03 & 43,41 & 59,55 & 50,35 \\
\hline & 40 & 70,35 & 60,38 & 53,93 & 44,85 & 61,06 & 51,47 \\
\hline & 80 & 70,72 & 60,59 & 54,84 & 45,52 & 61,78 & 51,99 \\
\hline & 160 & 71,12 & 60,36 & 55,41 & 45,56 & 62,29 & 51,93 \\
\hline & 320 & 71,14 & 60,36 & 55,36 & 45,50 & 62,26 & 51,89 \\
\hline & 640 & 70,99 & 60,08 & 55,32 & 45,36 & 62,18 & 51,69 \\
\hline \multirow[t]{9}{*}{ MTodas ${ }_{\text {Filtro }}$} & 3 & 68,52 & 59,55 & 49,62 & 41,78 & 57,55 & 49,11 \\
\hline & 5 & 68,86 & 59,87 & 51,64 & 43,50 & 59,02 & 50,39 \\
\hline & 10 & 68,86 & 59,34 & 53,75 & 44,87 & 60,37 & 51,10 \\
\hline & 20 & 69,27 & 59,23 & 55,27 & 45,79 & 61,48 & 51,65 \\
\hline & 40 & 69,47 & 59,24 & 56,58 & 46,75 & 62,37 & 52,25 \\
\hline & 80 & 69,94 & 59,38 & 57,56 & 47,35 & 63,15 & 52,69 \\
\hline & 160 & 70,26 & 59,39 & 57,85 & 47,37 & 63,46 & 52,70 \\
\hline & 320 & 70,60 & 59,44 & 58,28 & 47,54 & 63,85 & 52,83 \\
\hline & 640 & 70,25 & 59,15 & 57,41 & 46,84 & 63,19 & 52,28 \\
\hline \multirow[t]{9}{*}{ MSinergia } & 3 & 68,05 & 59,42 & 47,33 & 40,04 & 55,83 & 47,84 \\
\hline & 5 & 68,14 & 59,35 & 48,99 & 41,35 & 57,00 & 48,74 \\
\hline & 10 & 68,77 & 59,60 & 50,97 & 42,79 & 58,55 & 49,82 \\
\hline & 20 & 70,46 & 60,12 & 55,65 & 46,01 & 62,19 & 52,13 \\
\hline & 40 & 69,89 & 59,64 & 54,60 & 45,13 & 61,31 & 51,38 \\
\hline & 80 & 70,48 & 60,14 & 55,76 & 46,10 & 62,27 & 52,19 \\
\hline & 160 & 70,36 & 59,74 & 55,72 & 45,84 & 62,19 & 51,88 \\
\hline & 320 & 70,69 & 60,10 & 55,56 & 45,77 & 62,22 & 51,96 \\
\hline & 640 & 70,36 & 59,74 & 55,72 & 45,84 & 62,19 & 51,88 \\
\hline \multirow[t]{9}{*}{ MSinergia $_{\text {Filtro }}$} & 3 & 67,40 & 58,30 & 50,81 & 42,58 & 57,94 & 49,22 \\
\hline & 5 & 67,55 & 58,35 & 52,34 & 43,80 & 58,98 & 50,04 \\
\hline & 10 & 68,48 & 58,78 & 54,53 & 45,35 & 60,71 & 51,20 \\
\hline & 20 & 69,28 & 59,26 & 55,30 & 45,82 & 61,50 & 51,68 \\
\hline & 40 & 69,13 & 58,58 & 57,35 & 47,08 & 62,69 & 52,20 \\
\hline & 80 & 69,64 & 59,08 & 58,21 & 47,84 & 63,41 & 52,87 \\
\hline & 160 & 69,68 & 58,75 & 58,36 & 47,67 & 63,52 & 52,63 \\
\hline & 320 & 70,19 & 59,30 & 58,24 & 47,66 & 63,66 & 52,85 \\
\hline & 640 & 69,77 & 58,77 & 57,77 & 47,15 & 63,21 & 52,32 \\
\hline
\end{tabular}

Tabela B.3: Resultados completos dos vários modelos avaliados no Cenário Seletivo do Segundo HAREM. 
APÊNDICE B 


\section{Referências Bibliográficas}

[AF99] Carlos Daniel Chacur Alves e Marcelo Finger. Etiquetagem do português clássico baseado em corpus. Em IV Encontro para o Processamento Computacional da Língua Portuguesa Escrita e Falada (PROPOR99), Setembro 1999. 27

[Alp04] Ethem Alpaydin. Introduction to machine learning. The MIT Press, 2004. 19, 20, 22, 23

[Ber96] Adam Berger. A Brief Maxent Tutorial. Versão eletrônica disponível em http://www2.cs.cmu.edu/afs/cs/user/aberger/www/html/tutorial/tutorial.html. Adam Berger, 1996. 25

[Bic06] Eckhard Bick. Functional aspects in portuguese ner. Em Renata Vieira, Paulo Quaresma, Maria Nunes, Nuno Mamede, Cláudia Oliveira e Maria Dias, editors, Computational Processing of the Portuguese Language, volume 3960 of Lecture Notes in Computer Science, páginas 80-89. Springer Berlin / Heidelberg, 2006. 10.1007/11751984_9. 29, 38

[BPP96] Adam L. Berger, Vincent J. Della Pietra e Stephen A. Della Pietra. A maximum entropy approach to natural language processing. Comput. Linguist., 22:39-71, March 1996. 24

[Bri95] Eric Brill. Transformation-based error-driven learning and natural language processing: a case study in part-of-speech tagging. Comput. Linguist., 21:543-565, December 1995. 25

[BSAG98] Andrew Borthwick, John Sterling, Eugene Agichtein e Ralph Grishman. Exploiting diverse knowledge sources via maximum entropy in named entity recognition. Em In Proceedings Of The Sixth Workshop On Very Large Corpora, páginas 152-160, 1998. 31, 47

[Car06] Nuno Cardoso. Avaliação de sistemas de reconhecimento de entidades mencionadas. Dissertação de Mestrado, Faculdade de Engenharia da Universidade do Porto., Outubro 2006. 11

[Chi95] Nancy Chinchor. Statistical significance of muc-6 results. Em Proceedings of the 6th conference on Message understanding, MUC6 '95, páginas 39-43, Stroudsburg, PA, USA, 1995. Association for Computational Linguistics. 10

[CMP02] Xavier Carreras, Lluís Màrques e Lluís Padró. Named entity extraction using adaboost. Em Proceedings of CoNLL-2002, páginas 167-170. Taipei, Taiwan, 2002. 10

[CoG] Homepage do cogroo, corretor gramatical acoplÃ $j$ vel ao libreoffice. disponível em http: //ccsl.ime.usp.br/cogroo. acessado em 10 de abril de 2011. 38

[CoN10] Conll: The conference of signll. http://ifarm.nl/signll/conll, 2010. Último acesso em 20/09/2010. 11 
[dAF03] Archias Alves de Almeida Filho. Maximização de entropia em linguística computacional para língua portuguesa. Dissertação de Mestrado, Universidade de São Paulo, 2003. 6, 39

[DR72] J. N. Darroch e D. Ratcliff. Generalized iterative scaling for log-linear models. Annals of Mathematical Statistics, 43:1470-1480, 1972. 24

[dSM09] Cícero Nogueira dos Santos e Ruy Luiz Milidiú. Entropy guided transformation learning. Em Aboul-Ella Hassanien, Ajith Abraham, Athanasios Vasilakos e Witold Pedrycz, editors, Foundations of Computational, Intelligence Volume 1, volume 201 of Studies in Computational Intelligence, páginas 159-184. Springer Berlin / Heidelberg, 2009. 10.1007/978-3-642-01082-8_7. xi, 27, 28

[ES10] Asif Ekbal e Sriparna Saha. Classifier ensemble selection using genetic algorithm for named entity recognition. Research on Language Eamp; Computation, páginas 1-27, Dezembro 2010. 56, 66

[FIJZ03] Radu Florian, Abe Ittycheriah, Hongyan Jing e Tong Zhang. Named entity recognition through classifier combination. Em Walter Daelemans e Miles Osborne, editors, Proceedings of CoNLL-2003, páginas 168-171. Edmonton, Canada, 2003. 10

[FMS $\left.{ }^{+} 10\right]$ Cláudia Freitas, Cristina Mota, Diana Santos, Hugo Gonçalo Oliveira e Paula Carvalho. Second harem : advancing the state of the art of named entity recognition in portuguese. Em In The seventh international conference on Language Resources and Evaluation (LREC 2010), Malta, May 2010. 16

[Gd01] Caroline Varaschin Gasperin e Vera Lúcia Strube de Lima. Fundamentos do processamento estatístico da linguagem natural. Relatório Técnico 021, Faculdade de Informática, PUCRS, Rio Grande do Sul, Brasil, 2001. 3, 4, 6

[JM08] Daniel Jurafsky e James H. Martin. Speech and Language Processing (2nd Edition) (Prentice Hall Series in Artificial Intelligence). Prentice Hall, 2 edição, 2008. 25

[Lin10] Linguateca. Homepage do linguateca. http://www.linguateca.pt, 2010. Último acesso em 24/09/2010. 11

[MDC07] Ruy Luiz Milidiú, Julio Cesar Duarte e Roberto Cavalcante. Machine learning algorithms for portuguese named entity recognition. Inteligencia Artificial, Revista Iberoamericana de $I A, 11(36): 67-75,2007.29,30$

[MdSD08] Ruy Luiz Milidiú, Cícero Nogueira dos Santos e Julio Cesar Duarte. Portuguese corpusbased learning using ETL. Journal of the Brazilian Computer Society, 14:17-27, 122008. 30,59

[MS99] Christopher D. Manning e Hinrich Schütze. Foundations of Statistical Natural Language Processing. The MIT Press, Cambridge, England, 1999. 3, 5, 6, 23

[MS08] Cristina Mota e Diana Santos, editors. Desafios na avaliação conjunta do reconhecimento de entidades mencionadas: O Segundo HAREM. Versão eletrônica disponível em http://www.linguateca.pt/LivroSegundoHAREM/. Linguateca, 2008. xi, 12, 17

[muca] Homepage do muc-6. disponível em http://cs.nyu.edu/cs/faculty/grishman/muc6.html. acessado em 19 de setembro de 2010. 10

[mucb] Homepage do muc-7. disponível em http://www-nlpir.nist.gov/related_projects/muc/ proceedings/muc_7_toc.html. acessado em 19 de setembro de 2010. 10 
[NS07] David Nadeau e Satoshi Sekine. A survey of named entity recognition and classification. Em Linguisticae Investigationes, páginas 3-26, Janeiro 2007. 7, 10

[PD97] David D. Palmer e David S. Day. A statistical profile of the named entity task. Em Proceedings of Fifth ACL Conference for Applied Natural Language Processing (ANLP97), páginas 190-193, 1997. 10

[Rat98] Adwait Ratnaparkhi. Maximum Entropy Models for Natural Language Ambiguity Resolution. Tese de Doutorado, University of Pennsylvania, Philadelphia, PA, 1998. 25, 39, 46

[RN95] Stuart Russell e Peter Norvig. Artificial Intelligence: A Modern Approach. Prentice Hall. Segunda edição, 1995. 1, 19, 23

[RR09] Lev Ratinov e Dan Roth. Design challenges and misconceptions in named entity recognition. Em Proceedings of the Thirteenth Conference on Computational Natural Language Learning (CoNLL), páginas 147-155, 2009. 37, 42

[SC08] Diana Santos e Nuno Cardoso, editors. Reconhecimento de entidades mencionadas em português: Documentação e actas do HAREM, a primeira avaliação conjunta na área. Versão eletrônica disponível em http://www.linguateca.pt/LivroHAREM/. http://www.linguateca.pt, 2008. 1

[Seg07] Toby Segaran. Programming Collective Intelligence. O’Reilly Media, 2007. 19

[SPC06] Luís Sarmento, Ana Sofia Pinto e Luís Cabral. Repentino - a wide-scope gazetteer for entity recognition in portuguese. Em Renata Vieira, Paulo Quaresma, Maria da Graça Volpes Nunes, Nuno J. Mamede, Cláudia Oliveira e Maria Carmelita Dias, editors, Computational Processing of the Portuguese Language: 7th International Workshop, PROPOR 2006, páginas 31-40, Berlim/Heidelberg, 2006. Springer Verlag. 55

[TD03] Erik F. Tjong Kim Sang e Fien De Meulder. Introduction to the conll-2003 shared task: Language-independent named entity recognition. Em Walter Daelemans e Miles Osborne, editors, Proceedings of CoNLL-2003, páginas 142-147. Edmonton, Canada, 2003. 11

[the02] CoNLL: the conference of SIGNLL. Language-independent named entity recognition, conference on computational natural language learning-2002 (conll-2002). http://www. cnts.ua.ac.be/conll2002/ner, 2002. Último acesso em 20/09/2010. 11

[the03] CoNLL: the conference of SIGNLL. Language-independent named entity recognition, conference on computational natural language learning-2003 (conll-2003). http://www. cnts.ua.ac.be/conll2003/ner, 2003. Último acesso em 20/09/2010. 11

[Tjo02] Erik F. Tjong Kim Sang. Introduction to the conll-2002 shared task: Languageindependent named entity recognition. Em Proceedings of CoNLL-2002, páginas 155158. Taipei, Taiwan, 2002. 11 


\section{Índice Remissivo}

(Resultado-da-tarefa-de-identificacao-dos-dados-da-

Tabela-tabelaDePossiveisErrosNaAnotacaoDeUmSistemaDeREN, 15

Condicoes-para-permissao-do-etiquetamento-do-tokenti-de-uma-sentenca-de-tamanho-n, 42

Conjunto-de-caracteristicas-utilizadas-na-exploracaoda-estrutura-interna-da-palavra, 47

Corpus-utilizados-nos-experimentos-e-suas-distribuicoesde-EM-por-categorias, 45

dicionarios-utilizados-repentino, 55

Exemplo de Córpus Marcado: Excerto de Manuel

Bernardes, 4

exemploDeAvaliacaoDeREN, 7

exemploDeUsoMaxEnt-Ditribuicoes-Jabulane, 24

Exemplos de classificação de entidades e seus possíveis tipos., 2

Exemplos-de-moldes-de-predicados-contextuais, 40

Exemplos-de-sequencias-de-etiquetamento-inconsistente, 42

exemplosDeModelosTextChuncking, 28

exemplosDeModelosUsadosPorBrill, 25

ModeloDeRegras-TBL-NER, 30

Moldes-aplicados-sobre-b4, 40

Possiveis-anotacoes-de-um-sistema-hipotetico, 14

tab:Conjunto-de-Classes-de-Palavras-utilizadas-peloCoGrOO, 38

Tabela-de-Representacao-da-etiquetagem-apos-o-

filtro-de-entrada, 37

tabelaDePossiveisErrosNaAnotacaoDeUmSistemaDeREN, 7 